Portland State University

PDXScholar

6-2008

\title{
Techniques for Assessing the Socio-Economic Effects of Vehicle Mileage Fees
}

\author{
B. Starr McMullen \\ Oregon State University \\ Kyle Nakahara \\ Oregon State University \\ Smita Biswas \\ Oregon State University \\ Lei Zhang \\ Oregon State University \\ Divya Valluri \\ Oregon State University
}

Follow this and additional works at: https://pdxscholar.library.pdx.edu/trec_reports

Part of the Transportation Commons, Urban Studies Commons, and the Urban Studies and Planning Commons

Let us know how access to this document benefits you.

\section{Recommended Citation}

McMullen, B. Starr, Kyle Nakahara, Smita Biswas, Lei Zhang, Divya Valluri. Techniques for Assessing the Socio-Econimic Effects of Vehicle Mileage Fees. OTREC-RR-08-01. Portland, OR: Transportation Research and Education Center (TREC), 2008. https://doi.org/10.15760/trec.68

This Report is brought to you for free and open access. It has been accepted for inclusion in TREC Final Reports by an authorized administrator of PDXScholar. Please contact us if we can make this document more accessible: pdxscholar@pdx.edu. 


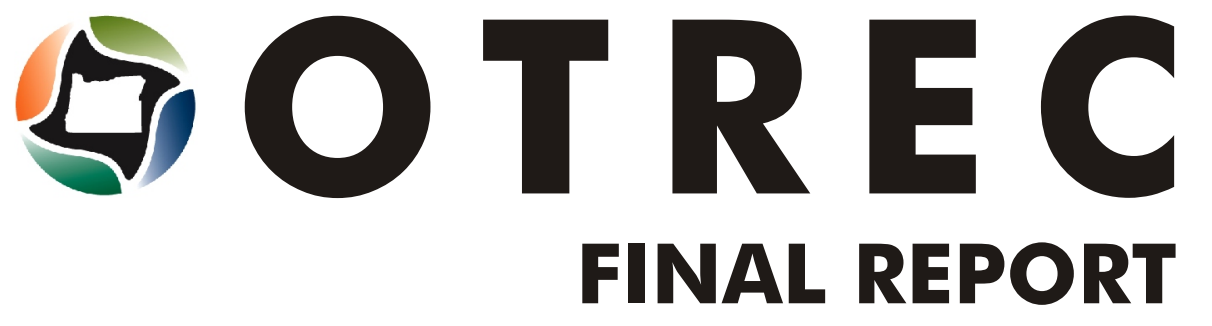

\section{Techniques for Assessing the Socio-Economic Effects of Vehicle Mileage Fees}

OTREC-RR-08-01 June 2008
A National University Transportation Center sponsored by the U.S. Department of Transportation's Research and Innovative Technology Administration
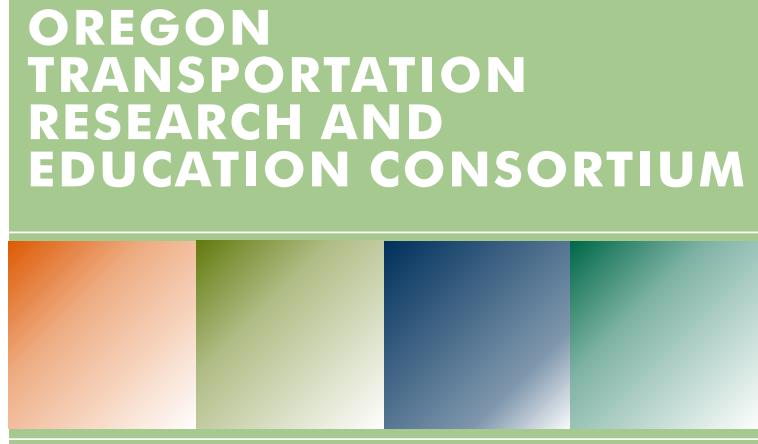

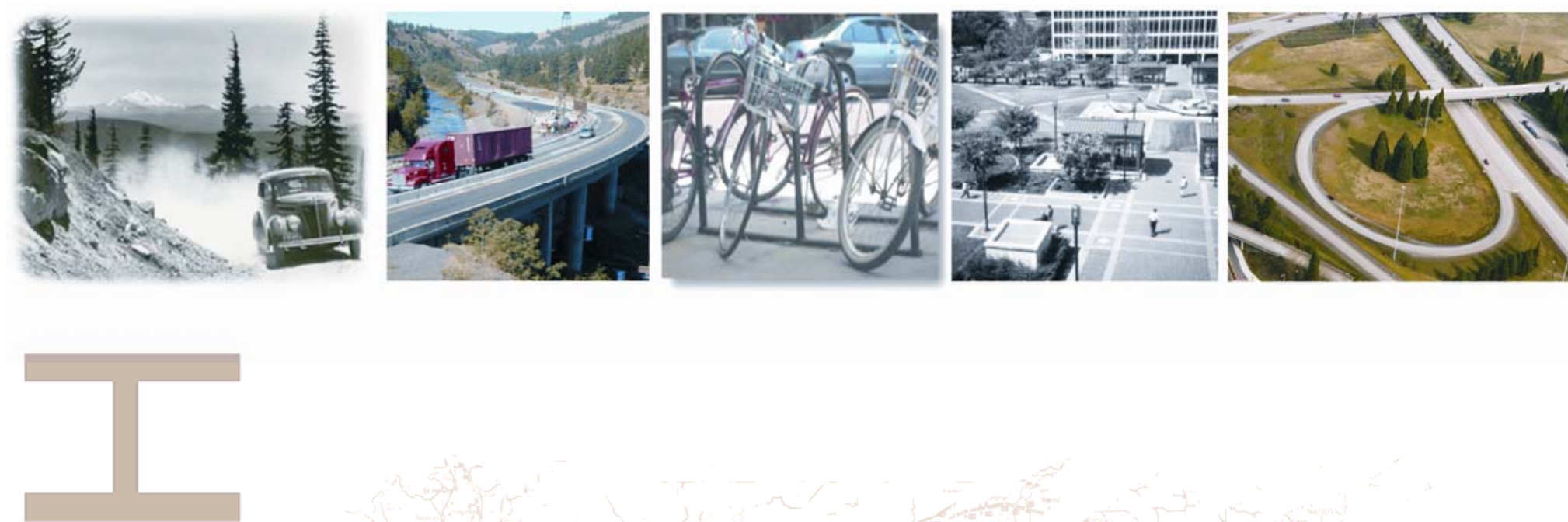

\title{
TECHNIQUES FOR ASSESSING THE SOCIO-ECONOMIC EFFECTS OF VEHICLE MILEAGE FEES
}

\author{
B. Starr McMullen \\ Lei Zhang \\ Oregon State University
}

FINAL REPORT

OTREC-RR-08-1

SPR 655
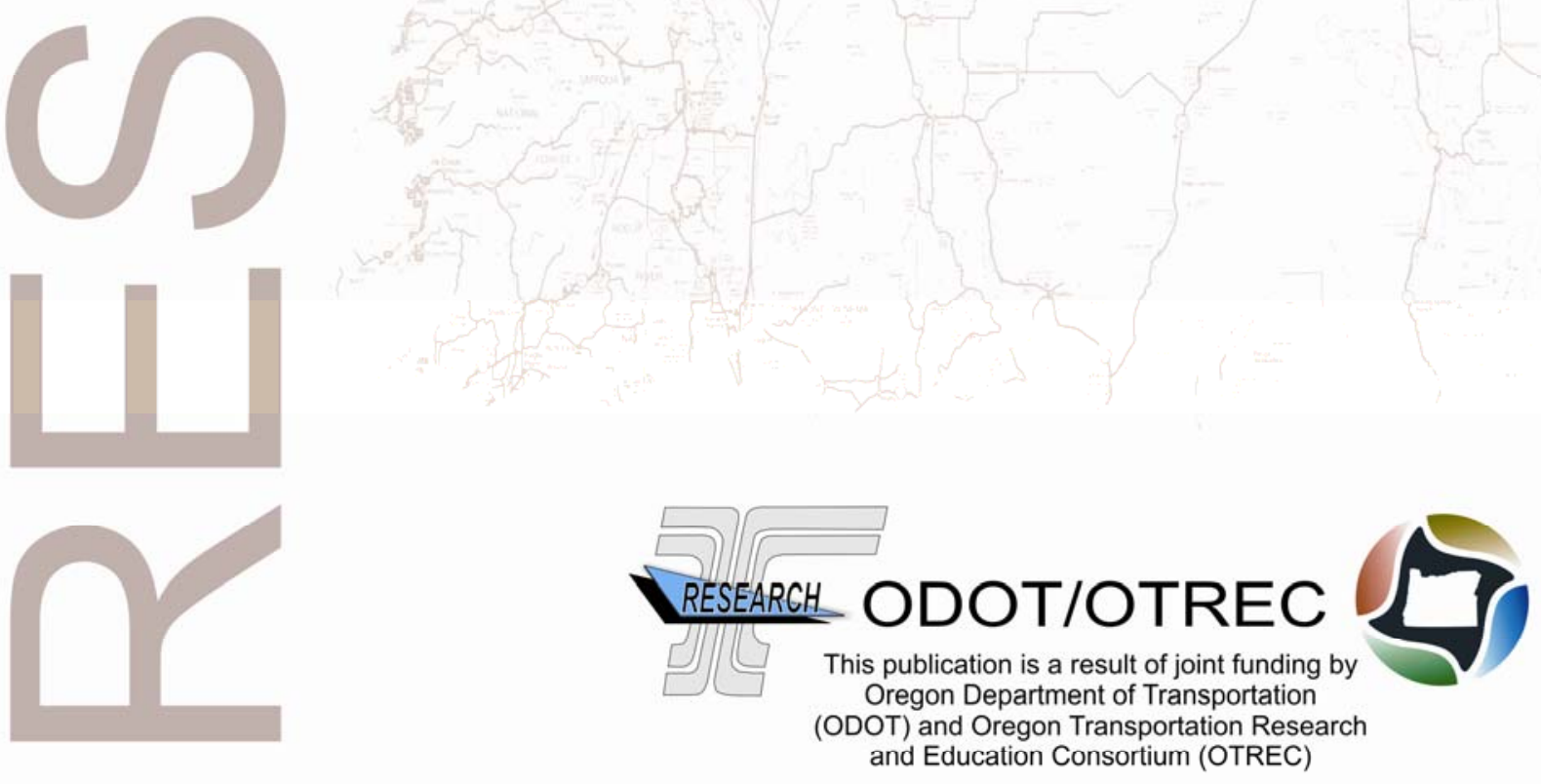


\title{
TECHNIQUES FOR ASSESSING THE SOCIO-ECONOMIC EFFECTS OF VEHICLE MILEAGE FEES
}

\author{
FINAL REPORT \\ OTREC-RR-08-1 \\ SPR 655
}

by

B. Starr McMullen, Professor of Economics, and Kyle Nakahara and Smita Biswas, Research Assistants

Department of Agricultural and Resource Economics

Oregon State University and

Lei Zhang, Assistant Professor, and Divya Valluri, Research Assistant

School of Civil and Construction Engineering

Oregon State University

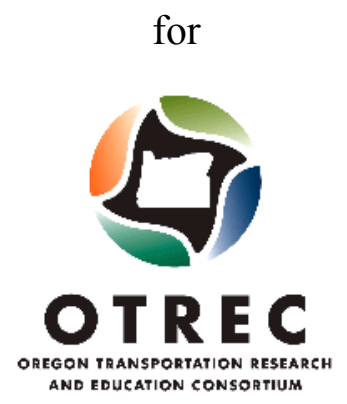

P.O. Box 751

Portland, OR 97207

and

Oregon Department of Transportation - Research Unit

200 Hawthorne Ave. SE, Suite B-240

Salem OR 97301-5192

and

Federal Highway Administration

400 Seventh Street, SW

Washington, DC 20590-0003

June 2008 


Technical Report Documentation Page

1. Report No.

FHWA-OR-RD-08-11

OTREC-RR-08-1

4. Title and Subtitle

Techniques for Assessing the Socio-Economic Effects of Vehicle Mileage Fees

5. Report Date

June 2008

6. Performing Organization Code

7. Author(s)

B. Starr McMullen, Kyle Nakahara, Smita Biswas

Dept of Agricultural \& Resource Economics

Lei Zhang, Divya Valluri

School of Civil and Construction Engineering

Oregon State University

9. Performing Organization Name and Address

10. Work Unit No. (TRAIS)

Oregon State University

Dept of Agricultural \& Resource Economics, 213 Ballard Extension Hall and

School of Civil and Construction Engineering, 220 Owen Hall

Corvallis, OR 97331

12. Sponsoring Agency Name and Address

Oregon Transportation Research and Education Consortium (OTREC)

P.O. Box 751, Portland, Oregon 97207

Oregon Department of Transportation

Research Unit

and Federal Highway Administration

200 Hawthorne Ave. SE, Suite B-240

400 Seventh Street, SW

8. Performing Organization Report No.

Salem, OR 97301-5192

Washington, DC 20590-0003

15. Supplementary Notes

16. Abstract

The purpose of this study was to develop tools for assessing the distributional effects of alternative highway user fees for light vehicles in Oregon. The analysis focused on a change from the current gasoline tax to a VMT fee structure for collecting highway user fees. A static model and a regression model were developed and used to assess the impact of such a change on households by income and by location (rural/urban). A discrete-continuous choice model was explored for addressing the more complex issue of how the change in policy would affect vehicle choice decisions in the long run and the resultant distributional impacts.

Results confirmed the regressive nature of the gasoline tax and showed that a change to a revenue neutral VMT fee of 1.2 cents per mile would result in a very small increase in regressivity (less than one percent for the lowest income group) in contrast to the five percent increase in regressivity caused by the increase in the price of gasoline between 2001 and 2006. The impact of a change to a VMT fee on rural areas was found to be opposite to that suggested by conventional wisdom. On average a household in a rural location would pay less under the revenue neutral VMT fee than under the gasoline tax, whereas those in urban areas would pay slightly more. Findings from the static and OLS models suggested that a change to a VMT fee is not likely to create a significant disincentive to purchase more fuel efficient or hybrid vehicles. The discrete-continuous model offered an appealing approach from a theoretical point of view to further address this question; however, the authors were not able to refine it enough to produce robust results.

Given that the impact on income groups was virtually identical in both the static and the more complex OLS regression models, it may be best for policymakers to use the simpler model, as it is easier to explain.

17. Key Words

HIGHWAY USER FEES; VMT FEE; SOCIOECONOMIC

IMPACTS; ECONOMIC MODELS; TAXATION; ELASTICITY

\section{Distribution Statement \\ Copies available from NTIS, and online at http://www.oregon.gov/ODOT/TD/TP RES/ and http://www.otrec.us}

\section{Security Classification (of this report) Unclassified}

\section{Security Classification (of this page) Unclassified}

\section{No. of Pages \\ $88+$ appendices}




\begin{tabular}{|c|c|c|c|c|c|c|c|c|c|}
\hline \multicolumn{10}{|c|}{ SI* (MODERN METRIC) CONVERSION FACTORS } \\
\hline \multicolumn{5}{|c|}{ APPROXIMATE CONVERSIONS TO SI UNITS } & \multicolumn{5}{|c|}{ APPROXIMATE CONVERSIONS FROM SI UNITS } \\
\hline Symbol & When You Know & Multiply By & To Find & Symbol & Symbol & When You Know & Multiply By & To Find & Symbol \\
\hline \multicolumn{5}{|c|}{ LENGTH } & \multicolumn{5}{|c|}{ LENGTH } \\
\hline in & inches & 25.4 & millimeters & $\mathrm{mm}$ & $\mathrm{mm}$ & millimeters & 0.039 & inches & in \\
\hline $\mathrm{ft}$ & feet & 0.305 & meters & $\mathrm{m}$ & $\mathrm{m}$ & meters & 3.28 & feet & $\mathrm{ft}$ \\
\hline yd & yards & 0.914 & meters & $\mathrm{m}$ & $\mathrm{m}$ & meters & 1.09 & yards & yd \\
\hline $\mathrm{mi}$ & miles & 1.61 & kilometers & $\mathrm{km}$ & $\mathrm{km}$ & kilometers & 0.621 & miles & $\mathrm{mi}$ \\
\hline \multicolumn{5}{|c|}{$\underline{\text { AREA }}$} & \multicolumn{5}{|c|}{$\underline{\text { AREA }}$} \\
\hline in $^{2}$ & square inches & 645.2 & millimeters squared & $\mathrm{mm}^{2}$ & $\mathrm{~mm}^{2}$ & millimeters squared & 0.0016 & square inches & in $^{2}$ \\
\hline $\mathrm{ft}^{2}$ & square feet & 0.093 & meters squared & $\mathrm{m}^{2}$ & $\mathrm{~m}^{2}$ & meters squared & 10.764 & square feet & $\mathrm{ft}^{2}$ \\
\hline $\mathrm{yd}^{2}$ & square yards & 0.836 & meters squared & $\mathrm{m}^{2}$ & $\mathrm{~m}^{2}$ & meters squared & 1.196 & square yards & $\mathrm{yd}^{2}$ \\
\hline $\mathrm{ac}$ & acres & 0.405 & hectares & ha & ha & hectares & 2.47 & acres & $\mathrm{ac}$ \\
\hline $\mathrm{mi}^{2}$ & square miles & 2.59 & kilometers squared & $\mathrm{km}^{2}$ & $\mathrm{~km}^{2}$ & kilometers squared & 0.386 & square miles & $\mathrm{mi}^{2}$ \\
\hline \multicolumn{5}{|c|}{$\underline{\text { VOLUME }}$} & \multicolumn{5}{|c|}{ VOLUME } \\
\hline $\mathrm{fl} \mathrm{oz}$ & fluid ounces & 29.57 & milliliters & $\mathrm{ml}$ & $\mathrm{ml}$ & milliliters & 0.034 & fluid ounces & $\mathrm{fl} \mathrm{oz}$ \\
\hline gal & gallons & 3.785 & liters & $\mathrm{L}$ & $\mathrm{L}$ & liters & 0.264 & gallons & gal \\
\hline $\mathrm{ft}^{3}$ & cubic feet & 0.028 & meters cubed & $\mathrm{m}^{3}$ & $\mathrm{~m}^{3}$ & meters cubed & 35.315 & cubic feet & $\mathrm{ft}^{3}$ \\
\hline $\mathrm{yd}^{3}$ & cubic yards & 0.765 & meters cubed & $\mathrm{m}^{3}$ & $\mathrm{~m}^{3}$ & meters cubed & 1.308 & cubic yards & $\mathrm{yd}^{3}$ \\
\hline \multicolumn{10}{|c|}{ NOTE: Volumes greater than $1000 \mathrm{~L}$ shall be shown in $\mathrm{m}^{3}$. } \\
\hline \multicolumn{5}{|c|}{$\underline{\text { MASS }}$} & \multicolumn{5}{|c|}{ MASS } \\
\hline $\mathrm{oz}$ & ounces & 28.35 & grams & $\mathrm{g}$ & $\mathrm{g}$ & grams & $\overline{0.035}$ & ounces & $\mathrm{oz}$ \\
\hline $\mathrm{lb}$ & pounds & 0.454 & kilograms & $\mathrm{kg}$ & $\mathrm{kg}$ & kilograms & 2.205 & pounds & $\mathrm{lb}$ \\
\hline $\mathrm{T}$ & short tons $(2000 \mathrm{lb})$ & 0.907 & megagrams & $\mathrm{Mg}$ & $\mathrm{Mg}$ & megagrams & 1.102 & short tons $(2000 \mathrm{lb})$ & $\mathrm{T}$ \\
\hline \multicolumn{5}{|c|}{ TEMPERATURE (exact) } & \multicolumn{5}{|c|}{ TEMPERATURE (exact) } \\
\hline${ }^{\circ} \mathrm{F}$ & Fahrenheit & $(\mathrm{F}-32) / 1.8$ & Celsius & ${ }^{\circ} \mathrm{C}$ & ${ }^{\circ} \mathrm{C}$ & Celsius & $1.8 \mathrm{C}+32$ & Fahrenheit & ${ }^{\circ} \mathrm{F}$ \\
\hline
\end{tabular}




\section{ACKNOWLEDGEMENTS}

The authors would like to thank the members of the Technical Advisory Committee for sharing their expertise throughout the study. The end product has greatly benefited from the contributions of this Committee. Brian Gregor and Becky Knudson (ODOT Transportation Planning Analysis Unit), Betsy Imholt, Jill L. Pearson and Jim Whitty (Oregon Innovative Partnerships Program), Jack Svadelnak (ODOT Financial Services), and Satvinder Sandhu (FHWA) provided comments, suggestions, and recommendations and contributed to a lively and productive discussion of the key issues. Special thanks to the Committee chair, Alan Kirk (ODOT Research Unit) who helped us maintain focus, provided detailed reviews of each and every draft of the report, and generally kept the project running smoothly and on time.

This project was funded by the Oregon Transportation Research and Education Consortium (OTREC).

\section{DISCLAIMER}

This document is disseminated under the sponsorship of the U.S. Department of Transportation University Transportation Centers Program and the Oregon Department of Transportation in the interest of information exchange. The United States Government and the State of Oregon assume no liability of its contents or use thereof.

The contents of this report reflect the views of the authors who are solely responsible for the facts and accuracy of the material presented. The contents do not necessarily reflect the official views of the United States Department of Transportation or the Oregon Department of Transportation.

The United States Government and the State of Oregon do not endorse products of manufacturers. Trademarks or manufacturers' names appear herein only because they are considered essential to the object of this document.

This report does not constitute a standard, specification, or regulation. 


\section{TECHNIQUES FOR ASSESSING THE SOCIO-ECONOMIC EFFECTS OF VEHICLE MILEAGE FEES}

\section{TABLE OF CONTENTS}

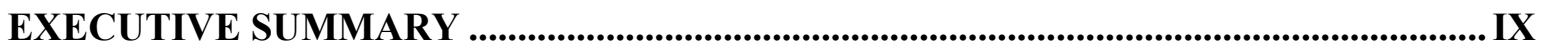

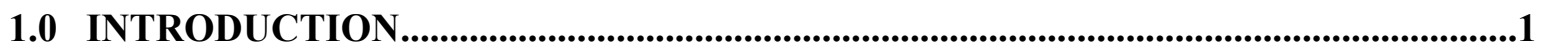

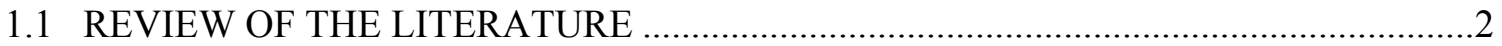

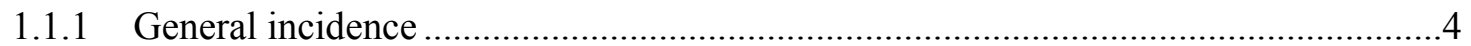

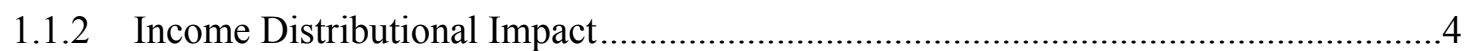

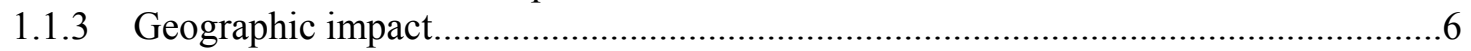

1.1.4 Impact on the Adoption of Alternative Fuel Vehicles............................................ 7

1.1.5 Other contexts in which a distance-based mileage fee has been examined ................8

2.0 MODELING THE IMPACT OF A VMT FEE ON OREGON HOUSEHOLDS ...........11

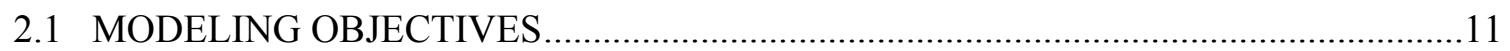

2.2 REVIEW OF PREVIOUS VEHICLE OWNERSHIP AND USE MODELS ..................12

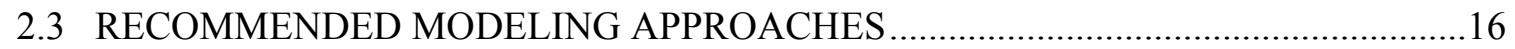

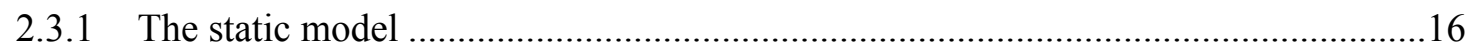

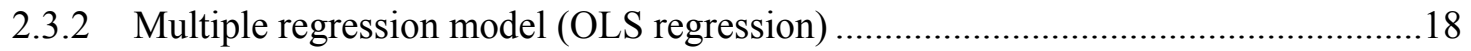

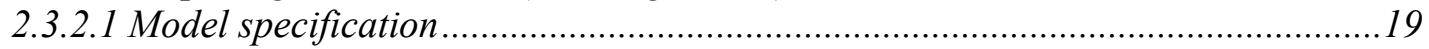

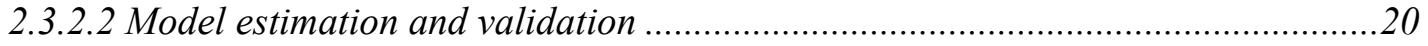

2.3.2.3 Model implementation and the distributional effects of a VMT fee......................20

2.3.3 Simultaneous Equation Model (SEM)....................................................................21

2.3.4 Discrete-Continuous Choice (DCC) Model ..........................................................22

2.3.4.1 Discrete choices of vehicle quantity and type ...................................................23

2.3.4.2 Continuous choice of vehicle use ..........................................................................24

2.3.4.3 Using the Discrete-Continuous Choice Model for policy analysis.......................25

2.4 SUMMARY OF THE RECOMMENDED MODELING APPROACHES ......................25

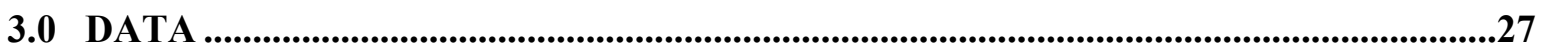

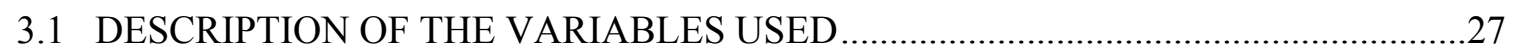

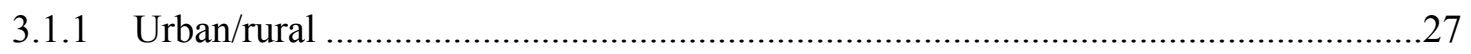

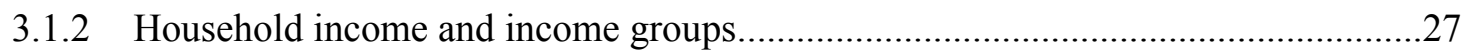

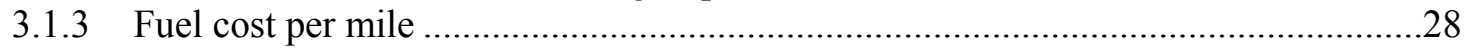

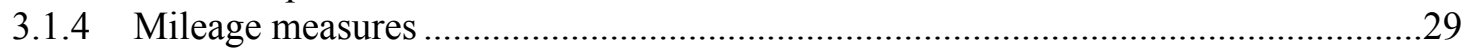

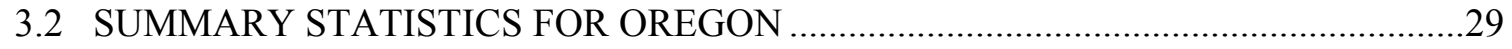

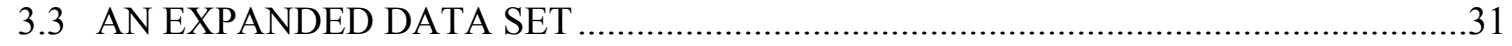

4.0 STATIC MODEL RESULTS …...........................................................................................35

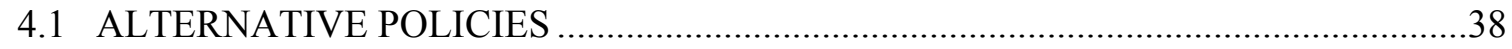

4.2 AN ALTERNATIVE WAY TO MEASURE REGRESSIVITY: THE SUITS INDEX ...40

5.0 REGRESSION MODEL RESULTS ....................................................................................43

5.1 OREGON SAMPLE REGRESSION RESULTS ....................................................4

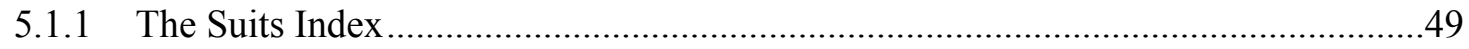




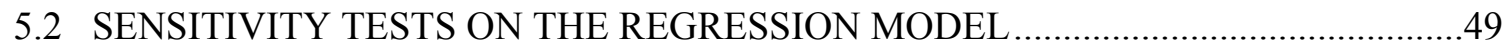

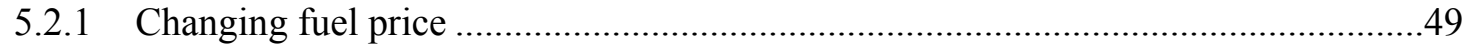

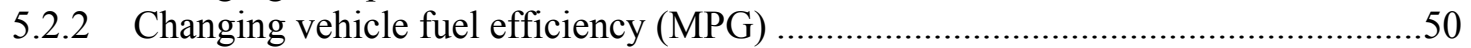

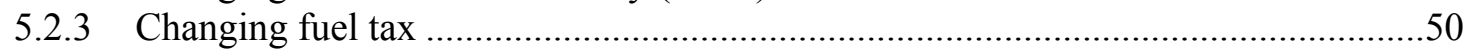

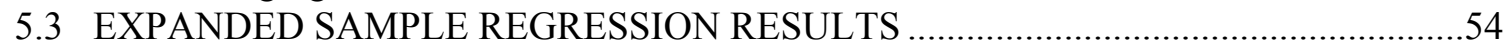

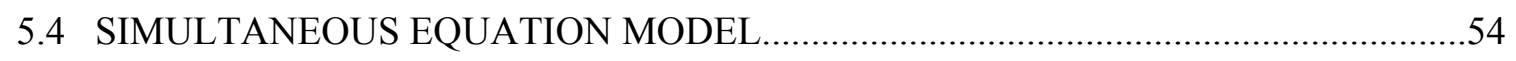

6.0 DISCRETE-CONTINUOUS CHOICE MODEL ........................................................55

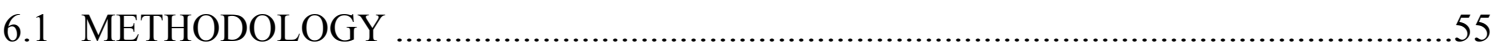

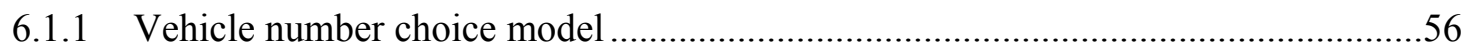

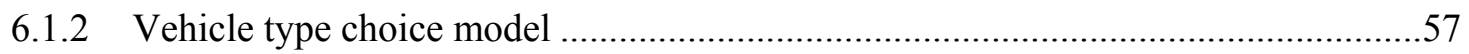

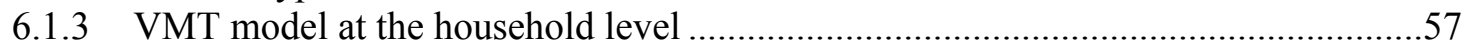

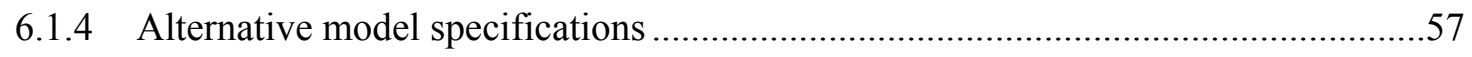

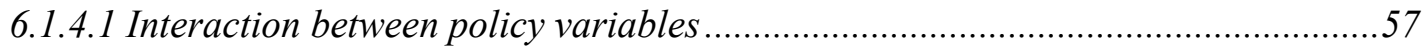

6.1.4.2 Interactions between the policy variables and cost variability by state .................58

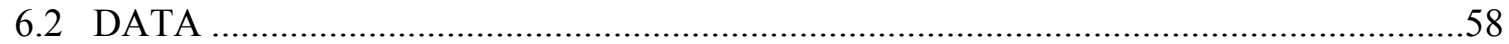

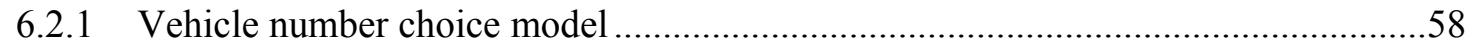

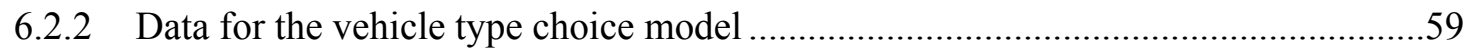

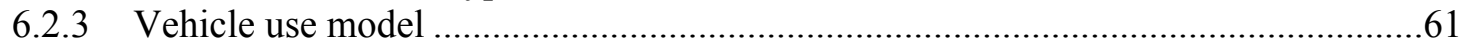

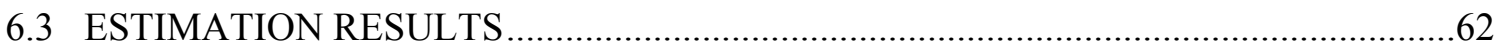

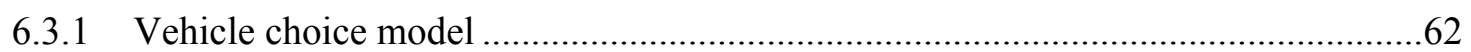

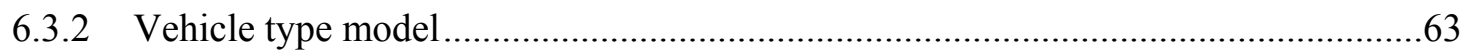

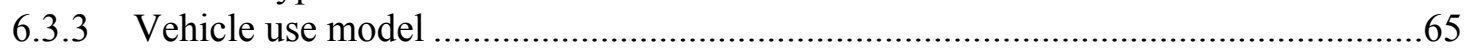

6.4 APPLICATIONS OF THE DISCRETE-CONTINUOUS-CHOICE MODELS FOR

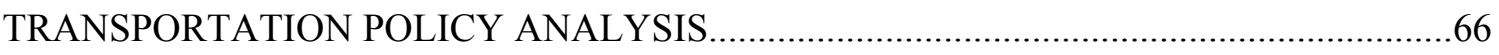

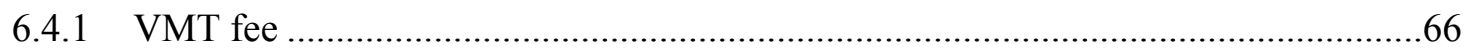

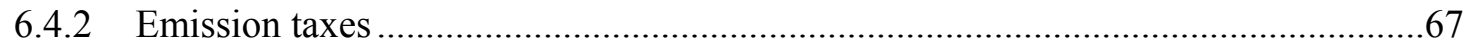

6.4.3 Policies that discourage vehicle ownership and use..........................................67

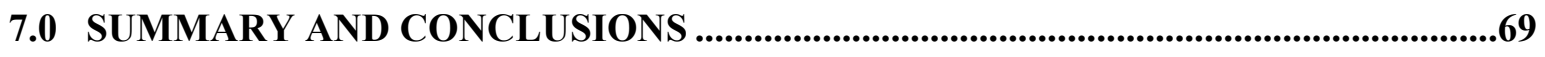

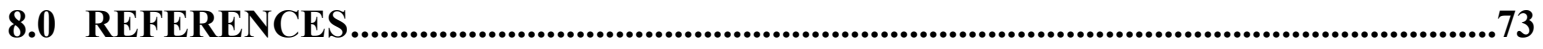

\section{APPENDICES}

APPENDIX A: INCOME GROUPS

APPENDIX B: SUITS INDEX, GRAPHS AND TABLES

APPENDIX C: DETAILED DATA DESCRIPTIONS

APPENDIX D: CONSUMER SURPLUS, REVENUE AND WELFARE DEFINITIONS 


\section{List of Tables}

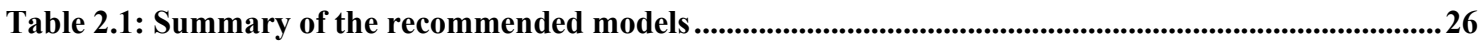

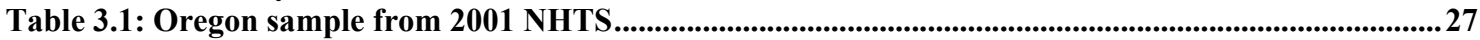

Table 3.2: Sample representation as compared to the Oregon Census 2000 .............................................28

Table 3.3: Number of Vehicles by Type and Location: Urban/Rural ..........................................................30

Table 3.4: Percent of Vehicles by Type and Location: Urban/Rural...........................................................30

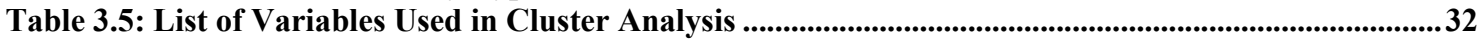

Table 3.6: Added observations from the NHTS as a result of the cluster analysis .........................................33

Table 4.1: Characteristics of households with zero vehicles ...................................................................................35

Table 4.2: Change in average annual household expenditures when switching from the gasoline tax to a

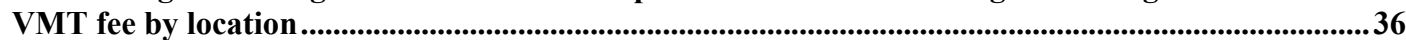

Table 4.3: Change in average annual household expenditures when switching from the gasoline tax to a

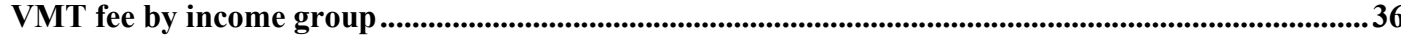

Table 4.4: Comparison of incidence of gasoline expenditures under a gasoline tax and a VMT fee:

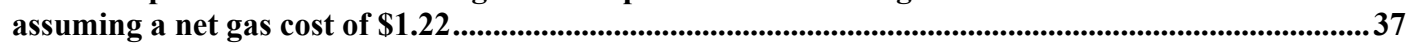

Table 4.5: Comparison of incidence of gasoline expenditures under a gasoline tax and a VMT fee: assuming a net gas cost of $\$ 2.40$

Table 4.6: Household annual expenditures on gasoline under Sample Scenario \#1* ......................................39

Table 4.7: Urban/rural household annual expenditure changes under Sample Scenario \#1*......................39

Table 4.8: Annual household expenditures by income group on gasoline under Sample Scenario \#2*......40

Table 4.9: Urban/rural annual household expenditures on gasoline under Sample Scenario \#2* ...............40

Table 5.1: Dependent variable - annual household miles (logarithmic) ${ }^{\dagger}$........................................................45

Table 5.2: Elasticity by income group - based on average income ...............................................................46

Table 5.3: Average changes in consumer surplus, tax revenue and welfare by income (\$/household) ....... 46

Table 5.4: Average changes in consumer surplus, tax revenue and welfare by location (\$/household) ...... 47

Table 5.5: Annual household expenditures on gasoline under Sample Scenario \#1 * ..................................4.

Table 5.6: Urban/rural annual household expenditure changes under Sample Scenario \# 1* ......................48

Table 5.7: Annual household expenditures on gasoline under Sample Scenario \#2* .......................................48

Table 5.8: Urban/rural annual household expenditures on gasoline under Sample Scenario 2* ...............48

Table 5.9: OLS Results Using the Expanded Seven State Sample $(n=3015)$.................................................54

Table 6.1: Descriptive statistics for vehicle number choice ......................................................................................59

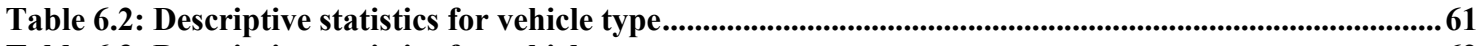

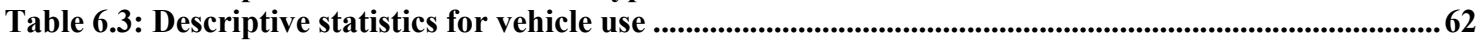

Table 6.4: Estimation results for Vehicle ownership model...................................................................63

Table 6.5: Results for vehicle type models - one-vehicle households.........................................................64

Table 6.6: Results for Vehicle type models - two-vehicle households..........................................................64

Table 6.7: Results for vehicle type models - three-vehicle households.......................................................65

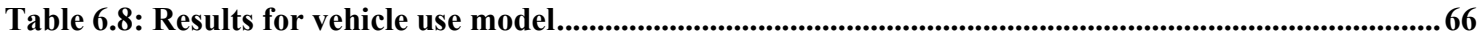

\section{List of Figures}

Figure 1.1: Per Mile Fuel Costs under Gas Tax and VMT Tax for Vehicles with Different Fuel ..................8

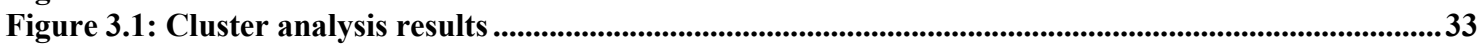

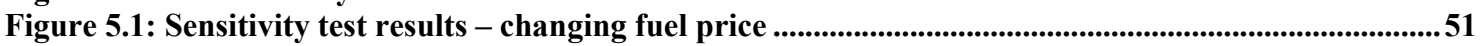

Figure 5.2: Sensitivity test results - changing household vehicle fuel efficiency (MPG)..............................52

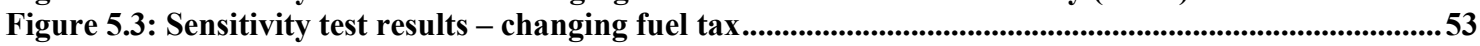

Figure 6.1: Diagrammatic representation of the discrete-continuous choice model.....................................56 


\section{EXECUTIVE SUMMARY}

This study developed tools for assessing the distributional effects of alternative highway user fees for light vehicles in Oregon. The analysis used the example of a change from the current gasoline tax to a VMT fee structure for collecting highway user fees. The questions addressed were as follows:

1) Would the change to a VMT fee be regressive, placing disproportionate hardship on those in lower income groups?

2) Would rural areas in Oregon be adversely impacted relative to urban areas?

3) Would a change to a VMT fee discourage people from acquiring alternative fuel vehicles or more fuel efficient vehicles and thus would be contrary to the state and national priority of reducing fossil fuel use?

A static model and a regression model were developed and used to provide answers to the first two questions. A discrete-continuous choice model was also explored and recommended for future development to better address the third issue.

Results indicated that the income distributional impact of changing to an approximately revenue-neutral VMT fee of 1.2 cents per mile would result in a slight increase in regressivity relative to the regressive structure of the current gasoline tax. The impact for the lowest income group amounted to a change of less than one percent of their income. As a comparison, the increase in total gasoline expenditures that was caused by the near doubling of gasoline prices from \$1.46/ gallon to \$2.64/gallon between 2001 and 2006 was over five percent of income for the lowest income group.

The impact of the change to a VMT fee on rural areas was found to be opposite to that suggested by conventional wisdom. On average a household in a rural location would pay less under a revenue-neutral VMT fee of 1.2 cents per mile than under the gasoline tax, whereas those in urban areas would pay slightly more. This was largely due to the lower overall average fuel efficiency in the rural vehicle fleet relative to the urban fleet and the greater number of miles driven on average by rural households.

Results suggested that a change to a VMT fee would not be likely to create a significant disincentive to purchase more fuel efficient or hybrid vehicles. This was because the change in fee structure had such a small impact on the cost of driving relative to the price of gasoline. Indeed, continued increases in gasoline prices would dwarf any change in per-mile costs caused by the change in user fee structure considered here. It is higher gasoline prices that are likely to produce the increases in driving costs of the magnitude necessary to create the incentive to adopt more fuel efficient vehicles.

The study concluded that a change from the current gasoline tax to a VMT fee structure of the type considered in this study, would have a negligible impact on income distribution. Further, concerns that rural households would be adversely impacted by the change in fee structure were unfounded, as rural households would actually benefit relative to urban households. Preliminary results suggested that the change in user fee structure considered 
here would not be likely to significantly impact vehicle choice. If future promotion of more fuel efficient vehicles is a policy priority, further development of the discrete-continuous choice model would be desirable to have a tool that can better predict how policy changes may affect vehicle choice in the long run. 


\subsection{INTRODUCTION}

The purpose of this study was to develop analytical tools for examining the distributional impact of changing from the current state gasoline tax to a vehicle miles traveled (VMT) fee. Interest in this topic has arisen because it has become evident that the gasoline tax - the primary way that highway user fees are collected at both state and federal levels in the U.S. may no longer be able to generate the funds needed to build and maintain the highway system. That this has become a national concern is evidenced by the 2006 Transportation Research Board Special Report \#285 submitted by the TRB committee for the study of the long-term viability of fuel taxes for highway finance (TRB 2006).

There are several reasons for the inadequacy of the gasoline tax as a long-term source of highway finance. First, public resistance to increases in the gasoline tax at both federal and state levels results in highway revenue growth falling short of the growth in highway costs. The current Oregon state gasoline tax of 24 cents per gallon has been in effect since 1991, when this tax represented over 20 percent of the price of a gallon of gasoline. Today, with gasoline prices around $\$ 4.00 /$ gallon, the 24-cent-per-gallon tax is about six percent of the price of gasoline. During this same time period, the purchasing power of highway revenues has eroded as the cost of construction materials such as concrete and steel has increased even faster than inflation.

Potentially exacerbating the highway finance shortfall in the future is the development of alternative fuels, which are not currently subject to gasoline/diesel fuel taxes, together with increases in fuel efficiency. These factors have made it clear that an alternative to the gasoline tax will be necessary if highways are to be maintained and built to meet current and future needs (Forkenbrock 2002).

This state of affairs in highway finance became such an important concern that the State of Oregon established a Road User Fee Task Force (RUFTF) in 2001 to consider alternatives to the gasoline tax for funding road maintenance and improvement. The RUFTF concluded that a distance-based fee, or vehicle miles traveled (VMT) fee, was one of the most promising alternatives to the gasoline tax.

One obstacle to collecting a VMT fee has been the absence of a technology sophisticated enough to count vehicle miles driven in the state. However, in a previous Oregon Department of Transportation (ODOT) study researchers at Oregon State University developed and tested a technology that would allow collection of highway user fees in this manner (Whitty, et al. 2006). With further development, the technology is no longer likely to be a real constraint on the establishment of a highway user fee.

Perhaps more problematic than the technology are public concerns regarding social equity and distributional effects of a VMT fee. In Oregon several concerns are expressed regularly to policymakers:

1. It has been suggested that the change in tax structure would shift the burden of the tax to lower income groups. 
2. There is a concern that the change in the tax structure would shift the burden of the tax to rural areas from urban areas, creating regional or geographic inequities.

3. Concerns have been expressed that such a shift in tax structure would discourage people from purchasing and driving alternative fuel vehicles, hybrids in particular.

The purpose of this research was to provide a perspective on these three issues that are often raised in objection to the implementation of a VMT fee. The following section in this chapter reviews the existing literature and approaches to these questions. Chapter 2 provides a discussion of the different models and methods that can be used to evaluate the impact of changing from the gasoline tax to a VMT fee. Chapter 3 reviews the data available for this study and provides summary statistics for the state of Oregon. Chapters 4 and 5 provide the results obtained for Oregon, first using a static model and then using an ordinary least squares (OLS) regression model that accounts for the feedback effects of a change in tax on demand. Chapter 6 presents the preliminary framework for a more sophisticated discrete choicecontinuous model that would allow longer-term impact evaluation. Conclusions are presented in the final chapter along with recommendations for future research on a distancebased fee.

\subsection{REVIEW OF THE LITERATURE}

From an economic point of view, and from the perspective of policymakers, the purpose of either a gasoline tax or a VMT fee is to charge an optimal road user fee. An optimal road user fee is one in which the users of the road pay the marginal costs they impose on the road system. There is an extensive literature on optimal road user fees under both congested and uncongested circumstances (Morrison 1986; Small, Winston and Evans 1989).

There are two components to a user fee for the road system: road wear costs and congestion costs. Maintenance costs for pavement are the primary component of road wear costs.

Congestion costs are incurred when traffic does not flow freely, indicating that road capacity has been reached (Small, Winston and Evans 1989).

When there is congestion, optimal user fees will be higher than in non-congested circumstances, and revenues collected may exceed those required to maintain the existing road system, thus providing funds for capacity increases. The implementation of optimal congestion fees and their political acceptability is the major focus of much research and experimentation in the area of road pricing. Except for a few select urban areas, congestion pricing is not in place and represents a major change from what road users are accustomed to paying.

Although this study could easily be extended to consider issues involved in charging congestion fees, the main focus here will be on road user fees under non-congested circumstances. What distinguishes this from congestion pricing is that in almost all countries, road users already pay a road user fee. Thus, a change from the gasoline tax to a VMT fee does not represent a new tax, but rather a different way of collecting user fees that are already being paid.

Indeed, the "user-pay" concept as a basic financing principle in transportation dates back to Pigou in the 1920s. Under ideal conditions, the revenue collected from marginal cost tolls will just be sufficient to finance the transportation network to its optimal level of capacity 
(Mohring and Harwitz 1962). In practice, however, this simple and elegant road pricing and investment principle encounters technological, institutional, and political difficulties.

In 1919 Oregon became the first state to impose a fuel tax to raise money to finance road maintenance and construction; other states quickly followed suit (McMullen 2005). In years past, the gasoline tax was generally seen as an equitable and efficient way of charging road user fees for light vehicles such as autos and pickup trucks, since there were not the large differences in fuel efficiency that we see today. Miles driven and thus road damage were highly correlated to gasoline consumption. Given the wide disparity of fuel efficiencies in the current vehicle fleet, however, the gasoline tax has become a less accurate reflection of the marginal costs users impose on the road system.

In the state of Oregon, heavy trucks (weighing over 26,000 pounds) are subject to a weightmile tax which provides a reasonably good approximation of the marginal damage that they do to the roads. In the case of heavy trucks, the damage that they do to the roads is exponentially and directly related to their weight (Small, Winston and Evans 1989). Thus, trucks operating in the state of Oregon already pay a distance-based fee and one that carries higher tax rates for truck configurations that impose greater costs on the road system. Light vehicles (up to 26,000 pounds) in Oregon still pay road user fees through fuel taxes.

Short run marginal road costs from autos and other light vehicles are directly related to miles driven and, despite increasing variance in vehicle weights (and fuel efficiency), there is not much difference in the damage done to the road by different types of light vehicles (whereas there is a big difference in damage to the road done by heavy trucks of different weight groups and with different axle configurations). Indeed, Merriss (2004) notes that the "difference in pavement damage imposed by a 6,000-pound large SUV versus a 3,500-pound compact car is inconsequential as compared to the difference in (pavement) damage imposed by either of these vehicles versus a fully-loaded 80,000-pound truck" (p.2).

Of the vehicle miles driven in the state of Oregon in 2002, 92 percent of the vehicle-miles driven were attributable to light vehicles. Thus, Merriss (2004) argues that the primary way light vehicles affect highway costs is through the sheer numbers of miles they drive and their impact on congestion, thus producing the demand for additional road capacity.

Konkelman and Shahib (2000) argue that light trucks and SUV's increase headways between vehicles, reducing the capacity at intersections and increasing urban congestion. Thus, in the long run, when capacity expansions are considered or when the goal is to alleviate congestion, it might be better to follow the current convention in use in the Oregon Highway Cost Allocation Study, and charge light vehicles on the basis of their passenger car equivalent (PCE) weighted vehicle-miles rather than vehicle miles alone.

Sorenson and Taylor (2005) argue that equity concerns are not so great for a "straight" distance-based user fee that is not linked to a congestion fee, and they suggest introducing a vehicle mile fee first and later revising it to accommodate congestion pricing.

Whatever the exact fee structure, the main goal for a state government is to charge road user fees that will provide an adequate source of finance for the highway system. It should be noted that Oregon dedicates all highway user fees to the Highway fund unlike many other states, which place highway user fees into a general fund, mixing revenue sources. The proposed change from a gasoline tax to a vehicle-mile or distance-based fee for light vehicles in Oregon would come closer to meeting this objective than the current gasoline tax. Indeed, 
a VMT fee is something that is being considered not only by the State of Oregon, but at the national level (TRB 2006).

The following sections discuss and provide a preliminary review of the potential socioeconomic/political impacts resulting from such a change in tax structure.

\subsubsection{General incidence}

To determine the distributional impact of changing from the gasoline tax to a VMT fee requires first determining the general incidence of the gasoline tax - who pays the gasoline tax, the gasoline retailer or the consumer?

Alm and Sonnoga (2005) find full shifting of gasoline taxes to the final consumer. Chouinard and Perloff (2004) find that while the federal gas tax falls about half on the consumer and half on the gasoline retailer, they find that virtually all of a state gasoline tax is borne by the retail customer. In addition, they find that the incidence of state gasoline taxes on the consumer is inversely related to the share of national gasoline tax sales in the state; thus a greater part of the state gas tax is borne by customers in states with a smaller share of the national gasoline bill. Based on these findings, in the case of Oregon it is reasonable to assume that it is the consumer, rather than the retailer, who ends up paying the state gasoline tax.

For a VMT fee, it is clear that the tax is being paid by the final consumer. Thus, for practical purposes it makes no difference which way the road user fee is collected; it is ultimately paid by the consumer in the state of Oregon.

\subsubsection{Income Distributional Impact}

Since the demand for gasoline is known to be inelastic, it is usually argued that the gasoline tax is regressive.

A 1990 Congressional Budget Office Report (CBO 1990) found that the tax on motor fuels was regressive relative to annual income but generally proportional with respect to total expenditures.

Sarah West $(2001,2005)$ explores the distributional impact of implementing vehicle emissions taxes on automobiles, and her work touches on a number of issues relevant to our study. West follows Poterba's (1991) suggestion that household expenditures be used rather than household income in examining tax incidence. His argument is that decisions regarding gasoline expenditures may be based on lifetime or permanent income rather than the annual income observed in a typical cross-section study. He uses annual expenditures as a proxy for permanent income, and his results show that low income households actually devote a smaller share of their expenditures to gasoline than higher income households. Further, he finds that households in the top five percent of the income distribution spend a smaller percent on gasoline, so that the gasoline tax actually is progressive over lower income groups and then turns regressive at higher levels of income.

West (2001) uses expenditures as a proxy for income and finds the gasoline tax to be progressive across lower income groups, a result she attributes to the greater elasticity of demand lower income groups have in response to changes in gasoline prices. In her empirical results, she also examines the impact of a per-mile emissions tax and finds that 
taxes on miles is progressive over lower income deciles (as a percentage of total household expenditures) but becomes regressive over the upper deciles.

For a gasoline tax, the regressivity depends in part on how responsive the miles driven by people in different income groups are to changes in the tax (included in the price of gasoline). It also depends on the type of vehicle driven by people in the different income groups as well as the number of miles driven by people in the various income groups.

West and Williams (2004) argue that ignoring demand responses to changes in gasoline prices will result in more regressive measures. Thus, one reason for West's (2001) results is that she finds that the elasticity of vehicle miles traveled (VMT) with respect to changes in the per mile cost of driving, is greater (-1.51) for those in the lowest decile of income than those in the higher deciles. (For example, she finds an elasticity of -0.75 for those in decile 8 in her sample.) This elasticity, combined with the fact that a large proportion of households in the lowest decile do not own vehicles and thus do not pay any gasoline tax, results in the gasoline tax being less regressive than conventional wisdom may dictate.

At this point it is important to raise the question of whether the finding that the gasoline tax is progressive at lower income levels is really providing the right information about the welfare of people in the lower income groups. While those in the lower income groups may pay proportionally less of their income in gasoline taxes than the upper income groups, this may well be because they face significant mobility and access limitations due to their income status. For instance, low income households are more likely to not own a vehicle; thus they do not bear the burden of gasoline taxes, but they may have mobility problems and suffer consequences in the job market as a result. The elderly also have lower vehicle ownership rates, so they appear to be less affected by gasoline taxes, but this reflects their mobility constraints. If all income levels had the same mobility and car ownership characteristics, it might be that the gasoline tax would be regressive over all income groups. Thus, care must be taken in interpreting these income incidence measures.

It is important to note that the incidence of the gasoline tax depends partly on the vehicle choice made by different income groups. West (2001) argues that households in the lower deciles own vehicles that have poorer gas mileage, making their per mile cost of gasoline higher than those in higher income groups. This contributes to making the price elasticity of that group more sensitive to changes in tax rates. Given that West's data comes from the 1980 's when auto manufacturers were just retooling and starting to produce more fuel efficient vehicles, this finding makes sense, because lower income people who were unable to purchase the new vehicles had to make do with less fuel efficient, older models.

In the 1990's, however, there have been mixed messages regarding fuel efficiency. On one hand there have been very fuel efficient cars that have come on the market, but conventional wisdom suggests that many people in the middle/upper income groups have gravitated towards heavier SUVs that get fewer miles per gallon. Thus the trend towards greater fuel efficiency slowed during the 1990's. This complicates the measurement of tax incidence and suggests that the gasoline tax may not be as regressive as once thought. Clearly any study of the incidence of the gasoline tax needs to consider the vehicle mix across income groups as well as the elasticity of demand for gasoline across income groups.

Interestingly, Zupnick (1975) looked at the incidence of gasoline taxes during the 1969-70 period using annual income data (rather than consumer expenditures) and a static model that does not account for demand responses. He found similar results to West and Proterba: that 
the gasoline tax was progressive over lower income groups and then turned regressive for upper middle and upper income groups. Zupnick's conclusion was that it was the middle class that incurred the largest burden from the gasoline tax.

Finally, there was a big change in gasoline prices between the Zupnick and West study period, and nominal gasoline prices today are much higher than those experienced in either of the earlier periods. Today fuel taxes are small compared to the price of gasoline. Vehicle choice and usage will depend on overall gasoline price, not the fuel tax. Thus, the distributional effects from more recent data may be different than those from earlier studies.

The West (2005) and Proterba (1991) studies examined incidence for the entire U.S. using the measure of consumption expenditure from the Consumer Expenditure Survey (CES). For the state of Oregon, however, the CES did not provide a large enough data set for this study. In addition to income distribution, the investigators also wanted to see how a change in the road user tax structure would change the way in which individual households traded off using different household vehicles (in particular high- versus low-mileage vehicle use). Information on individual vehicle usage (miles) was not available in the CES data set; only total household mileage was given.

Thus, the investigators used the National Household Travel Survey (NHTS) as the primary data source for this study. Data were available on individual household vehicles; however only annual household income was available, not annual expenditures as advocated by West and Proterba. Fortunately, Zupnick's results indicated that the possible bias, introduced by using annual income rather than expenditures, may not be a serious problem.

\subsubsection{Geographic impact}

In the state of Oregon there is a deep concern that changing from the gasoline tax to a VMT fee will adversely impact rural areas relative to urban areas. It is usually argued that since there are fewer transportation alternatives in rural areas, the demand for miles driven in rural areas will likely be more inelastic than in urban areas. Changing the pricing mechanism may thus have little (or no) impact on driving behavior in rural areas. In other words, the elasticity of demand for vehicle miles, in response to a change in tax, is inelastic.

However, the response of VMT to changes in the cost of driving also will depend on the type of vehicles driven in rural areas relative to urban areas. The total impact on the rural/urban areas will depend on the number of miles driven by those impacted by a tax change.

Assuming a flat revenue-neutral VMT fee, the current 24 cents-per-gallon gasoline tax would change to a 1.2 cents-per-mile distance-based fee. Under this VMT fee people who drive vehicles with a fuel efficiency of less than 20 miles per gallon ( $\mathrm{mpg}$ ) would actually pay less in road user fees than under the gasoline tax. Those who now drive vehicles with fuel efficiency exceeding $20 \mathrm{mpg}$ would pay more. Thus, the distributional impact on urban/rural as well as high/low income groups depends in turn on what type of vehicle is used by the different households. 


\subsubsection{Impact on the Adoption of Alternative Fuel Vehicles}

Finally there is concern that owners of fuel efficient vehicles would end up having to pay more in road user fees under a VMT fee than under the current gasoline tax. Will this discourage the use of fuel efficient vehicles, hybrids in particular?

If a vehicle gets $50 \mathrm{mpg}$, under the current Oregon gasoline tax it would be paying $\$ 0.24 / 50$ miles or about $\$ 0.0048$ ( 0.48 cents) per mile. This amount is $40 \%$ of the 1.2 cents per mile estimated for a revenue-neutral VMT fee. If gasoline, exclusive of tax were $\$ 3.75$ per gallon, the $50 \mathrm{mpg}$ vehicle driver would be paying 7.5 cents per mile in gasoline expense plus 0.48 cents per mile in tax, or about 7.98 cents per mile. With a VMT fee this would rise to 8.7 cents per mile, increasing the per-mile combined gasoline and tax cost of driving by 0.72 cents, about 9 percent. Recent AAA estimates of per-mile total costs of driving range between 50 cents and 66 cents per mile; thus the 0.72 cents higher cost due to a VMT fee would translate into less than a $2 \%$ difference in the overall driving cost per mile. Is this enough to make people decide not to buy a hybrid?

Unfortunately, there is not yet a good enough data set available to estimate a demand function for hybrid vehicles that would allow calculation of the price elasticity of demand for a change of this magnitude in operating expenses. However, given the fact that this represents a very small amount compared to the purchase price of the vehicle, it is likely that the impact would be negligible. In fact, current sales of hybrids are taking place despite the fact that the new vehicle price of a hybrid is often $\$ 2,000-5,000$ more than the purchase price for a comparable regular fuel vehicle.

In addition, while some hybrid vehicles get very high fuel economy (greater than $40 \mathrm{mpg}$ ), others do not. In particular, many of the newer hybrids are aimed at the SUV market, and while the fuel economy of these vehicles is higher than a comparable non-hybrid model, it is possible that people who were driving more fuel efficient smaller cars are now buying larger vehicles with the same mileage as their smaller car. The net result could be the same amount of total fuel consumed, but an increase in the average size of vehicles. Such an outcome would mirror the phenomenon observed in the 1990s: as vehicles became more fuel efficient the vehicle mix turned more towards larger vehicles.

It should be noted that the point of hybrid subsidies is not to reduce fuel consumption in the short run but to promote the development of a market to improve a fuel saving technology and reduce the cost of the technology. It is also hoped that in the medium to long run it will substantially reduce fuel consumption.

There is also the interrelated question of the distributional impact of promotion of hybrid vehicles. West (2005) argues that policymakers have tended to try and promote the use of hybrids through various types of subsidies such as tax credits on new cars. Since these vehicles usually cost more and are usually purchased by those in the higher range of the income distribution, she claims that either gasoline taxes or mile-based fees are significantly less regressive than these subsidies.

It is, of course, possible to charge different VMT fee rates depending on the vehicle size or passenger car equivalents (PCE). Indeed, promoters of high fuel efficiency vehicles often suggest charging "gas guzzlers" (which are usually higher weight, larger vehicles) a higher fee to encourage people to switch to more fuel efficient and environmentally friendly vehicles. However, given the currently contemplated mileage fees in the 1-2 cent per mile 
range, Forkenbrock (2000) argues that "it is not clear that varying per-mile rates among types of passenger vehicles will constitute a significant incentive to purchase and operate environmentally friendly vehicles" (p. 97).

Figure 1.1 illustrates the impact of a change from a 24 cent-per-gallon gasoline tax to a 1.2 cent-per-mile VMT fee on drivers of vehicles with differing fuel efficiency.

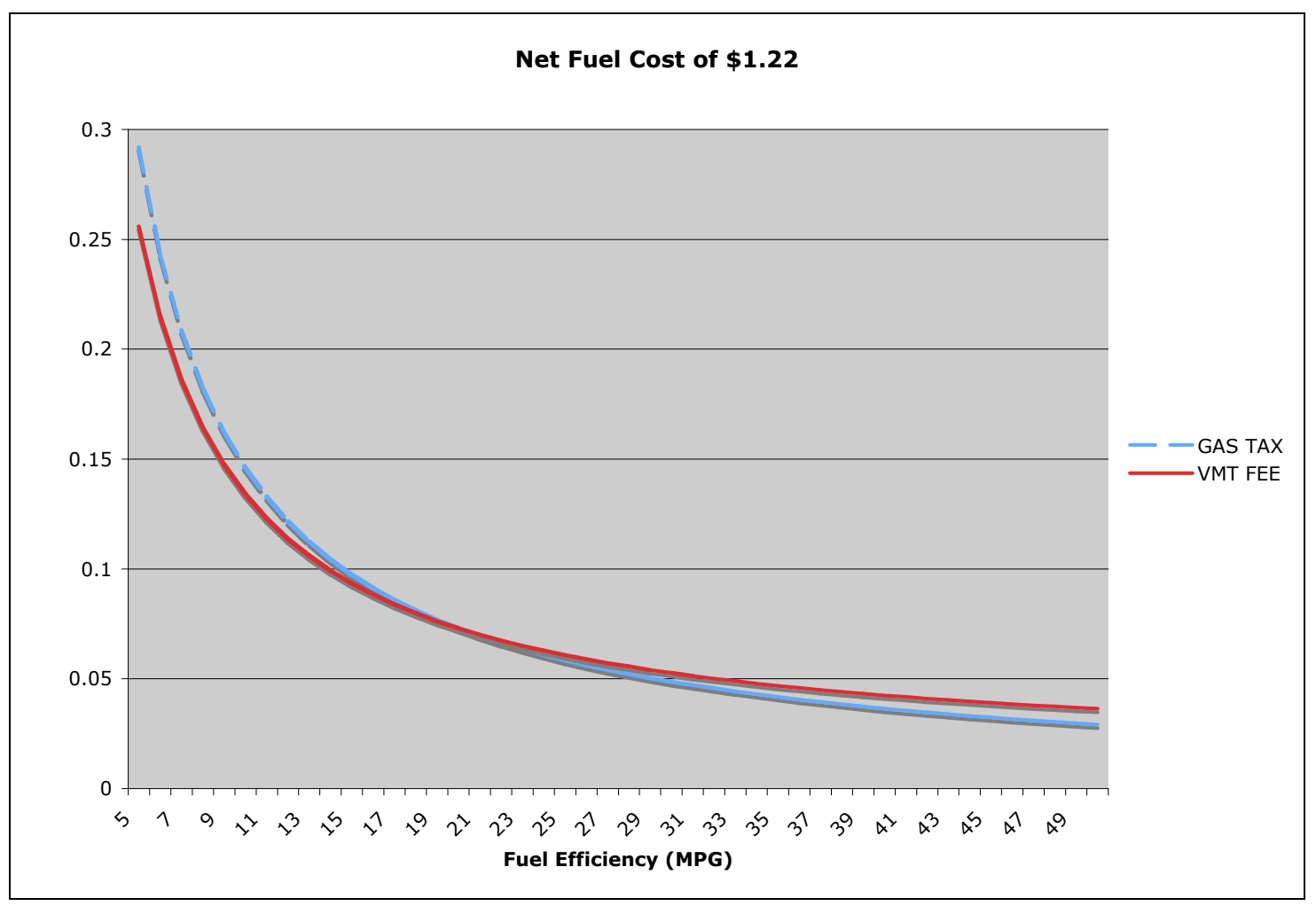

Figure 1.1: Per Mile Fuel Costs under Gas Tax and VMT Tax for Vehicles with Different Fuel

Clearly people with vehicles that get less than 20 mpg would pay less under a VMT fee and those with vehicles attaining more than $20 \mathrm{mpg}$ would pay more, but is the amount enough to cause a significant change in behavior?

Ball (2007) in a recent Wall Street Journal article quotes Robert Socolow, professor at Princeton University as saying that a carbon emissions cap that raises the price of gasoline by 30 cents a gallon would be "... not enough to prod many people to go out and buy a more efficient car." Indeed, recent increases in the retail price of gasoline have been in this range and thus provide a unique opportunity to observe the impact on fuel efficient automobile purchases in the next few years.

\subsubsection{Other contexts in which a distance-based mileage fee has been examined}

Although there are no studies that empirically examine the use of a VMT fee for collecting road user fees, there is a developing literature that looks at vehicle mileage fees as a 
mechanism for collecting emissions taxes. West (2005) and Parry and Small (2005) all find the mileage fee to be a much better instrument for approximating optimal emissions fees than a gasoline tax. Thus, a VMT fee for road users may well have the additional social benefit of reducing emissions.

Finally, DeCorla-Souza (2001), Litman (1999, 2006), and Edlin (2002) discuss the benefits of distance-based insurance. Greater economic efficiency can be achieved by turning fixed costs, such as vehicle insurance, into variable costs. In theory, fixed costs are not considered when making marginal decisions. For example, once a driver pays the insurance premium, there is no incentive to limit the distance driven; in fact, assuming there is some utility to gain from increasing miles driven, there is actually an incentive to drive more.

A distance-based fee gives all drivers the option to reduce miles driven and save money. DeCorla-Souza (2001) uses social cost estimates from Delucchi (1997) to estimate the impacts of an optional distance-based insurance program including the effect on externalities such as pollution and accidents. He estimates that the total value of social benefits from an optimal distance-based insurance charge program could be as large as $\$ 2,914$ per mile under congested road conditions.

Thus it is timely to provide a complete analysis of the overall socio-economic impact of changing from the gasoline tax to a VMT fee. In addition to providing state Departments of Transportation with a more reliable source of revenue, such a system might provide added social benefits as described above. This study thus explores some analytical tools policymakers might use to evaluate the socio-economic impacts. 


\subsection{MODELING THE IMPACT OF A VMT FEE ON OREGON HOUSEHOLDS}

This chapter examines alternative methodologies for analyzing the impact of a change from a gasoline tax to a VMT fee on households and regions.

The first methodology pursued is referred to as the static model. This is a method frequently used by the U.S. Congress Joint Committee on Taxation (JCT) to evaluate the distributional impact of changes in tax structure on households in different income groups. This method assumes that the tax change itself will cause no behavioral response. Although this method is known to overstate increases in tax burden and understate decreases in tax burden, the JCT advocates this approach largely on the grounds that it is easily understood by policymakers who may get lost in details of more complex analyses. This is particularly appropriate if the changes are likely to be very small.

The other approaches discussed in this chapter involve models that account for behavioral responses to changes in the cost of driving that are caused by the change in tax structure. Three econometric modeling approaches are found particularly suitable for this objective: multiple regression analysis, a simultaneous equation model, and a discrete-continuous choice model. These models vary in their behavioral realism, data requirements, and policy sensitivity.

This chapter begins the discussion of the alternative econometric approaches with a review of the modeling objectives. Following this is a review of previous research on vehicle ownership and use models. The chapter concludes with a summary of the advantages and disadvantages of each approach.

\subsection{MODELING OBJECTIVES}

Given the current Oregon state gasoline tax of $\$ 0.24$ per gallon, drivers pay different amounts of taxes per mile driven due to variations in vehicle fuel efficiency (i.e., miles per gallon). A 1.2 cents-per-mile VMT fee would result in a revenue-neutral change under the assumption that the average vehicle in Oregon has a 20 miles-per-gallon (mpg) fuel efficiency. Therefore, under such a VMT fee the effective fuel cost per mile including taxes would increase for a vehicle with fuel efficiency greater than $20 \mathrm{mpg}$ and decrease for a vehicle with fuel efficiency less than $20 \mathrm{mpg}$.

According to the standard microeconomic demand theory, a change in fuel cost per mile can be expected to induce a range of behavioral responses from Oregon households. In the near term, households may change their total number of trips, destinations, modes, routes, and the relative use of different household vehicles (if the households have more than one type of vehicle, e.g., a car and an SUV). In the medium term, households can change both the number and the type of vehicles they own. In the long term, per-mile fuel cost changes may even affect households' residential and employment location decisions, though such relocation effects should not be very significant. 
The near-term and medium-term potential demand responses can be divided into two categories: changes in vehicle use (measured by vehicle miles driven) and changes in vehicle ownership (number and type of vehicles). It should be noted that these demand responses are interrelated. For instance, an increase in the fuel cost per mile should cause a household to drive less in the short run. However, if the household decides to purchase new vehicles with lower fuel costs per mile sometime in the future, the total household vehicle use could increase again; (this is the "rebound" effect of increasing fuel efficiency).

It is also expected that a change to a VMT fee would not affect all Oregon households the same. First, different households exhibit dissimilar vehicle ownership characteristics. The impact of a flat-rate VMT fee on households that primarily own fuel efficient vehicles should differ from the impact on households that primarily own pickup trucks and SUVs. In addition, households with multiple vehicles and multiple vehicle types can switch their vehicle use more towards the vehicle(s) with relatively lower fuel cost per mile.

Second, households with lower incomes are likely to be more sensitive to per-mile fuel cost changes. Third, households living in different regions can respond differently to changes in fuel cost per mile. For instance, it is often argued that rural households drive more than urban households due to different land use patterns. Urban residents also enjoy better public transit services and more destination options than their rural counterparts. Consequently, urban households could more easily adjust their travel behavior if a VMT fee were implemented. The distributional effects of the VMT fee are therefore multifold, which imposes challenges on model capabilities.

The purpose of this study is to provide the necessary analytical tools to compare the incidence of a VMT fee to the incidence of the current per-gallon gasoline tax. The modeling objective is therefore to quantify the vehicle ownership and use changes for different household groups in response to the conversion from the gasoline tax to a flat-rate VMT fee. It is also desirable that the models developed in this project can estimate the demand responses to graduated (i.e., variable-rate) VMT fees (by location, by fuel efficiency, etc.). Results from the modeling can be used in policy analysis to estimate the distributional effects of various VMT fee structures.

Data availability is an important issue for all empirical modeling work. A summary of data availability and a detailed description of the main data source - the National Household Travel Survey (NHTS) - are presented in the following chapter. It is sufficient here to note that the ability to successfully estimate all of the models discussed in this chapter depends critically on the availability of requisite data.

\subsection{REVIEW OF PREVIOUS VEHICLE OWNERSHIP AND USE MODELS}

Choices of automobile ownership and use have been extensively studied by economists, land use and transportation planners, public policy analysts, environmental protection agencies, and automobile manufacturers. Models of vehicle ownership and use have been successfully developed and applied in previous research to conduct a variety of important planning and policy analyses: 
1. Estimating the impact of fuel efficiency regulations and technologies on automobile ownership and use patterns (Goldberg 1998; Greene, et al. 1999; Small and Van Dender 2006);

2. Analyzing the automobile demand and travel demand responses to gasoline price changes (Haughton and Sarkar 1996; Puller and Greening 1997); Bento, et al. 2005; Bomberg and Kockelman 2000);

3. Assessing the overall and distributional effects of mileage-based vehicle pollution control policies and emissions taxes (Walls and Hanson 1999; West 2004);

4. Estimating the benefits from mileage-based vehicle insurance (DeCorla-Souza 2001);

5. Forecasting future demands for various types of automobiles (often conducted by automobile manufactures);

6. Forecasting future automobile use, level of congestion, and mobile-source emission levels for land use development and transportation investment analysis (conducted by states and Metropolitan Planning Organizations).

Earlier research on automobile demand (number and type) employed aggregate models developed from national or state-level time series data (Chow 1957; Kain and Beesley 1965; Mogridge 1967; Chamberlain 1974). Although aggregate demand models are useful in forecasting future aggregate vehicle shares by types, they ignore the impact of distinct household characteristics (e.g., income, size, location) on automobile demand, and do not consider individual households' choices of vehicle ownership or use.

Small and Van Dender (2006) have developed a simultaneous equation model (SEM) of vehicle fleet size, fuel efficiency, and vehicle use choices at the state level using a U.S. panel data set. Their model consists of three simultaneous regression equations (i.e., the dependent variable in one equation is also the independent variable in one or more other equations, allowing simultaneous or two-way influences); it is used to estimate the rebound effect of fuel efficiency standards. Their SEM model could be adapted to conduct household-level vehicle ownership and use analysis under certain assumptions.

A disaggregate modeling paradigm is necessary for this project because of the project focus on the distributional effects at the household level. Therefore, aggregate demand models that group households by large spatial analysis units (e.g., cities, states, nations) were not further reviewed by the research team.

Discrete choice models enable a disaggregate level of analysis and have dominated recent vehicle ownership studies (i.e., studies on the number and type of vehicles chosen by individual households). The majority of vehicle ownership models rely on multinomial, ordered, or nested logit specifications. Various vehicle ownership indicators have been estimated by the discrete choice models, including the following:

- the choice of the most recent vehicle purchased (Lave and Train 1979; Kitamura, et al. 2000);

- the make, model, and vintage of the household vehicle holdings (Manski and Sherman 1980);

- the vehicle that is most driven (Choo and Mokhtarian 2004); 
- the joint choice of vehicle number/make/model/vintage (Berkovec 1985);

- the joint choice of vehicle make/model/vintage and vehicle acquisition type (Mannering, et al. 2002); and

- the joint choice of vehicle type and vehicle age (Berkovec and Rust 1985; Mohammadian, et al. 2003).

Bhat and Pulugurta (1998) compared a multinomial logit model to an ordered logit model when estimating a household's total number of vehicles owned, and they found that the multinomial logit model had better performance. The significant explanatory variables used in these vehicle ownership models were reviewed by Choo and Mokhtarian (2004) including vehicle price, vehicle operating and maintenance cost, fuel cost, household size, income, household composition (numbers of workers, adults, children, etc.), location, residential density, transit accessibility, household head's characteristics (age, gender, education, etc.), and vehicle characteristics (fuel efficiency, passenger/cargo capacity, head room, shoulder room, etc.). Given the complexity of these models, they required an extensive data base to provide robust results.

Vehicle use, measured by vehicle miles traveled (VMT), is frequently analyzed with regression models. Most of these regression models are developed for household-level analysis, with annual household VMT being the dependent variable, and with fuel cost, household socio-demographic factors, and vehicle characteristics being the explanatory variables (Mannering and Winston 1985; Train 1986; Bhat and Sen 2004; West 2004). Greene, et al. (1999) developed a vehicle-level VMT model for households with multiple vehicles. Their model estimates the use of a particular vehicle as a function of the use of other vehicles owned by the same household. This model specification considers the possibility that a household may drive a specific vehicle more when the relative driving costs of individual household vehicles change due to exogenous factors. For instance, when fuel cost increases, a household that owns a car and a truck may choose to use the car more often to reduce the total household fuel expenditure. Mannering and Winston (1985) show empirically that the elasticity of household VMT with respect to fuel cost per mile is significantly higher (in terms of the absolute value) for one-vehicle households than for multiple-vehicle households, which suggests that there is substitution among multiple household vehicles .

It is important for vehicle ownership and use studies to recognize that households choose jointly the number of vehicles to own, the type of each household vehicle, and the amount each vehicle is driven. Households that expect to have high levels of vehicle use are more likely to own multiple vehicles and more likely to own fuel efficient vehicles. Households' vehicle number and type choices in turn constrain day-to-day vehicle use decisions. As households choose to own more vehicles, the variety-seeking behavior in vehicle type choices also becomes more apparent. Therefore, instead of estimating vehicle ownership and vehicle use separately, more advanced models should jointly consider the discrete vehicle ownership choices and the continuous vehicle use choices.

Most previous joint vehicle ownership and use models are variants of the discrete-continuous choice model developed by Dubin and McFadden (1984). Originally, the discrete-continuous choice model was used to simultaneously estimate the demand for and the usage of electrical appliances. The model is derived from a single indirect utility function and thus enjoys a solid microeconomic theoretical foundation. Those who have subsequently applied the Dubin and McFadden approach for estimating vehicle ownership and use include Mannering and Winston (1985), Train (1986), Berkowitxz(1990), Hensher, et al. (1992), Goldberg (1998), 
West (2004), and Bento, et al. (2005). In these joint choice models, the discrete vehicle number choices (no vehicle, one vehicle, two vehicles, etc.) and type choices (car, SUV, minivan, pickup truck, etc.) are considered with multinomial logit or nested logit specifications, and the continuous vehicle use choices (vehicle miles driven) are modeled with regression equations.

The discrete-continuous model specification allows each of the three vehicle-related choice dimensions (number, type, and use) to influence the other two choice dimensions through hierarchical choice structures, inclusive values, and correction terms. Mannering and Hensher (1987) note that full-information maximum likelihood estimation should produce unbiased coefficient estimates for discrete-continuous choice models simultaneously, while sequential estimation procedures are easier to implement in practice.

Although the standard discrete-continuous choice model has a strong behavioral foundation and good policy sensitivity, Bhat and Sen (2004) have documented several theoretical and practical issues associated with the previous discrete-continuous modeling approaches. First of all, these approaches do not recognize that households own a mixture of vehicle types to satisfy different functional needs (e.g., transporting people, transporting household goods, vacation travel). The diminishing marginal returns in using a single vehicle type cannot be handled by the standard vehicle-type discrete choice models. They have also noted that due to the large number of different vehicle types, enumerating all possible vehicle type bundles a household may choose from can cause an explosion in the number of alternatives in the choice set (e.g., $m$ vehicles, $n$ makers, $p$ models for each maker, and $q$ vintages result in $m \cdot n \cdot p \cdot q$ vehicle bundles). This limitation makes it difficult in the analysis to include households owning more than two vehicles.

Zhao and Kockelman (2000) and West (2004) also mention the problem of large choice sets. One remedy is to combine multiple vehicle bundles with small sample sizes into a single larger vehicle bundle, so that the total number of choice alternatives can be reduced and becomes more manageable. Finally, modeling the continuous dimension of vehicle use could be cumbersome in the standard discrete-continuous choice model because in theory a number of regression equations need to be individually specified and estimated for households with different vehicle number and type combinations. But it should be noted that West (2004) only estimated a one-size-fits-all vehicle use model for all households in her study, and that Train (1986) estimated two vehicle use models for households with one vehicle and two vehicles respectively. Their models appear to provide satisfactory statistical significance and reasonable forecasts.

Recognizing the limitations of the standard discrete-continuous choice models, Bhat, et al. (2004) applied the multiple discrete-continuous extreme value (MDCEV) model to vehicle ownership and use research. The MDCEV model is still based on the canonical utilitymaximization theory, but considers the diminishing returns in owning and using multiple vehicles of the same type. It assumes that households maximize utility by jointly choosing the number of vehicles to own in each vehicle type category (car, SUV, minivan, truck), and the annual miles of use of each owned vehicle type. To enable the subsequent simulated maximum likelihood estimation, it is also assumed that the total household annual vehicle miles driven is fixed and given, which makes the MDCEV model, in its present form, more appropriate for estimating long-term household vehicle fleet changes than for short-term vehicle use changes. It is interesting to note that some empirical evidence suggests that households tend to respond to fuel cost changes by owning different types of vehicles instead of changing vehicle use (Small 1999). 
Household vehicle ownership models have also been developed outside the discrete choice framework. Zhao and Kockelman (2000) proposed a multivariate negative binomial (MNB) model to investigate households' distinctions in vehicle purchases among passenger cars, SUVs, pickups, and minivans. This model structure is capable of capturing unobserved heterogeneity across the vehicle ownership levels and is equivalent to a multinomial distribution of the combinations of vehicles owned, conditioned on a negative binomial of the total vehicles owned. The model has been successfully estimated with the 1995 National Personal Travel Survey data. Compared to standard discrete choice models, the MNB vehicle ownership model does not require the enumeration of all possible vehicle type bundles. However, the MNB model does not provide a direct welfare measure, and it is harder to integrate with continuous vehicle use models.

\subsection{RECOMMENDED MODELING APPROACHES}

The research team considered the following modeling approaches for this project (all at the household level):

1. The static model which assumes no behavioral response;

2. Multiple regression model of vehicle use with fixed vehicle ownership;

3. Simultaneous equation model of vehicle fleet size, fuel efficiency, and vehicle use decisions; and

4. Discrete-continuous choice model of joint vehicle number, type, and use choices.

All of these approaches differ in their underlying behavioral assumptions, functional forms, data requirements, model capabilities, and policy sensitivity. However, only the latter three are capable of estimating demand responses to the conversion from the per-gallon fuel tax to a VMT fee. All of the models can be used to assess the impact of this policy change on individual households or household groups.

Note that commercial truck trips will not be considered by any of these models. The reason is that in the state of Oregon heavy trucks already pay a weight-mile tax and thus would not face any change in user fees as a result of the policy change being analyzed.

The specification, estimation, validation, and implementation of the recommended models are discussed in detail in the following sections, as well as the methods for applying the model results to analyze the distributional effects of a VMT fee.

\subsubsection{The static model}

The static model assumes no behavioral changes by vehicle owners in response to the change in tax, which essentially assumes that the price elasticity of demand for miles is zero. These measures are calculated assuming that all vehicle drivers drive exactly the same vehicles for exactly the same distances both before and after the change in tax structure. Since this method ignores the demand responses that are likely to occur in response to the change in driving cost caused by a change to a VMT fee, these figures will overstate the projected impacts of the change in tax structure. 
The first step is to calculate the total household expenditures on gasoline under the gasoline tax and then again under a 1.2 cents-per-mile VMT fee.

For the gasoline tax the number of miles driven by the household (MILES) is divided by the weighted average fuel efficiency for the household vehicles (average miles per gallon, $M P G$ ), to get the number of gallons of gasoline purchased by the household (GALLONS).

$$
G A L L O N S=\frac{M I L E S}{M P G}
$$

To get total expenditures (GASTOTEX) under the gasoline tax, the number of gallons (GALLONS) is multiplied by the average price paid for fuel (PGAS), where PGAS includes the current gasoline tax of 24 cents per gallon.

$$
\text { GASTOTEX }=(\text { PGAS })(\text { GALLONS })
$$

The calculation for total expenditures under a vehicle miles traveled (VMT) fee of 1.2 cents per mile is made by taking the current gas price $(P G A S)$ and subtracting the 24 cents per gallon gasoline tax to get the net price of gasoline, NETPGAS:

$$
N E T P G A S=P G A S-0.24
$$

Then NETPGAS is multiplied by the number of gallons for the household (GALLONS), and the amount spent on the VMT fee is added in by multiplying 1.2 times the number of miles (MILES) driven:

$$
\text { VMTTOTEX }=\text { NETPGAS•GALLONS }+0.012 \bullet M I L E S
$$

The net change in household expenditures is the difference between household expenditures under the two tax regimes:

$$
\text { EXCHANGE }=\text { VMTTOTEX-GASTOTEX }
$$

A negative value for $E X C H A N G E$ indicates that the change to a VMT fee will reduce household expenditures on gasoline and road tax; a positive value indicates an increase in expenditures when switching to the VMT fee.

The incidence of household expenditures on gasoline and tax is defined as a percent of household income (INCOME):

For the gasoline tax: 
GASTOTEX / INCOME

For the VMT fee:

VMTTOTEX / INCOME

The formula to measure the incidence of just the gasoline tax (TOTALGASTAX) is shown as:

$$
\frac{\text { TOTALGASTAX }}{I N C O M E}=\frac{0.24 G A L L O N S}{I N C O M E}
$$

The formula to measure the incidence of the VMT fee (TOTALVMTTAX) is shown as:

$$
\frac{\text { TOTALVMTTAX }}{\text { INCOME }}=\frac{0.012 M I L E S}{I N C O M E}
$$

However, these two measures will yield very small numbers, as the tax totals alone are a very small percent of income.

To derive an incidence measure for the aggregate of households in various groups (such as income or rural/urban groups), one simply aggregates relevant measure over households in the group. So, for instance, a measure of the incidence of gasoline taxes by income group $j$, is the sum of the total gas tax paid by each of the $i$ households in income group $j$ :

$$
\sum_{i=1}^{I} \frac{\text { TOTALGASTAX }}{I N C O M E_{i}}
$$

\subsubsection{Multiple regression model (OLS regression)}

Without considering vehicle quantity and type choices, one can focus on the changes in the usage and relative usage of existing household vehicles due to a change to a VMT fee. In the short run, vehicle use changes result from households adjusting trip frequencies, trip chains, destinations, modes, vehicle occupancies, and routes. In the long run, location choices (e.g., relocation to areas closer to work/non-work destinations, or to areas with better transit services and bike/pedestrian-facilities) may also shift vehicle use patterns. The total vehicle use at the household level, measured by the total annual vehicle miles driven on all vehicles, should be a function of the per-mile driving cost, income, location, current vehicle ownership, and other relevant household characteristics. The per-mile driving cost borne by a household contains vehicle depreciation cost, operating cost, maintenance cost, insurance cost, and fuel cost including all applicable taxes. However, fuel cost per mile is the only cost variable included in the regression model, because the other cost components are influenced by vehicle quantity and type choices (assumed to be fixed in this case) and fuel cost per mile is the only cost component that will be affected by a change to a VMT fee. 
The multiple regression model states that the total miles driven by a household $(M)$ is a function of the fuel cost per mile $\left(P_{M}\right)$, household income $(I)$, household location $(U)$, number of vehicles currently owned by the household $(V)$, and a vector of other household characteristics $\left(\mathbf{H H}_{\mathbf{M}}\right)$.

$$
M=f\left(P_{M}, I, U, V, \mathbf{H H}_{\mathbf{M}}\right)
$$

Fuel cost per mile for household vehicle $v\left(P_{M, v}\right)$ is determined by the fuel price without state gasoline tax $\left(P_{F}, \$ /\right.$ gallon $)$, vehicle fuel efficiency $(E$, miles per gallon), state gasoline tax ( $T_{G}$, if any, $\$ /$ gallon $)$, and VMT fee $\left(T_{M}\right.$, if any, $\$ /$ mile):

$$
P_{M, v}=\frac{P_{F}+T_{G}}{E}+T_{M}
$$

If a household owns multiple vehicles, $P_{M}$ is defined as the weighted average of all household vehicles with the miles driven on individual vehicles $\left(M_{v}\right)$ being the weights.

$$
P_{M}=\frac{\sum_{v=1}^{V}\left(M_{v} \bullet P_{M, v}\right)}{M}
$$

\subsubsection{Model specification}

The model in Equation 2-8 can be specified as a simple linear regression model with total miles driven being the dependent variable. However, a log-log functional form has been shown to be superior in previous research and would allow easier computation of demand elasticities:

$$
\begin{aligned}
& \ln M=\beta_{1}+\beta_{2} \ln P_{M}+\beta_{3} \ln I+\beta_{4} \ln U+\beta_{5} \ln V \\
& +\beta_{6}\left(\ln I \bullet \ln P_{M}\right)+\beta_{7}\left(\ln U \bullet \ln P_{M}\right)+\beta_{8}\left(\ln V \bullet \ln P_{M}\right)+\boldsymbol{\beta} \bullet \ln \left(\mathbf{H H}_{\mathbf{M}}\right)
\end{aligned}
$$

where:

$\ln ($.$) is the natural logarithm function,$

$M$ is total household miles driven,

$I$ is household income,

$P_{m}$ is the weighted average household fuel cost per mile,

$U$ is the urban/rural location indicator,

$V$ is the number of vehicles in the household, and

HH is a vector of household characteristics.

Demand elasticity $(e)$ is defined as the percentage change of total household vehicle miles driven due to a one percent increase of fuel cost per mile: 


$$
e=\frac{\Delta M / M}{\Delta P_{M} / P_{M}}=\frac{\partial M}{\partial P_{M}} \bullet \frac{P_{M}}{M}=\beta_{2}+\beta_{6} \ln I+\beta_{7} \ln L+\beta_{8} \ln V
$$

For instance, if $e$ is equal to -1.5 for a particular household, it implies that a one percent increase in fuel cost per mile will cause this household to reduce their total annual miles driven by 1.5 percent. The three interaction terms (the $6^{\text {th }}, 7^{\text {th }}$ and $8^{\text {th }}$ terms) on the right hand side of the regression equation allow the demand elasticity with respect to fuel cost per mile to vary among households with different income, location, and vehicle ownership. It is expected that households with higher income (low price elasticity in general), living in rural areas (fewer travel options and lower density land use patterns), and owning more vehicles (possible substitutions among multiple household vehicles) to be less sensitive to changes in fuel cost per mile and therefore have lower demand elasticities. Without the interaction terms in Equation 211, all households in Oregon would be effectively assumed to have the same sensitivity to fuel cost changes, an obviously unreasonable assumption.

Although household income and vehicle ownership data were readily available in various data sources, it was less straightforward to define household location.

Decision makers in Oregon were interested in the potentially different impacts of the VMT fee on urban and rural households. However, the National Household Travel Survey (NHTS) dataset only provided a crude urban/rural indicator variable.

Aside from income, location, and vehicle ownership, other household characteristics can also significantly affect total vehicle miles driven, including household size, household composition (number of workers, adults, children, etc.), and household head characteristics (age, gender, education, etc.). These socio-demographic variables were available to the research team, to be considered in subsequent model development stages.

\subsubsection{Model estimation and validation}

The multiple regression model was estimated from the NHTS data using ordinary least square techniques. After coefficients were empirically derived, the modelestimated and observed household vehicle miles driven were compared for model validation purposes. It would be desirable to use an independent validation dataset; however, the NHTS 2001 dataset only included 348 valid household observations in Oregon. The research team addressed this issue of small sample size in two ways. First, a cluster analysis was conducted to identify states that had similar travel and vehicle ownership characteristics. Second, a number of sensitivity tests were conducted on the estimated model to ensure the regression model produced reasonable forecasts. The validity of the regression model was tested by arbitrarily changing independent variables (fuel price, fuel efficiency, income, household size, etc.) and observing the estimated changes in the dependent variable (total vehicle miles driven).

\subsubsection{Model implementation and the distributional effects of a VMT fee}

A VMT fee would lead to a change of fuel cost per mile in the regression equation (211) according to the definition of fuel cost per mile in Equation (2-9). The fuel cost 
per mile with the existing gasoline tax is $P_{M, \text { Before }}=\left(P_{F}+0.24\right) / E$, and changes to $P_{M, A f t e r}=\left(0.012+P_{F} / E\right)$ under a $\$ 0.012 /$ mile flat-rate VMT fee. The total miles driven by any household in the sample before $\left(M_{\text {Before }}\right)$ and after $\left(M_{\text {After }}\right)$ a change to a VMT fee can be computed from the regression model. The total fuel-related payment $(F)$ and total road use fee payment $(T)$ by each household would be:

$$
\begin{array}{cc}
F_{\text {Before }}=P_{M, \text { Before }} \bullet M_{\text {Before }} ; & F_{\text {After }}=P_{M, \text { After }} \bullet M_{\text {Before }} \\
T_{\text {Before }}=\frac{0.24}{E} \bullet M_{\text {Before }} ; & T_{\text {After }}=0.02 \bullet M_{\text {After }}
\end{array}
$$

These results at the individual household level can be easily aggregated into household groups by income, location, vehicle ownership, and other household characteristics, which can show the distributional impact of a $\$ 0.012 /$ mile VMT fee on various types of households in Oregon. The distributional effects of graduated or variable VMT fee structures could be evaluated in a similar fashion, except that the changes in fuel cost per mile would depend on the actual rate structure.

\subsubsection{Simultaneous Equation Model (SEM)}

The regression model discussed in Section 2.3.2 has several advantages. It is relatively easy to estimate, has minimum data requirements, and provides good policy sensitivity (i.e., is capable of evaluating various mile tax rate structures). However, the regression model makes the strong behavioral assumption that households would respond to a change to a VMT fee by changing vehicle use only. This assumption may not be as unrealistic as many might think, because the fuel cost changes due to a VMT fee are expected to be quite small. One could argue that vehicle purchase decisions are unlikely to be affected by small fuel cost changes. However, empirical evidence suggests that in responses to fuel price spikes, households often change their vehicle types rather than reduce their total vehicle use (Small 1999, Kockelman 2006). Mannering and Winston (1985) find that the long-run vehicle use elasticity with respect to operating cost changes are significantly smaller than the short-run elasticity, also suggesting vehicle ownership changes.

The simultaneous equation model presented in this section recognizes that households choose the number of vehicles to own (V), the average fuel efficiency of household vehicles $(E)$, and the total vehicle miles driven $(M)$ simultaneously (i.e., the three choices are interdependent) when fuel cost per mile changes. The actual model identification is provided in Equation Set 2-14. To capture the interdependencies of vehicle ownership and use decisions, these three variables enter the equation set as both dependent and independent variables.

$$
\begin{aligned}
& V=f\left(M, P_{V}, P_{F}, I, U, \mathbf{H H}_{\mathbf{V}}\right) \\
& E=g\left(M, V, \Delta P_{V}, P_{F}, I, U, \mathbf{H H}_{\mathbf{E}}\right) \\
& M=h\left(V, P_{M}\left(P_{F}, E\right), I, U, \mathbf{H H}_{\mathbf{M}}\right)
\end{aligned}
$$

Vehicle number choice $(V)$ is a function of vehicle use $(M)$, average purchase price of vehicles $\left(P_{V}\right)$, fuel price $\left(P_{F}\right)$, household income $(I)$, location $(U)$, and other household 
characteristics $\left(\mathbf{H H}_{\mathbf{V}}\right.$, e.g., number of workers, household size, number of children, household head's age, gender, and education). Vehicle fuel efficiency $(E)$ is a function of vehicle use $(M)$, number of vehicles $(V)$, difference in the purchase price of fuel efficient and fuel inefficient vehicles $\left(\Delta P_{V}\right)$, price of fuel $\left(P_{F}\right)$, income $(I)$, location $(U)$, and other household characteristics $\left(\mathbf{H H}_{\mathbf{E}}\right.$; a different subscript is used because it is possible that a different set of other household characteristics may influence vehicle fuel efficiency choices). Finally, vehicle miles driven $(M)$ is a function of the number of household vehicles $(V)$ and fuel cost per mile $\left(P_{M}\right)$, which is a function of fuel price and fuel efficiency, income $(I)$, location $(U)$, and other household characteristics $\left(\mathbf{H H}_{\mathbf{M}}\right)$.

The actual specification of each of the three functions is similar to the log-log specification in Equation 2-11 in Section 2.3.2. Again, the income, location, and vehicle quantity variables were interacted with fuel cost variables to allow different demand elasticities across households. Compared to the multiple regression model, the SEM model required additional information about vehicle price, which was collected by the research team from standard vehicle price database and the 2001 Ward's Automotive Yearbook (Wards 2001).

In order to apply standard estimation procedures for SEM models such as the three-stage least square method, it is necessary to consider vehicle quantity as a continuous variable. The estimated vehicle quantity will be rounded into the nearest integer values. This rounding process will not affect the validity of the vehicle type and use forecasts. Similar to the regression model in Section 2.3.2, the SEM model will produce estimates of household vehicle miles driven before and after a change to a VMT fee. However, the SEM estimates represent the long-run vehicle use adjustment with vehicle quantity and type changes already taken into account, while the regression model estimates represent the short-run vehicle use changes with fixed vehicle quantity and type. The SEM estimates, therefore, can be expected

to be smaller than the regression mode estimates. In other words, if a VMT fee has a negative impact on a particular household, the negative impact will be overestimated by the regression model.

Among the software packages that are capable of estimating SEM models, the research team chose STATA.

\subsubsection{Discrete-Continuous Choice (DCC) Model}

Discrete choice models or qualitative choice models predict the decisions made by an individual (vehicle ownership choice, mode choice, vehicle use, etc.) as a function of a number of factors which seem to influence the decision making process. The individual is presumed to have made the choice from a discrete set. Discrete choice models are widely used to predict the mode choice of individuals in transportation modeling. The most prominent discrete choice models used currently include logit, generalized extreme value, probit, and mixed logit. These models can effectively analyze the variables which are not continuous but still vary over time. Regression models on the other hand can effectively analyze the continuous variables.

When an individual is provided with two qualitative choices such as the number of cars to own or the number of miles to drive, the first choice is between a discrete set of alternatives say 0,1 or 2 . The second choice is among a continuous set of alternatives such as any number of miles. A discrete choice model can be used to estimate the first choice but cannot estimate the second one. Thus, in most of the studies which have used this approach the vehicle number choice was estimated using a discrete choice model and then vehicle use 
(miles traveled) was estimated using linear regression. In this case we need both a discrete and continuous model to (Train 1993). Hence, a combination of these two models known as the discrete-continuous choice model can be used here.

The discrete-continuous choice model was introduced by Dubin and McFadden (1984) when they suggested that, in order to estimate the demand for electricity, a derived demand, one has to simultaneously estimate the demand for the durables that ultimately drive the demand for energy.

Sarah E. West (2001) used this approach to examine the distributional effects of vehicle pollution control policies by estimating the joint demand for vehicles and miles. Train (1993) estimated the demand for cars and light trucks while taking into account the interdependence between the number of vehicles a household chooses to own and the type chosen.

Mohammadian and Miller (2003) developed a household automobile type choice model at a disaggregate level to estimate the consumer demand for personal-use vehicles given the available choices. Mannering and Winston (1985) used this approach to analyze the impact of vehicle ownership on the utilization. Other people who have used this approach include Lave and Train (1979) and Berkowitz (1990).

The simultaneous equation model (SEM) relies on more realistic behavioral assumptions than the multiple regression model. The SEM model requires, however, that vehicle quantity be considered as a continuous variable. The fact is that vehicle quantities are indeed discrete integer variables $(0,1,2,3 \ldots)$, and the discrete-continuous choice (DCC) model is able to deal with these variables. The drawback is that it also has increased data requirements and involves greater model complexity. The following sections describe the discrete and the continuous components in a standard DCC model.

\subsubsection{Discrete choices of vehicle quantity and type}

Vehicle quantity $(V: 0,1,2,3 \ldots)$ and vehicle type ( $T$ : car, SUV, minivan, pickup truck) are both discrete variables in the DCC model. A household chooses how many cars to own $(V)$ based on the expected vehicle use $(\bar{M})$, the average vehicle price on the market $\left(P_{V}\right)$, fuel price $\left(P_{F}\right)$, income $(I)$, location $(U)$, and other household characteristics $\left(\mathrm{HH}_{\mathrm{V}}\right)$. If a household chooses to own only one vehicle, the household then needs to choose the vehicle type $(T)$ from the four available types based on the average price of vehicles by type $\left(P_{V, T}\right)$, the average fuel cost per mile by vehicle type $\left(P_{M, T}\right)$, income $(I)$, location $(U)$, and other household characteristics $\left(\mathrm{HH}_{\mathrm{T}}\right)$, as shown in Equation 2-15.

$$
\begin{aligned}
V & =f\left(\bar{M}, P_{V}, P_{F}, I, U, \mathbf{H H}_{\mathbf{v}}, \rho_{V}\right) \\
T & =g\left(P_{V, T}, P_{M, T}, I, U, \mathbf{H H}_{\mathbf{T}}, \rho_{T}\right)
\end{aligned}
$$

If a household chooses to own multiple vehicles, $T$ should be interpreted as vehicle bundles (e.g. car-car, car-SUV, car-minivan-pickup). The number of possible vehicle bundles increases exponentially as the number of household vehicles increases. This issue can be partially addressed by excluding households with more than three vehicles from the analysis and by combining vehicle bundles with few observations 
into larger bundles. (Excluding households with more than three vehicles would result in only a small loss in the total number of observations, according to the NHTS 2001 Oregon sample.)

Due to the categorical nature of the dependent variables, these two functions can be specified either as two interrelated multinomial logit models, or as a single nested logit model. Standard statistical tests (Dubin and McFadden 1984; Ben-Akiva and Lerman 1985) can facilitate the selection between the two alternative specifications. $P_{V}$ is either a correction term (if quantity and type choices are specified as non-nested choices) or the inclusive value from the lower-level vehicle type choice nest (if quantity and type choices are specified as nested choices). $P_{T}$ is a correction term that considers the different numbers of make/models in alternative vehicle bundles. (e.g., there are more car models than minivan models, and therefore, all other things equal, households are more likely to purchase a car due to the large selection). The correction terms can be computed by an approximation method developed in McFadden (1978).

Multinomial and nested logit models can be estimated by several commercial software packages including LIMDEP and GAUSS. The research team preferred LIMDEP due to its low cost (\$795 for an academic license) and its special focus on models of categorical variables.

\subsubsection{Continuous choice of vehicle use}

Given the choices of vehicle quantity and vehicle types, households then choose how many miles to drive in each vehicle. The simplest approach is to estimate a single multiple regression model of vehicle miles traveled (VMT) at the household level (West 2004), i.e., a household-level VMT use model. Another approach is to estimate vehicle miles driven at the individual vehicle level for households with different numbers of vehicles separately (Train 1986), i.e., a vehicle-level VMT model. The specification of the household-level vehicle use model is similar to the regression model in Section 2.3.2:

$$
M_{(V, T)}=f\left(P_{M(V, T)}, I, U, V, \mathbf{H H}_{\mathbf{M}}, \rho_{V, T}\right)
$$

The subscript $(V, T)$ implies that the variables are conditional on the vehicle quantity and type choices in the discrete choice model. A correction term, $\rho_{V, T}$, is necessary to ensure the consistency of coefficient estimates, because the random error term in the vehicle use equation is expected to be correlated with vehicle type choices. This correction term can be computed using choice probabilities from the vehicle quantity and type choice models (Dubin and McFadden 1984).

If a household chooses not to own automobiles, a vehicle use model is obviously not needed. If a household owns one vehicle, the household- and vehicle-level VMT models are equivalent. For households choosing to own multiple vehicles, there exist substitutional effects between household vehicles, which may be better captured by vehicle-level VMT models. For instance, a fuel price increase can make the fuel- 
efficient vehicle in a multiple-vehicle household more attractive, and subsequently driven more, while the use of other household vehicles decreases.

Let $i$ and $j$ denote vehicles in a household. The miles driven on vehicle $i$ should be a function of the fuel cost per mile of vehicle $i$, and the fuel cost per mile of all other household vehicles (For all $j \neq i$ ):

$$
M_{i}=h\left(P_{M, i}, \mathbf{P}_{\mathbf{M}, \mathbf{j},} I, U, \mathbf{H H}_{\mathbf{M}}\right)
$$

The estimation, validation, and implementation procedures for the vehicle-level VMT model are the same as those for the household-level VMT models.

\subsubsection{Using the Discrete-Continuous Choice Model for policy analysis}

The DCC model estimates the probability that a household would choose to own a specific number of vehicles $(p(v))$, and conditional on the vehicle quantity choice, the probability that the household chooses to own a particular vehicle type bundle $(p(t \mid v))$, and conditional on vehicle quantity and type choices, the vehicle miles driven by the household in each vehicle $\left(M_{i} \mid t, v\right)$. Therefore, the expected total miles driven by the household $(M)$ according to the DCC model is:

$$
M=\sum_{v=1}^{V} \sum_{t=1}^{T} \sum_{i=1}^{I}[(M i \mid t, v) \bullet p(t \mid v) \bullet p(v)]
$$

The distributional effects of a VMT fee can then be estimated. The subsequent steps for policy analysis are similar to those of the original regression model in Section 2.3.2.

\subsection{SUMMARY OF THE RECOMMENDED MODELING APPROACHES}

Table 2.1 summarizes the properties of the recommended modeling approaches in three categories: behavioral realism, policy sensitivity, and practicality. 
Table 2.1: Summary of the recommended models

\begin{tabular}{|c|c|c|c|c|}
\hline $\begin{array}{l}\text { RECOMMENDED MODELS } \\
\text { MODEL PROPERTIES }\end{array}$ & $\begin{array}{l}\text { Static } \\
\text { Model }\end{array}$ & $\begin{array}{c}\text { Multiple } \\
\text { Regression }\end{array}$ & $\begin{array}{l}\text { Simultaneous } \\
\text { Equations }\end{array}$ & $\begin{array}{c}\text { Discrete- } \\
\text { Continuous } \\
\text { Choice }\end{array}$ \\
\hline 1. Behavioral Realism & Poor & Average & Good & Great \\
\hline 1.1. Consider changes in total vehicle use? & No & Yes & Yes & Yes \\
\hline $\begin{array}{l}\text { 1.2. Consider changes in the distribution of } \\
\text { vehicle uses among multiple vehicles? }\end{array}$ & No & Yes & Yes & Yes \\
\hline 1.3. Consider changes in vehicle quantity choice? & No & No & Yes & Yes \\
\hline 1.4. Consider changes in vehicle type choice? & No & No & Yes & Yes \\
\hline $\begin{array}{l}\text { 1.5. Recognize the discrete nature of vehicle type } \\
\text { and quantity choices? }\end{array}$ & No & No & No & Yes \\
\hline 2. Policy Sensitivity & Good & Good & Average & Good \\
\hline 2.1. Consider the distributional effects? & Yes & Yes & Yes & Yes \\
\hline 2.2. Able to evaluate flat-rate mileage taxes? & Yes & Yes & Yes & Yes \\
\hline $\begin{array}{l}\text { 2.3 Able to evaluate mileage tax rates } \\
\text { differentiated based on location? }\end{array}$ & Yes & Yes & Yes & Yes \\
\hline $\begin{array}{l}\text { 2.4. Able to evaluate mileage tax rates } \\
\text { differentiated based on fuel efficiency? }\end{array}$ & Yes & Yes & No & Yes \\
\hline $\begin{array}{l}\text { 2.5. Able to evaluate mileage tax rates } \\
\text { differentiated based on congestion? }\end{array}$ & No & No & No & No \\
\hline 3. Practicality & Great & Great & Good & Average \\
\hline 3.1 Data Availability & Good & Good & Good & Poor \\
\hline 3.2 Ease of Estimation & Great & Great & Good & Average \\
\hline 3.3 Results can be easily interpreted & Great & Great & Good & Good \\
\hline
\end{tabular}




\subsection{DATA}

The 2001 National Household Travel Survey (NHTS) was the main data source for this study. This survey was conducted by the United States Department of Transportation and the Bureau of Transportation Statistics.

Within the NHTS data set, there were five files: household, vehicle, persons, daily trips and long trips. All of the variables used in the empirical estimation for the modeling came from the household and vehicle files. For Oregon the number of observations for each of these files in 2001 is shown in table 3.1.

Table 3.1: Oregon sample from 2001 NHTS

\begin{tabular}{l|r|r|r}
\hline & \multicolumn{3}{|c}{ Number Of Observations } \\
\hline File & \multicolumn{1}{|c|}{ Total } & \multicolumn{1}{c}{ Urban } & \multicolumn{1}{c}{ Rural } \\
\hline Household & 407 & 295 & 112 \\
\hline Vehicle & 893 & 588 & 305 \\
\hline
\end{tabular}

Although there were 407 Oregon households in the NHTS, the number of households included in each part of the analysis for this study varied depending on whether every household had complete data for the model. When a household did not have a complete data set, it was dropped from that part of the analysis.

\subsection{DESCRIPTION OF THE VARIABLES USED}

\subsubsection{Urban/rural}

Urban and rural indicators in the NHTS are based on Census classifications. According to the Census, urban is defined as having more than 1,000 people per square mile in their city or town and more than 500 people per square mile in surrounding areas. All other areas are defined as rural. The models used an urban/rural dummy variable with a value of one when the household was located in an urban area, zero otherwise.

\subsubsection{Household income and income groups}

There are two variables in the NHTS that refer to household income - HHFAMINC and HHINCTTL. The former leaves blank those household members whose income was not stated. HHINCTTL randomly assigns those blanks a value within the range of those household members whose income was recorded. This study used HHFAMINC to create the household income variable. This income variable therefore likely understated the true household income value for some households.

Since each household only indicated an income range rather than a level of income, this study assigned each household the median income value for their income group. This approach was not optimal, but it was all that could be done with the data, and it followed others who 
have used similar data sets with similar measures of income (Zupnick 1978; Lee 2000). For the exact methodology used in assigning income to individual households, see Appendix A.

Table 3.2 below compares the distribution of incomes groups in both the Census and the NHTS data set. Eight groups are listed here to give a better illustration of the actual distribution relative to the Census. From these categories, this study divided the NHTS sample into the six income groups for the analysis.

Table 3.2: Sample representation as compared to the Oregon Census 2000

\begin{tabular}{l|r|r}
\hline Income Range (\$) & $\begin{array}{c}\text { \%o of Sample }- \\
\text { Census }\end{array}$ & $\begin{array}{c}\text { \%o of Sample - } \\
\text { NHTS }\end{array}$ \\
\hline$<10,000$ & 8.6 & 5.17 \\
\hline $10,000 \sim 14,999$ & 6.5 & 6.55 \\
\hline $15,000 \sim 24,999$ & 13.4 & 14.83 \\
\hline $25,000 \sim 34,999$ & 13.9 & 21.72 \\
\hline $35,000 \sim 49,999$ & 17.7 & 18.62 \\
\hline $50,000 \sim 74,999$ & 20.2 & 12.41 \\
\hline $75,000 \sim 99,999$ & 9.7 & 3.10 \\
\hline $100,000+$ & 10 & \\
\hline
\end{tabular}

The highest income group is defined as a household with income greater than or equal to $\$ 100,000$. The Oregon 2000 Census reported that only $1.8 \%$ of all Oregon households had an income greater than $\$ 200,000$ (with no upper bound). Thus, this study used $\$ 200,000$ as an upper bound for the highest income group and assigned these households a household income value of $\$ 150,000$.

Previous studies on VMT demand suggest using household expenditures in place of income as a measure of well-being (West 2002; Walls and Hansen 1999). However, household expenditure data was not available

\subsubsection{Fuel cost per mile}

The 2001 NHTS provides an estimated gas price for each vehicle. However, these prices, which are based on the fuel type as indicated by the household and on gasoline price data collected by the Energy Information Administration (EIA), produce a relatively uniform distribution, ranging from approximately $\$ 1.41$ to $\$ 1.47$ per gallon, with the majority of households spending approximately $\$ 1.46$ per gallon (Energy Information Administration 2003). Detailed gas prices are available from various sources, one of them being the Oil Price Information Service (OPIS). It would be possible to get prices from different cities or counties within Oregon on a weekly, monthly or annual basis. Unfortunately, the NHTS data does not include a location indicator; so the study could not match gas prices to individual household locations. Thus, the analysis assumed that Oregon households faced an average retail price for gas of $\$ 1.46$ in 2001, which included the 24 cents-per-gallon gasoline tax.

The gas price per gallon was divided by fuel efficiency, to obtain the fuel cost per mile for each vehicle in a household. The household fuel cost per mile under the gasoline tax was calculated by taking the mile-weighted average of gasoline cost per mile for all household vehicles. 
The NHTS provides two fuel efficiency estimates - the Environmental Protection Agency (EPA) estimate and the Energy Information Administration (EIA) estimate. Rather than using the EPA fuel efficiency estimates, which are known to be overstated, this analysis used the EIA fuel efficiency measures. For the state of Oregon, the average fuel efficiency was $20.75-21.23$ miles per gallon for vehicles in urban areas, and 19.78 miles per gallon for vehicles in rural areas. At a fuel efficiency of 20 miles per gallon a 1.2 cents-per-mile VMT fee would be equivalent to the current 24 cents per gallon gasoline tax. Thus, on average, rural households would pay slightly less in road user fees per mile than their urban counterparts after a conversion to a VMT fee.

To calculate the fuel cost per mile under the VMT fee, the state gasoline tax ( 24 cents per gallon for Oregon) was subtracted from the gas price; the net gas cost was then divided by the fuel efficiency for each vehicle, the per-mile fee was added; and then a weighted average was calculated. (See Table A.2 in Appendix A for more details.)

\subsubsection{Mileage measures}

Self-reported annual miles for each vehicle were used for this study. Household miles were therefore the sum of all individual vehicle miles for all household vehicles.

\subsection{SUMMARY STATISTICS FOR OREGON}

The summary statistics for the most part were consistent with previous studies.

According to the Oregon data observations from the 2001 NHTS data used in this study, the average household in Oregon owned 2.19 vehicles. Urban households owned an average of 1.99 vehicles, while rural households owned 2.72 vehicles on average.

The households were initially placed into one of 18 income groups. ${ }^{1}$ The average household income group for the NHTS sample was 9.26, implying an average household income of slightly above $\$ 44,999$ (since the upper bound household income in Group 9 was \$44,999).

Surprisingly, the average rural household income group - 9.38 - was higher than the urban group (9.23), a finding somewhat counter to conventional wisdom. One possible explanation for the apparent higher average income for rural households was that there tended to be more members in the rural households (2.49), than in the urban households (2.43). The average household size for Oregon was 2.44 members per household.

A more likely explanation for this unexpected result comes from the definition of urban and rural households adopted by the NHTS in placing households in one of the two groups. The NHTS uses the Census Bureau definition which classifies a place as "urban" using a complex algorithm involving population size (2,500 or more) and population density (500 per square mile or more); all other places are identified as "rural". The Census definition overstates rural areas by counting as rural many small areas that have strong ties to urban areas. The people in those areas classified as "rural" may well have much higher incomes than those in what would be considered rural Oregon by state policy makers (Crandall and Weber 2005).

\footnotetext{
${ }^{1}$ Due to the relatively small number of Oregon households in the NHTS sample, there were very few households in some of the 18 income groups. Thus for the analysis the Oregon households were organized into six income groups so as to provide a reasonable number of households in each category.
} 
Crandall and Weber (2005) argue that the Census definition of urban and rural may not be ideal, because it fails to incorporate the fact that areas around urban or metropolitan cities, which are 'rural' according to the Census, still have full access to urban transportation systems and other services that truly isolated areas may not have access to. Instead, they propose an alternative definition that incorporates location relative to large cities and whether or not there are linkages to those cities. Such a classification system would more accurately model a household's access to transportation and employment opportunities. Unfortunately, the NHTS does not provide the households' city or county location. The NHTS does include data on population density at the block and tract level; however, households are assigned to one of eight categories, and this variable was therefore not viewed as an accurate measure.

The average vehicle in Oregon was driven $8,859.39$ miles in 2001. The average vehicle in $\underline{\text { urban }}$ areas was driven 8,796.01 miles, compared to 8,989.71 miles in rural areas.

The average household member in Oregon drove 15.01 miles to work in 2001. The average household member in an urban area drove 13.75 miles, while the average household member in a rural area drove 18.46 miles to work.

The average vehicle age for Oregon was 11.40 years. On average, vehicles in rural areas tended to be slightly older than those in urban areas -12.02 years in rural areas and 11.08 years in urban areas.

As expected, car choice appeared to vary by location. As seen in Tables 3.3 and 3.4, a larger proportion in urban areas owned automobiles, vans, and smaller vehicles than in rural areas. Those in rural areas were more likely to own trucks.

Table 3.3: Number of Vehicles by Type and Location: Urban/Rural

\begin{tabular}{l|c|r|r|r|r|r|r|r}
\hline & \multicolumn{10}{c}{ Number Of Vehicles } \\
\hline & Car & Van & \multicolumn{1}{c|}{ SUV } & Truck & \multicolumn{1}{c}{ R.V. } & Motorcycle & \multicolumn{1}{c}{ Other } & \multicolumn{1}{c}{ Total } \\
\hline Urban & 297 & 44 & 79 & 123 & 12 & 27 & 4 & 586 \\
\hline Rural & 113 & 16 & 40 & 112 & 5 & 10 & 9 & 305 \\
\hline
\end{tabular}

Source: 2001 NHTS data for Oregon

Table 3.4: Percent of Vehicles by Type and Location: Urban/Rural

\begin{tabular}{l|c|c|c|r|r|r|r}
\hline & \multicolumn{7}{c}{ Number Of Vehicles } \\
\hline & Car & Van & SUV & Truck & R.V. & Motorcycle & \multicolumn{1}{c}{ Other } \\
\hline Urban & 0.507 & 0.075 & 0.135 & 0.210 & 0.020 & 0.046 & 0.007 \\
\hline Rural & 0.370 & 0.052 & 0.131 & 0.367 & 0.016 & 0.033 & 0.030 \\
\hline
\end{tabular}

Thus, given the vehicle mix in urban versus rural Oregon, it was not clear that the rural part of the state would be adversely impacted overall by a change to a VMT fee. Rural drivers appeared to be driving less fuel efficient vehicles, on average, and those are the ones that would actually experience a decrease in per mile road taxes under a VMT fee.

On average, households in this analysis held on to their vehicles for twelve years in rural areas and eleven years in urban areas, a few more years than other estimates (Barnes and Langworthy 2003). 
The NHTS sample included 407 Oregon households with a total of 893 vehicles. From this sample, the authors assigned weighted averages based on vehicle miles for fuel efficiency and fuel cost per mile. If a household was missing fuel efficiency for one or multiple vehicles, that vehicle was assigned the average of the household's remaining vehicles' fuel efficiency. If fuel price was missing, the missing value was assigned the sample average, since there was a relatively uniform distribution of prices.

If annual miles were not reported, or were reported as missing in the sample, it was assumed that the vehicle was not used in that year, and these vehicles were ignored. Thus, these vehicles were also excluded in the household vehicle count. For example, if a household reportedly owned four vehicles, but reported zero miles for one vehicle, the vehicle count was readjusted to three. Furthermore, recreational vehicles were also ignored, and households' vehicle counts were again adjusted accordingly. All of the other data used in this analysis were from the NHTS data set.

After these adjustments, if a household was missing any of the variables included in the analysis, the household was excluded. For the static model analysis this resulted in a sample of 367 households. The additional data required for the OLS regression reduced the sample to 339 Oregon households.

\subsection{AN EXPANDED DATA SET}

The discrete-continuous choice (DCC) model requires substantially more data than the static model or the regression models. This requirement resulted in a significant reduction in the number of usable households from the Oregon sample, and such a small sample size would have prevented the analysis from producing meaningful results. Thus, an attempt was made to expand the data set for the DCC model by utilizing households from other comparable states. The authors used cluster analysis to identify states that had characteristics most similar to Oregon for the additional households in this expanded analysis.

The cluster analysis used a table with 51 observations (50 states and the District of Columbia) and 39 variables. The available variables were narrowed down to a list of 17, with some derived from the original 39. The cluster analysis applied a mathematical algorithm to find the states most similar to Oregon with respect to these variables. For example, as Oregon had a very high rural population, the cluster analysis separated states with high or low rural populations while accounting for other variables, such as personal income, total population and total miles driven per capita in rural or urban areas. Table 3.5 shows the variables chosen for use in the cluster analysis

The data used in this cluster analysis were from the Federal Highway Administration's (FHWA) Highway Statistics, an annual summary of various highway statistics for each state and the District of Columbia (FHWA 2002). To coincide with the 2001 NHTS data set, the analysis used the 2001 highway statistics. Although there were several tables available for each year, the data was drawn from the 'Selected Measures for Peer State' table. 
Table 3.5: List of Variables Used in Cluster Analysis

\begin{tabular}{l|l}
\hline Variable Name & Measures \\
\hline Urban Lane Miles Divided by Total Lane Miles & Urban road proportion \\
\hline Rural VMT Divided by Rural Lane Miles & Proxy for rural congestion \\
\hline Urban VMT Divided by Urban Lane Miles & Proxy for urban congestion \\
\hline Rural Lane Mi. Divided by Total Rural Land Sq.Mi. & Rural road density \\
\hline Urban Lane Mi. Divided by Total Urban Land Sq.Mi & Urban road density \\
\hline Urban Land Sq.Mi. Divided by Total Land Sq.Mi. & Urban land proportion \\
\hline Rural Population Divided by Rural Land Sq.Mi. & Rural population density \\
\hline Urban Population Divided by Urban Land Sq.Mi. & Urban population density \\
\hline Total Population Per Square Mile & Total population density \\
\hline Urban Population Divided by Total Population & Urban population proportion \\
\hline Personal Income Per Capita & \\
\hline Personal Gross State Product Per Capita & \\
\hline Percent of Total VMT Driven by Trucks in Rural Areas & \\
\hline Percent of Total VMT Driven by Trucks in Urban Areas & \\
\hline Rural VMT Divided by Rural Population & Rural VMT per capita \\
\hline Urban VMT Divided by Urban Population & Urban VMT per capita \\
\hline Total VMT Per Capita & Per capita VMT for state \\
\hline Source: FHWA Highway Statistics 2001 (http://www.fhwa.dot.gov/ohim/hs01/index.htm)
\end{tabular}

The STATA Data Analysis and Statistical Software was used to run a hierarchical clustering based on complete linkages. This method is appropriate when non-chaining similarities exist and when the number of total groups is not clear. Each value first had to be transformed into $\mathrm{Z}$-scores to account for the fact that the variables are measured in different units. For example, it would be inaccurate to compare a proportion (such as the urban proportion of total lane miles) and personal income per capita as measured in dollars. There were several ways to standardize the data. The authors chose to use the following method:

$$
X_{\text {new }}=\left(X_{\text {old }}-X_{\text {mean }}\right) / X_{\text {StDev }}
$$

where

$X_{\text {new }}$ was the standardized value,

$X$ old was the original value,

$X_{\text {mean }}$ was the variable's mean, and

$X$ StDev was the standard deviation of the variable.

Based on this analysis the state found to be most similar to Oregon was Nebraska, followed by Wisconsin. Other states found to be similar to Oregon included Colorado, Washington, Michigan, Virginia, Minnesota, Texas, Utah, and Oklahoma. The complete results are shown in Figure 3.1. Texas and Wisconsin (referred to as "add-on states") elected to have larger samples drawn for the 2001 NHTS and were therefore over-represented; thus they were excluded. The 2001 NHTS survey did not provide enough observations in Nebraska or Oklahoma, so these were also excluded from the analysis. The remaining six states that showed similar travel patterns as Oregon are listed in Table 3.6, as well as the number of additional observations. 


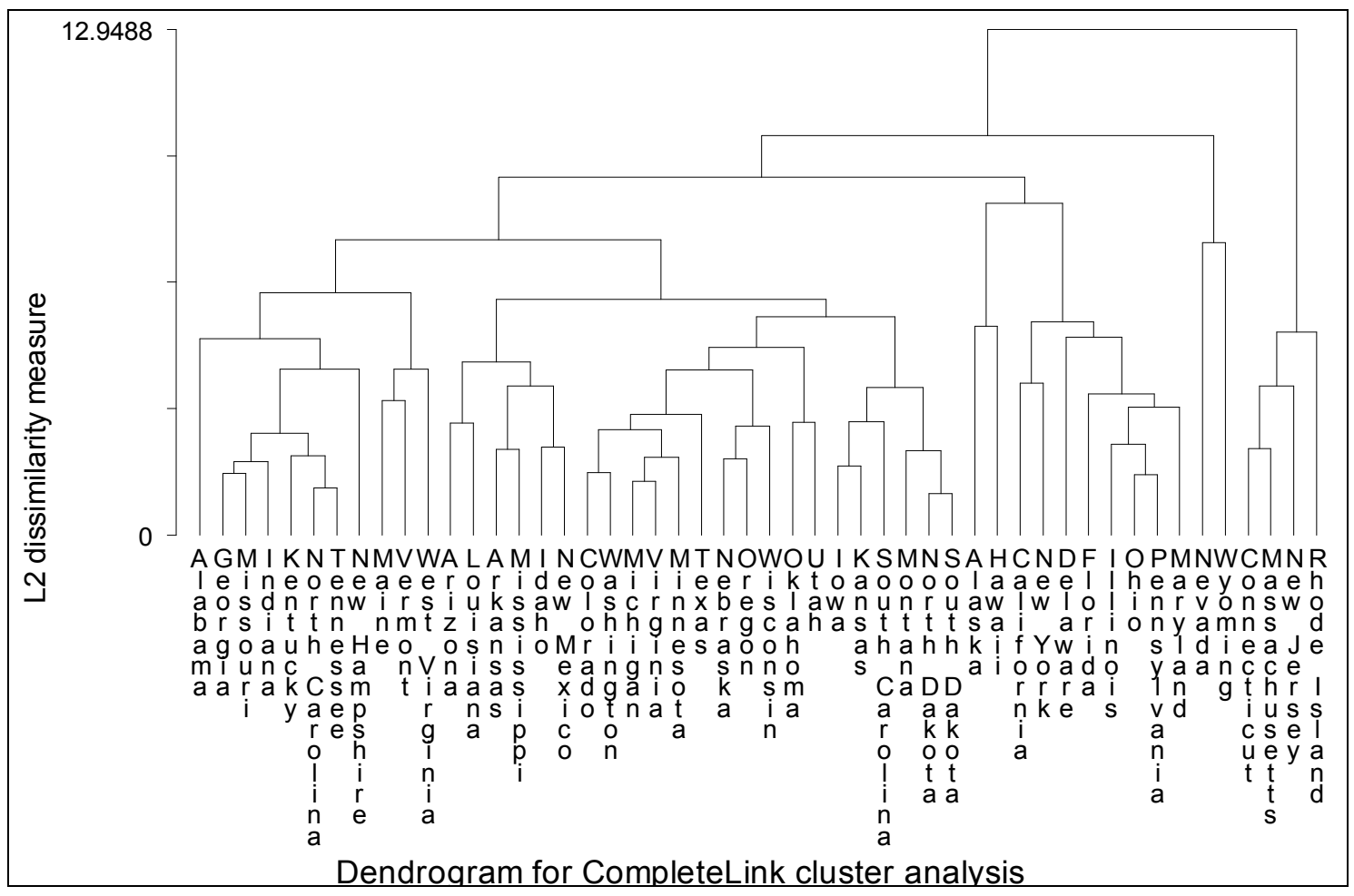

Figure 3.1: Cluster analysis results

Table 3.6: Added observations from the NHTS as a result of the cluster analysis

\begin{tabular}{l|c}
\hline State & \# Households In NHTS \\
\hline Colorado & 466 \\
\hline Washington & 705 \\
\hline Michigan & 992 \\
\hline Virginia & 737 \\
\hline Minnesota & 681 \\
\hline Utah & 200 \\
\hline Total & 3581 \\
\hline
\end{tabular}




\subsection{STATIC MODEL RESULTS}

In the Oregon 2001 NHTS data set, the average gasoline price paid per gallon was $\$ 1.46$, which included the 24 cents-per-gallon gasoline tax. Thus, the average price of gasoline net of the gasoline tax was $\$ 1.22$. To update the results to a more realistic gasoline price, the authors later did the same calculations using a price of $\$ 2.64$ per gallon $(\$ 2.40$ per gallon net of the 24 cents-per-gallon gasoline tax.)

Of interest was how a change from the 24 cents-per-gallon gasoline tax to a 1.2 cents per mile VMT fee would affect the per-mile total gasoline costs for vehicles with different fuel efficiencies. Vehicles that achieved less than 20 miles per gallon would pay less under the VMT fee, while those that got over 20 miles per gallon would pay more.

Given that the NHTS Oregon data sample exhibited an average fuel efficiency of 20.75 miles per gallon, if all vehicles were driven the same number of miles, one would expect a decrease in expenditures on road use after a change to a VMT fee. The actual impact would depend on the relative number of miles driven by vehicles of differing fuel efficiencies. The net change in expenditures and incidence, based on location and assuming a net fuel cost of $\$ 1.22$, was calculated excluding households with missing fuel efficiency data.

West (2005) reports that incidence is less regressive if all households are included, not just those that have vehicles. This result suggests that in West's sample zero vehicle households were more frequent in the lower income classes. There were 32 households in the Oregon NHTS sample with zero vehicles. Nineteen households reported that they owned zero vehicles, while thirteen households were assigned a value of zero for the number of vehicles, because they either did not report annual miles for all vehicles or they reported zero miles for all vehicles. As seen in Table 4.1, households with zero vehicles were overwhelmingly urban households, and they also appeared to be those in the lower income groups (less than $\$ 29,999$ annual household income).

Table 4.1: Characteristics of households with zero vehicles

\begin{tabular}{l|c}
\hline & $\begin{array}{c}\text { Number of Households } \\
\text { with Zero Vehicles }\end{array}$ \\
\hline Urban with zero vehicles & 29 \\
\hline Rural with zero vehicles & 3 \\
\hline Household head - Male & 16 \\
\hline Household head - Female & 16 \\
\hline Income Group 1 $(\$ 0 \sim \$ 14,999)$ & 13 \\
\hline Income Group 2 $(\$ 15,000 \sim \$ 29,999)$ & 10 \\
\hline Income Group 3 $(\$ 30,000 \sim 44,999)$ & 4 \\
\hline Income Group 4 $(\$ 45,000 \sim 59,999)$ & 2 \\
\hline Income Group 5 $(\$ 60,000 \sim 74,999)$ & 2 \\
\hline Income Group 6 (\$75,000 \$200,000) & 0 \\
\hline Missing Income Group & 1 \\
\hline
\end{tabular}

The results for urban and rural vehicle expenditures under the two fee structures (gas tax and VMT fee), both including and excluding households with zero vehicles is shown in Table 4.2. 
Table 4.2: Change in average annual household expenditures when switching from the gasoline tax to a VMT fee by location

\begin{tabular}{l|c|c|c|c}
\hline \multicolumn{1}{l}{ Including Households with Zero Vehicles } \\
\hline Urban & 286 & $\begin{array}{c}\text { Average Gas Tax } \\
\text { Expenditures }\end{array}$ & $\begin{array}{c}\text { Average VMT Fee } \\
\text { Expenditures }\end{array}$ & $\begin{array}{c}\text { Net Change in } \\
\text { Expenditure }\end{array}$ \\
\hline Rural & 111 & $\$ 1,122.85$ & $\$ 1,122.31$ & $-\$ 0.53$ \\
\hline Excluding Households with Zero Vehicles & $\$ 1,556.92$ & $\$ 1,543.68$ & $-\$ 13.24$ \\
\hline \multicolumn{2}{|c|}{} & $\begin{array}{c}\text { Average Gas Tax } \\
\text { Expenditures }\end{array}$ & $\begin{array}{c}\text { Average VMT Fee } \\
\text { Expenditures }\end{array}$ & $\begin{array}{c}\text { Net Change in } \\
\text { Expenditure }\end{array}$ \\
\hline Urban & 258 & $\$ 1,188.11$ & $\$ 1,188.02$ & $-\$ 0.09$ \\
\hline Rural & 108 & $\$ 1,456.18$ & $\$ 1,438.49$ & $-\$ 17.69$ \\
\hline
\end{tabular}

The results show that the change from the gasoline tax to a VMT fee would have the net result of reducing average expenditures for all households. However, the average savings from the conversion would be greater for the average rural household than for the average urban household. This is probably attributable to the fact that on average rural households drove vehicles with lower miles per gallon than those in urban areas. However, the average rural household in the sample also drove more miles than the average urban household. Obviously, the change in average household expenditures was less when including those households that had zero vehicles, a result demonstrated in the table.

The impact on household gasoline and tax expenditures by income group, both including and excluding zero vehicle households, is shown in Table 4.3.

Table 4.3: Change in average annual household expenditures when switching from the gasoline tax to a VMT fee by income group

\begin{tabular}{|c|c|c|c|c|}
\hline \multicolumn{5}{|c|}{ Including Households with Zero Vehicles } \\
\hline \multirow{2}{*}{$\begin{array}{l}\text { Income Group } \\
0-\$ 14,999\end{array}$} & \multirow{2}{*}{$\begin{array}{r}\text { \#HHs } \\
52\end{array}$} & $\begin{array}{c}\text { Average Gas Tax } \\
\text { Expenditures }\end{array}$ & $\begin{array}{l}\text { Average VMT Fee } \\
\text { Expenditures }\end{array}$ & $\begin{array}{c}\text { Change in } \\
\text { Expenditure }\end{array}$ \\
\hline & & $\$ \quad 494.18$ & $\$ \quad 500.04$ & $\$ 5.86$ \\
\hline$\$ 15,000 \sim \$ 29,999$ & 85 & $\$ \quad 809.86$ & 814.44 & $\$ 4.58$ \\
\hline$\$ 30,000 \sim 44,999$ & 69 & $\$ 1,105.95$ & $\$ 1,101.81$ & $-\$ 4.14$ \\
\hline$\$ 45,000 \sim 59,999$ & 64 & $\$ 1,545.26$ & $\$ 1,545.48$ & $\$ \quad 0.22$ \\
\hline$\$ 60,000 \sim 74,999$ & 42 & $\$ 1,770.33$ & $\$ 1,746.20$ & $-\$ 24.13$ \\
\hline$\$ 75,000 \sim \$ 200,000$ & 67 & $\$ 1,992.60$ & $\$ 1,986.59$ & $-\$ 6.00$ \\
\hline \multicolumn{5}{|c|}{ Excluding Households with Zero Vehicles } \\
\hline Income Group & \#HHs & $\begin{array}{c}\text { Average Gas Tax } \\
\text { Expenditures }\end{array}$ & $\begin{array}{c}\text { Average VMT Fee } \\
\text { Expenditures }\end{array}$ & $\begin{array}{c}\text { Change in } \\
\text { Expenditure }\end{array}$ \\
\hline$\$ 0-\$ 14,999$ & 39 & $\$ \quad 658.90$ & $\$ \quad 666.72$ & $\$ 7.81$ \\
\hline$\$ 15,000 \sim \$ 29,999$ & 75 & $\$ 917.84$ & $\$ 923.03$ & $\$ \quad 5.19$ \\
\hline$\$ 30,000 \sim 44,999$ & 65 & $\$ 1,174.01$ & $\$ 1,169.61$ & $-\$ 4.40$ \\
\hline$\$ 45,000 \sim 59,999$ & 62 & $\$ 1,595.10$ & $\$ 1,595.33$ & $\$ 0.23$ \\
\hline$\$ 60,000 \sim 74,999$ & 40 & $\$ 1,858.85$ & $\$ 1,833.51$ & $-\$ 25.34$ \\
\hline$\$ 75,000 \sim \$ 200,000$ & 67 & $\$ 1,992.60$ & $\$ 1,986.59$ & $-\$ \quad 6.00$ \\
\hline
\end{tabular}

As explained above, including households with zero vehicles resulted in smaller average gasoline expenditures and thus less impact on average gasoline expenditures. This is because 
households with zero vehicles would not be at all affected by a change in tax structure, because they would not spend anything on gasoline in either case. Thus, it would appear that the relevant changes to examine are those from the sample that does not include zero-vehicle households.

Table 4.3 shows that, on average, those in the lowest income group would pay \$7.81 more per year in gasoline expenditures under a 1.2 cents-per-mile VMT fee, and the second lowest income group would pay an additional $\$ 5.19$ per year. The group with the highest average benefit from the change would be the $\$ 60,000$ - $\$ 74,999$ income group, which would see, on average, a reduction in gasoline expenditures of about $\$ 25$ per year. This is followed by those with incomes over $\$ 75,000$, which gain about $\$ 6.00$ per year, and those in the $\$ 30,000$ $\$ 44,999$ income group, which gains about $\$ 4.40$.

To get a better idea of the impact of this change on the regressivity of gasoline expenditures including the tax, the incidence for each income group was calculated (Table 4.4). As previous researchers have found, gasoline expenditures, including the gasoline tax are regressive, a finding that also holds true in Oregon. A VMT fee would also result in a regressive expenditure structure. (A regressive tax is one that takes a greater percentage of income from those in lower income groups.)

Table 4.4: Comparison of incidence of gasoline expenditures under a gasoline tax and a VMT fee: assuming a net gas cost of $\$ 1.22$

\begin{tabular}{|c|c|c|c|c|}
\hline \multirow{2}{*}{ Income Group } & \multicolumn{2}{|c|}{$\begin{array}{c}\text { Expenditures as \% of Income with } \\
\text { Gasoline Tax }\end{array}$} & \multicolumn{2}{|c|}{$\begin{array}{c}\text { Expenditures as \% of Income with } \\
\text { VMT Fee }\end{array}$} \\
\hline & $\begin{array}{c}\text { All } \\
\text { Households } \\
\end{array}$ & $\begin{array}{c}\text { Excluding 0-vehicle } \\
\text { HHs } \\
\end{array}$ & $\begin{array}{c}\text { All } \\
\text { Households }\end{array}$ & $\begin{array}{c}\text { Excluding 0-vehicle } \\
\text { HHs } \\
\end{array}$ \\
\hline $0-14,999$ & $4.97 \%$ & $6.63 \%$ & $5.03 \%$ & $6.71 \%$ \\
\hline$\$ 15,000 \sim \$ 29,999$ & $3.61 \%$ & $4.09 \%$ & $3.63 \%$ & $4.11 \%$ \\
\hline$\$ 30,000 \sim 44,999$ & $2.97 \%$ & $3.17 \%$ & $2.97 \%$ & $3.16 \%$ \\
\hline$\$ 45,000 \sim 59,999$ & $2.97 \%$ & $3.06 \%$ & $2.97 \%$ & $3.06 \%$ \\
\hline$\$ 60,000 \sim 74,999$ & $2.62 \%$ & $2.75 \%$ & $2.59 \%$ & $2.72 \%$ \\
\hline$\$ 75,000 \sim \$ 200,000$ & $1.81 \%$ & $1.81 \%$ & $1.81 \%$ & $1.81 \%$ \\
\hline
\end{tabular}

However, what is of interest here is the difference between the two tax structures, focusing on the results that exclude zero-vehicle households (since those households are not impacted). The lowest two income groups showed slight increases in incidence (.08 and .02 percent of income) while the $\$ 30,000-\$ 44,999$ and $\$ 60,000-\$ 74,999$ income groups showed slight decreases (.01 and .03 percent of income). The other income groups showed no change in incidence.

The very small changes in incidence reflect the fact that the taxes themselves represent a very small portion of total household expenditures - much smaller than the cost of gasoline itself.

To demonstrate how small the impact of the change in tax structure is relative to the effect of a change in the price of gasoline between 2001 and 2006, the above analysis was re-run using a gasoline price of $\$ 2.64$ per gallon (a $\$ 2.40$ gas price net of the gasoline tax). These results are shown in Table 4.5.

What becomes immediately obvious is that the regressivity of gasoline expenditures increased substantially from that shown in Table 4.4. While moving from the gasoline tax to 
a VMT fee produced an increase in incidence for the lowest income group of .08 percent when the net gasoline price was $\$ 1.22$ per gallon, the near doubling of gasoline prices resulted in an increased incidence with the gasoline tax from $6.63 \%$ to $11.99 \%$ - an increase in incidence of 5.33 percent.

Table 4.5: Comparison of incidence of gasoline expenditures under a gasoline tax and a VMT fee: assuming a net gas cost of $\$ \mathbf{2 . 4 0}$

\begin{tabular}{l|r|r|r|r}
\hline \multirow{2}{*}{ Income Group } & \multicolumn{2}{|c|}{$\begin{array}{c}\text { Expenditures as \% of Income with } \\
\text { the Gasoline Tax }\end{array}$} & \multicolumn{2}{c}{$\begin{array}{c}\text { Expenditures as \% of Income with } \\
\text { the VMT Fee }\end{array}$} \\
\cline { 2 - 5 } & $\begin{array}{c}\text { All } \\
\text { Households }\end{array}$ & $\begin{array}{c}\text { Excluding 0-vehicle } \\
\text { HHs }\end{array}$ & $\begin{array}{c}\text { All } \\
\text { Households }\end{array}$ & $\begin{array}{c}\text { Excluding 0-vehicle } \\
\text { HHs }\end{array}$ \\
\hline $0-14,999$ & $9.68 \%$ & $11.99 \%$ & $9.74 \%$ & $12.07 \%$ \\
\hline$\$ 15,000 \sim \$ 29,999$ & $6.59 \%$ & $7.40 \%$ & $6.62 \%$ & $7.42 \%$ \\
\hline$\$ 30,000 \sim 44,999$ & $5.40 \%$ & $5.73 \%$ & $5.38 \%$ & $5.72 \%$ \\
\hline$\$ 45,000 \sim 59,999$ & $5.36 \%$ & $5.54 \%$ & $5.36 \%$ & $5.54 \%$ \\
\hline$\$ 60,000 \sim 74,999$ & $4.73 \%$ & $4.98 \%$ & $4.70 \%$ & $4.94 \%$ \\
\hline$\$ 75,000 \sim \$ 200,000$ & $3.28 \%$ & $3.28 \%$ & $3.27 \%$ & $3.27 \%$ \\
\hline
\end{tabular}

From this analysis it becomes clear that while a change from the gasoline tax of 24 cents per gallon to a VMT fee of 1.2 cents per mile could have a slight impact on incidence, is it miniscule compared to the impact that is felt due to the general rise in gasoline prices.

\subsection{ALTERNATIVE POLICIES}

As mentioned earlier, a change to a VMT fee has raised concerns, because the change in tax structure would effectively lower the cost of driving for "gas guzzlers" and increase the total amount paid by those driving more fuel efficient cars (although the changes are likely to be very small compared to the overall cost of gasoline). Thus, such a change is seen as being in conflict with alternate goals of increasing the use of hybrid vehicles and reducing the dependence on fossil fuels.

A VMT fee could be formulated in a way that minimizes or reverses this unintentional impact of the policy change. Sample Scenario \#1 would be a VMT fee structure that maintains the gasoline tax for those vehicles with fuel efficiency of less than 20 miles per gallon and charges a flat 1.2 cents-per-mile VMT fee to those vehicles with fuel efficiency over 20 miles per gallon. This policy would keep "gas guzzlers" from realizing a lower cost of driving (which could encourage them to drive even more). Note that since a VMT fee of 1.2 cents per mile would be a revenue-neutral change in fee structure, Sample Scenario \#1 would actually result in an increase in revenues collected by the state.

The distributional impact of Sample Scenario \#1 is shown in Tables 4.6 and 4.7. Note that households in every income group would pay more in user fees under this scenario. The increase in the user fee for those in the lowest income group would be about twice what it would be under a flat VMT fee of 1.2 cents per mile levied on all vehicles. However, those in the highest income groups would not gain (in terms of paying less in user fees) as they would under a flat VMT fee policy. Indeed, those in the two highest income groups would end up paying between $\$ 22$ and \$31 more per household instead of paying less under the flat VMT fee scenario. 
Table 4.6: Household annual expenditures on gasoline under Sample Scenario \#1*

\begin{tabular}{l|c|c|c|c|c}
\hline $\begin{array}{l}\text { Income } \\
\text { Group }\end{array}$ & $\begin{array}{c}\text { Average } \\
\text { Expenditures } \\
\text { Under Gas } \\
\text { Tax (\$) }\end{array}$ & $\begin{array}{c}\text { Average } \\
\text { Expenditures } \\
\text { Under VMT } \\
\text { Fee of } \\
\mathbf{\$ . 0 1 2} / \mathbf{m i l e} \mathbf{( \$ )}\end{array}$ & $\begin{array}{c}\text { Average } \\
\text { Change in } \\
\text { user fee paid } \\
\text { under VMT } \\
\text { Fee of } \\
\mathbf{\$ . 0 1 2} / \mathbf{m i l e}\end{array}$ & $\begin{array}{c}\text { Average } \\
\text { Expenditures } \\
\text { Sample } \\
\text { Scenario \#1 } \\
\mathbf{( \$ )}\end{array}$ & $\begin{array}{c}\text { Average } \\
\text { Change in } \\
\text { user fee paid } \\
\text { under Sample } \\
\text { Scenario \#1 }\end{array}$ \\
\hline 1 & $\$ 658.90$ & $\$ 666.72$ & $\$ 7.82$ & $\$ 675.36$ & $\$ 16.46$ \\
\hline 2 & $\$ 917.84$ & $\$ 923.03$ & $\$ 5.19$ & $\$ 935.01$ & $\$ 17.17$ \\
\hline 3 & $\$ 1,174.01$ & $\$ 1,169.61$ & $-\$ 4.40$ & $\$ 1,191.91$ & $\$ 17.90$ \\
\hline 5 & $\$ 1,595.10$ & $\$ 1,595.33$ & $\$ 0.23$ & $\$ 1,623.57$ & $\$ 28.47$ \\
\hline 6 & $\$ 1,858.85$ & $\$ 1,833.51$ & $-\$ 25.34$ & $\$ 1,881.25$ & $\$ 22.40$ \\
\hline *Gasoline tax of $\$ .24$ for vehicle with $\mathrm{mpg}<20 ;$ VMT fee of $\$ .012$ for vehicles with $\mathrm{mpg}>20$ & $\$ 31.08$ \\
\hline
\end{tabular}

As shown in Table 4.7, under Sample Scenario \#1 both urban and rural household would pay more, although the increase for urban households would be slightly larger. By comparison, a flat VMT fee would result in a reduction in fees paid by rural households and a very small increase for urban households under the simple VMT fee.

Table 4.7: Urban/rural household annual expenditure changes under Sample Scenario \#1*

\begin{tabular}{|c|c|c|c|c|c|}
\hline Location & $\begin{array}{c}\text { Average } \\
\text { Expenditures } \\
\text { Under Gas Tax } \\
(\$) \\
\end{array}$ & $\begin{array}{c}\text { Average } \\
\text { Expenditures } \\
\text { Under flat VMT } \\
\text { Fee } \\
(\$) \\
\end{array}$ & $\begin{array}{c}\text { Average } \\
\text { Change in } \\
\text { user fee paid } \\
\text { under flat } \\
\text { VMT fee } \\
\end{array}$ & $\begin{array}{c}\text { Average } \\
\text { Mixed Policy } \\
\text { Expenditures } \\
\text { (\$) } \\
\end{array}$ & $\begin{array}{c}\text { Average } \\
\text { Change in } \\
\text { user fee paid } \\
\text { under } \\
\text { Sample } \\
\text { Scenario \#1 } \\
\end{array}$ \\
\hline Rural & $\$ 1,600.17$ & $\$ 1,586.56$ & $-\$ 13.61$ & $\$ 1,621.93$ & $\$ 21.76$ \\
\hline Urban & $\$ 1,249.55$ & $\$ 1,251.58$ & $\$ 2.03$ & $\$ 1,272.24$ & $\$ 22.69$ \\
\hline
\end{tabular}

It is also possible that Sample Scenario \#1 might not provide enough of an incentive for people to purchase more fuel efficient vehicles. Thus it is also useful to consider a "step" fee policy whereby vehicles would incur increasingly higher VMT fees, the lower the fuel efficiency of the vehicle. In Sample Scenario \#2 vehicles that achieve less than the median fuel efficiency (approximately $18 \mathrm{mpg}$ ) would pay 2 cents per mile; those between the median efficiency and $20 \mathrm{mpg}$ would pay 1.5 cents per mile; and those with a fuel efficiency of above $20 \mathrm{mpg}$ would pay only 1 cent per mile in VMT fees. The incidence of this scenario on income groups and urban/rural groups is shown in Tables 4.8 and 4.9. 
Table 4.8: Annual household expenditures by income group on gasoline under Sample Scenario \#2*

\begin{tabular}{|c|c|c|c|c|}
\hline $\begin{array}{l}\text { Income } \\
\text { group }\end{array}$ & \# hhs & $\begin{array}{c}\text { Average revenue } \\
\text { with } 24 \text { cents per } \\
\text { gallon gas tax } \\
\end{array}$ & $\begin{array}{c}\text { Average revenue } \\
\text { with "step" VMT } \\
\text { fee }\end{array}$ & $\begin{array}{l}\text { Average revenue change } \\
\text { from gas tax to "step" } \\
\text { VMT fee } \\
\end{array}$ \\
\hline 1 & 39 & $\$ 108.31$ & $\$ 123.60$ & $\$ 15.29$ \\
\hline 2 & 75 & $\$ 150.88$ & $\$ 176.66$ & $\$ 25.78$ \\
\hline 3 & 65 & $\$ 192.99$ & $\$ 223.88$ & $\$ 30.89$ \\
\hline 4 & 62 & $\$ 262.21$ & $\$ 305.32$ & $\$ 43.11$ \\
\hline 5 & 40 & $\$ 305.56$ & $\$ 380.27$ & $\$ 74.71$ \\
\hline 6 & 67 & $\$ 327.55$ & $\$ 404.11$ & $\$ 76.56$ \\
\hline
\end{tabular}

Sample Scenario \#2 would results in all income groups paying more, but the increase in fees paid is progressively higher for higher income groups and lower for those in lower income groups.

Table 4.9: Urban/rural annual household expenditures on gasoline under Sample Scenario \#2*

\begin{tabular}{|c|c|c|c|c|}
\hline Location & \# hhs & $\begin{array}{c}\text { Average revenue } \\
\text { with } 24 \text { cents per } \\
\text { gallon gas tax } \\
\end{array}$ & $\begin{array}{l}\text { Average revenue } \\
\text { with "step" } \\
\text { VMT fee } \\
\end{array}$ & $\begin{array}{l}\text { Average revenue change } \\
\text { from gas tax to "step" } \\
\text { VMT fee }\end{array}$ \\
\hline Rural & 108 & $\$ 263.04$ & $\$ 317.40$ & $\$ 54.36$ \\
\hline Urban & 256 & $\$ 205.41$ & $\$ 238.46$ & $\$ 33.05$ \\
\hline
\end{tabular}

Sample Scenario \#2 would increase the taxes paid by both rural and urban areas, but in this case it the rural areas would end up paying more. This is due to the combined effects of rural areas having vehicles with lower average fuel efficiency and rural households driving more miles.

Thus, both sample scenarios would have the effect of increasing fees paid by all groups. Sample Scenario \#1 would result in both urban and rural areas paying more. However, Sample Scenario \#1 has urban areas paying more than rural areas whereas rural areas would pay almost twice that paid by urban areas under Sample Scenario \#2.

\subsection{AN ALTERNATIVE WAY TO MEASURE REGRESSIVITY: THE SUITS INDEX}

The Suits Index (Suits 1977) is a way to measure the overall regressivity of a tax, or to compare the changes in regressivity as a result of a structural or policy change. In this study one can compare the regressivity of the gasoline tax to a VMT fee. The Suits Index, bounded between -1 and +1 , is convenient in that it provides one number that can be compared across tax regimes. A value of -1 would indicate that the lowest income group bears the entire burden of the tax; a value of +1 would indicate that the highest income group bears the entire tax burden. A value of 0 would indicate that the proportion of the overall tax paid by each income group is exactly equal to the proportion of the population represented by that income group. (For a more detailed explanation of the Suits index, see Appendix B.) 
Under the gasoline tax the Suits Index is -0.176 , while the Index is -0.225 under a flat 1.2 cents per mile VMT fee, implying the VMT fee would shift some of the tax burden from the higher income groups to the lower income groups, making it more regressive. The Suits Index for Sample Scenario \#1 is -.185, indicating a greater degree of regressivity than the gasoline tax but less than that of a flat VMT fee. The Suits Index for Sample Scenario \#2 is -.162, indicating that although everyone would pay more under Sample Scenario \#2, this policy would result in a less regressive tax structure than the other alternatives, including the current gas tax.

As mentioned earlier, the analysis discussed in this chapter assumes that a change to a VMT fee (which would result in a change in the per-mile cost of driving for some households) would not have an impact on demand (the number of miles driven). If those household groups in which the per-mile cost of gas increased were to respond by decreasing their driving, the increase in incidence for those groups would be less. Of course, it is also possible that those households experiencing a decrease in per-mile driving cost would drive more and thus may benefit from the change in tax. What actually occurs would depend on the demand response to the change in per-mile costs.

Accordingly, the next stage of this research focused on developing an estimate of the demand response to the per-mile driving cost changes that would be caused by the change in tax and then recalculating the incidence to include the impact of the demand response 


\subsection{REGRESSION MODEL RESULTS}

With the regression model, also known as the Ordinary Least Squares (OLS) model, one addresses the relationship between household miles and vehicle type by including a substitution dummy variable equal to one if the household has more than one type of vehicle and zero otherwise. The inclusion of this variable allows one to calculate different elasticities for households with multiple vehicle types and those without. Households with multiple vehicle types are expected to be less responsive to fuel cost per mile changes, since they are able to substitute away from vehicles with a higher fuel cost per mile.

The OLS model for this analysis is based on the following equation:

$$
M=f\left(P_{M}, I, P_{M} * I, U, C, S U B, P_{M} * S U B, \overrightarrow{H H}_{M}\right)
$$

where

$M$ is the total annual miles driven by the household;

$P_{M}$ is the fuel cost per mile under the gasoline tax;

$I$ is annual household income;

$U$ is a dummy variable equal to one if the household is located in an urban area, and zero otherwise;

$C$ is the number of vehicles the household owns;

$S U B$ is a dummy variable that takes the value of one if the household has more than one type of vehicle such as a car and truck and zero otherwise;

$P_{M} * I$ is an interaction term between the fuel cost per mile and income;

$P_{M} * S U B$ is an interaction term between the fuel cost per mile and the substitution dummy

variable; and

$\overrightarrow{H H}_{M}$ is a vector of household characteristics that includes the number of children (CHILD), number of workers (WORK) and a dummy variable that takes the value of one if the household respondent is male and zero otherwise (MALE).

For details and definitions for each of the variables, see Appendix C, Section C.1.

As the fuel cost per mile increases, one would expect households to reduce miles driven; so the coefficient on the average fuel cost per mile should be negative. Assuming miles driven is a normal good, one expects the sign on income to be positive, suggesting that as household income increases, the household is able to spend more of its income on miles. One expects the coefficient on the location variable to be negative, which would imply that households in urban areas drive less than those in rural areas due to shorter commutes to work and more developed surroundings.

If households have more than one vehicle, they are more likely to drive more miles. Households with multiple types of vehicles are able to substitute between vehicles in response to other variables, such as the fuel cost per mile. This flexibility may encourage them to drive more, relative to other households that are not able to substitute between 
vehicles. West (2002) states that, "Male-headed households are even more likely to own two vehicles than they are to own one.",

As the number of children or the number of workers increase, one would expect households to drive more, out of necessity. Households may have to take their children to more activities, increasing miles traveled (West 2002). West finds that male-headed households drive more miles than those headed by females.

The interaction term between the fuel cost per mile and income allows for different impacts on different income groups. As the fuel cost per mile increases, one would expect households with higher incomes to drive more miles than those with lower incomes, because those in the higher income groups will not feel as great a burden on their total income with the increasing fuel cost per mile. That is, those in higher income groups are expected to have a more inelastic demand, as demonstrated by West (2002). Similarly, the interaction term between the fuel cost per mile and the substitution dummy variable allows for different impacts on those with multiple vehicle types and those without. Presumably, households with multiple vehicle types are able to substitute between their vehicles, and the coefficient should therefore be positive. Thus, relative to households who cannot substitute between vehicle types as the fuel cost per mile increases, households with multiple vehicle types are more likely to drive more miles.

The OLS regression was run on household annual miles with the fuel cost per mile under the current gasoline tax. ${ }^{3}$ A change in policy to a 1.2 cents-per-mile VMT fee was captured by subtracting the $\$ 0.24$ tax out of the gasoline price, dividing the remaining net gas cost by the fuel efficiency and then adding a $\$ 0.012$ VMT fee. ${ }^{4}$ The new fuel cost per mile - under the VMT fee - was thus different for every household, unless the household had an average fuel efficiency equal to $20 \mathrm{MPG}^{5}$ The incidence calculations below compare the fitted values from the OLS regression and the recalculated fitted values under the new fuel cost per mile variable, based on the estimated parameters.

\subsection{OREGON SAMPLE REGRESSION RESULTS}

The authors estimated a simple Ordinary Least Squares (OLS) regression of annual household miles using the sample of 339 Oregon households from the 2001 National Household Travel Survey (NHTS). The results are shown in Table 5.1. All signs were as expected, based on economic theory and the findings of previous studies. All coefficient estimates have the expected signs, and the adjusted $\mathrm{R}^{2}$ for the model is 0.46 .

\footnotetext{
2 Our data support West's statement. The correlation coefficient between our male dummy variable and vehicle count variable was approximately 0.16 . Though not particularly high, there was a positive correlation between the two variables.

3 See A2 in the Appendix for the calculation of fuel cost per mile.

$4 \quad$ Empirical studies show that nearly the entire state gasoline tax burden is placed on the consumer, which justifies subtracting the entire \$0.24 tax from the gasoline price (Chernick and Reschovsky, 1997 and Chouinard and Perloff, 2003).

$5 \quad$ ODOT based the $\$ 0.012$ per mile fee on the concept of a revenue neutral VMT fee, using an average fuel efficiency of $20 \mathrm{mpg}$ for all non-commercial vehicles in Oregon. Thus the average household should be unaffected by the policy change. This study uses the change in fuel expenditures by households as a measure of well-being.
} 
Table 5.1: Dependent variable - annual household miles (logarithmic) ${ }^{\dagger}$

\begin{tabular}{|c|c|c|c|}
\hline Variable Name & Coefficient & Standard Error & T-statistic \\
\hline Constant & $-17.72 *$ & 6.239724 & -2.84 \\
\hline$P_{M}$ & $-8.76^{*}$ & 2.388977 & -3.67 \\
\hline$I$ & $2.21 *$ & 0.613436 & 3.60 \\
\hline$P_{M} * I$ & $0.72 *$ & 0.2352192 & 3.05 \\
\hline$P_{M} * S U B$ & 0.44 & 0.4005742 & 1.09 \\
\hline$U$ & $-0.16^{*}$ & 0.0950097 & -1.67 \\
\hline$C$ & $0.54 *$ & 0.1290508 & 4.18 \\
\hline SUB & 1.39 & 1.050415 & 1.32 \\
\hline MALE & $0.17 *$ & 0.0874272 & 1.94 \\
\hline WORK & $0.21^{*}$ & 0.0528672 & 3.95 \\
\hline CHILD & 0.04 & 0.0393044 & 0.91 \\
\hline
\end{tabular}

Income and vehicles owned by a household were found to have a positive and significant effect on miles driven. The dummy variable for urban households was significant and suggests that urban households drive fewer miles than rural households. Households with male respondents drive more miles than households with female respondents. Household annual miles increase as the number of workers increases, as expected. As the fuel cost per mile increases, households reduce the overall number of miles driven; however, the overall reduction depends on household income and whether or not the household is able to substitute between vehicle types. The fuel cost per mile and the interaction term between the fuel cost per mile and income were statistically significant. However, the interaction term between the fuel cost per mile and the substitution variable was not found to be significant.

As the number of children increases, one would expect the household to drive more miles as suggested by the model; however, this was not statistically significant. Though the substitution variable was not statistically significant, it had the expected sign, as discussed in Chapter 4. That is, if a household is able to substitute between vehicles, one would expect them to drive more miles relative to a household (all else equal) that is unable to substitute between vehicles.

One can interpret the coefficients of the logarithmic terms as elasticities. The model assumes that the elasticity of annual household miles driven with respect to fuel cost per mile varies across income groups. As expected, higher income groups, on average, are less responsive to changes in the fuel cost per mile, as shown in Table 5.2. The coefficient of the interaction term between the fuel cost per mile and the substitution dummy variable also allows for the elasticity to vary between households that are able to substitute between vehicle types, and those that cannot. Though not statistically significant, this coefficient was as expected and indicates that households that are not able to substitute between vehicle types have a more elastic demand, as expected. ${ }^{6}$ These households are more sensitive to changes in the fuel cost per mile. It should be noted that the elasticities will vary by households; however, this analysis used the average income value for each group to provide an approximation.

\footnotetext{
${ }^{6}$ The elasticity of miles driven with respect to the fuel cost per mile can be calculated as: $\varepsilon_{M, P_{M}}=-8.6814+0.71 * I+0.4548 * S U B$.
} 
Table 5.2: Elasticity by income group - based on average income

\begin{tabular}{|c|c|c|c|}
\hline Income Group & Average Income & $\begin{array}{c}\text { Elasticity with } \\
\text { SUB }\end{array}$ & $\begin{array}{c}\text { Elasticity } \\
\text { without SUB }\end{array}$ \\
\hline 1 & $\$ 9,055.90$ & 1.79 & 2.23 \\
\hline 2 & $\$ 21,983.11$ & 1.16 & 1.59 \\
\hline 3 & $\$ 36,899.07$ & 0.78 & 1.22 \\
\hline 4 & $\$ 51,952.61$ & 0.54 & 0.98 \\
\hline 5 & $\$ 67,394.80$ & 0.35 & 0.79 \\
\hline 6 & $\$ 106,043.36$ & 0.03 & 0.47 \\
\hline
\end{tabular}

The next step was to estimate the welfare impacts and changes in consumer surplus that would occur with a change from the current 24 cents-per-gallon gasoline tax to a 1.2 centsper-mile VMT fee. The authors assumed a linear demand function.

Generally, welfare is defined as the total consumer and producer surplus gained (or lost) as a result of - in this case - the policy change. To society as a whole, it does not matter whether consumers or producers gain more. Thus, a positive welfare gain may reflect an overall gain for consumers or producers. In this case the producer is the government agency that collects the tax, so the change in surplus going to the producer is the change in revenues collected by the agency. (See Appendix D for welfare, consumer, and producer surplus equations.)

Tables 5.3 and 5.4 show the average changes in consumer surplus, tax revenue and welfare by income group and by urban versus rural households. As expected, the changes in tax revenue collected by the state agency as a result of a change from the gas to a VMT fee were smaller in this analysis than they were in the static model, which did not account for changes in miles driven in response to the change in the cost of driving. However, the change in tax revenue paid by a consumer only tells part of the story. If consumers end up driving more than they did before the change in fees, the consumers derive a benefit from the additional travel that is reflected in the measures of consumer surplus.

Table 5.3: Average changes in consumer surplus, tax revenue and welfare by income (\$/household)

\begin{tabular}{c|r|rrr}
\hline Income Group & $\begin{array}{c}\text { Average Change in } \\
\text { Consumer Surplus }\end{array}$ & $\begin{array}{c}\text { Average Change in } \\
\text { Taxes paid }\end{array}$ & $\begin{array}{c}\text { Average Change in } \\
\text { Welfare }\end{array}$ \\
\hline 1 & $-\$ 7.51$ & $\$ 5.03$ & $-\$ 2.48$ \\
\hline 2 & $-\$ 6.47$ & $-\$ 4.24$ & $-\$ 0.34$ \\
\hline 3 & $\$ 9.36$ & $\$ 8.06$ & $\$ 5.12$ \\
\hline 4 & $-\$ 2.41$ & $-\$ 12.92$ & $\$ 5.57$ \\
\hline 5 & $\$ 28.48$ & $-\$ 2.60$ & $\$ 15.56$ \\
\hline 6 & $\$ 12.77$ & $\$ 10.17$ \\
\hline
\end{tabular}

The overall impact on social welfare is the sum of the change in consumer surplus and the change in producer surplus. So for instance, in the case of Income Group 1, there would be an average loss in consumer surplus of $\$ 7.51$ that represents both the additional amount paid in taxes and the value of the reduced travel that would be caused by the increase in the cost of driving. Part of this would be transferred to the government agency in the form of increased revenue of $\$ 5.03$. The net impact on social welfare would be a loss equal to $\$ 7.51-\$ 5.03=$ $\$ 2.48$ (-\$2.48 in Table 5.3). Note that these represent very small changes; even for a household in the lowest income group this represents a change in expenditures that is less than $1 / 10$ of one percent of income. 
Overall those in the highest income groups would have a net gain: they would pay less to drive and this would stimulate additional travel that benefits them. However, given the extremely small difference relative to their income (again less than $1 / 10$ of one percent), this is not likely to alter behavior significantly.

Thus, in the case of a demand curve with some elasticity, the change in consumer surplus places a dollar value on the welfare impact on consumers in each group - including both the change in taxes paid and the value the consumer places on the induced change in miles driven. Note that the general pattern of the consumer surplus change in this model is very similar to the change in taxes paid in the static model, and in both cases the impact on households is extremely small relative to their household income or their total annual expenditures on driving. This suggests that policymakers who just need a "ballpark" estimate of the impact of a change in highway user fees could use the results provided by the static model, which requires less data analysis than calculations based on the OLS regression model. However, it also should be noted that this may only be true for small changes similar to the magnitudes considered in this study.

Table 5.4: Average changes in consumer surplus, tax revenue and welfare by location (\$/household)

\begin{tabular}{l|r|r|r}
\hline Location Group & $\begin{array}{c}\text { Average Change in } \\
\text { Consumer Surplus }\end{array}$ & $\begin{array}{c}\text { Average Change in } \\
\text { Tax Revenue }\end{array}$ & $\begin{array}{c}\text { Average Change in } \\
\text { Welfare }\end{array}$ \\
\hline Rural & $\$ 17.40$ & $-\$ 9.46$ & $\$ 7.93$ \\
\hline Urban & $-\$ 0.62$ & $\$ 4.89$ & $\$ 4.27$ \\
\hline
\end{tabular}

The OLS results for the Urban/Rural impacts were again similar to the static result: urban households would pay slightly more under a VMT fee and rural households would pay less. However, the large change in consumer surplus for rural households reflects their benefits from increased travel that would be induced by the lower cost of driving under a VMT fee.

Once again, the study examined the impact of sample VMT fee scenarios that could be considered to try and encourage use of more efficient vehicles and reduce driving. Table 5.5 shows the difference between the gasoline tax incidence and the incidence under VMT fee Sample Scenario \#1. Again, in this case households in every income group would pay more per year; however, there was not a clear impact on overall social welfare. There were consumer surplus losses for all income groups.

Table 5.5: Annual household expenditures on gasoline under Sample Scenario \#1*

\begin{tabular}{c|r|r|r}
\hline Income Group & $\begin{array}{c}\text { Average Change in } \\
\text { Consumer Surplus }\end{array}$ & $\begin{array}{c}\text { Average Change in } \\
\text { Taxes paid }\end{array}$ & $\begin{array}{c}\text { Average Change in } \\
\text { Welfare }\end{array}$ \\
\hline 1 & $-\$ 11.80$ & $\$ 13.52$ & $\$ 1.72$ \\
\hline 2 & $-\$ 16.23$ & $\$ 16.25$ & $\$ 0.01$ \\
\hline 3 & $-\$ 11.81$ & $\$ 9.07$ & $-\$ 2.74$ \\
\hline 4 & $-\$ 27.51$ & $\$ 33.33$ & $-\$ 1.19$ \\
\hline 5 & $-\$ 19.12$ & $\$ 22.82$ & $-\$ 2.20$ \\
\hline 6 & $-\$ 25.02$ & $\$ 17.93$ &
\end{tabular}

* Gasoline Tax of $\$ .24$ for vehicle with mpg $<20$; VMT of $\$ .012$ for vehicles with mpg $>20$

As shown in Table 5.6, for rural households, Sample Scenario \#1 would mean an increase in taxes paid and a loss of consumer surplus that reflects less driving. In this case, urban 
households would pay more per year, but the increase in fees paid would be larger for rural households.

Table 5.6: Urban/rural annual household expenditure changes under Sample Scenario \#1*

\begin{tabular}{|l|c|c|c|}
\hline Location Group & $\begin{array}{c}\text { Average Change in } \\
\text { Consumer Surplus }\end{array}$ & $\begin{array}{c}\text { Average Change in } \\
\text { Tax Revenue }\end{array}$ & $\begin{array}{c}\text { Average Change in } \\
\text { Welfare }\end{array}$ \\
\hline Rural & $-\$ 17.81$ & $\$ 19.68$ & $\$ 1.88$ \\
\hline Urban & $-\$ 19.46$ & $\$ 18.90$ & $-\$ 0.55$ \\
\hline
\end{tabular}

For Sample Scenario \#2, results for the distributional impact are presented in Table 5.7. Here the losses in consumer surplus for the highest income group would be almost six times as large as those for the lowest income group, although again all groups would end up losing both in terms of consumer surplus and in terms of additional taxes paid per year.

Table 5.7: Annual household expenditures on gasoline under Sample Scenario \#2*

\begin{tabular}{c|r|r|r|r}
\hline $\begin{array}{c}\text { Income } \\
\text { group }\end{array}$ & \# hhs & $\begin{array}{c}\text { Average change in } \\
\text { consumer surplus }\end{array}$ & $\begin{array}{c}\text { Average change } \\
\text { in tax revenue }\end{array}$ & $\begin{array}{c}\text { Average change } \\
\text { in welfare }\end{array}$ \\
\hline 1 & 39 & $-\$ 8.68$ & $\$ 11.11$ & $\$ 2.43$ \\
\hline 2 & 74 & $-\$ 17.77$ & $\$ 20.42$ & $\$ 2.65$ \\
\hline 3 & 61 & $-\$ 29.69$ & $\$ 30.74$ & $\$ 1.06$ \\
\hline 4 & 60 & $-\$ 33.92$ & $\$ 36.23$ & $\$ 2.31$ \\
\hline 5 & 39 & $-\$ 63.32$ & $\$ 80.30$ & $\$ 16.97$ \\
\hline 6 & 66 & $-\$ 62.34$ & $\$ 86.99$ & $\$ 24.64$ \\
\hline
\end{tabular}

*Step fee: a) MPG $<$ median MPG pays 2 cents cents/mile; b) between median MPG to 20 pays 1.5 cents/mile; c) $\mathrm{MPG}>20$ pays $1 \mathrm{cent} / \mathrm{mile}$

Finally, Table 5.8 shows the impacts on the rural/urban households resulting from Sample Scenario \#2. This alternative would impose even larger negative impacts on both urban and rural households than Sample Scenario \#1, and rural households would pay an average of over \$58 more per year than under the current gasoline tax.

Table 5.8: Urban/rural annual household expenditures on gasoline under Sample Scenario 2*

\begin{tabular}{l|r|r|r|r}
\hline Location & \# hhs & $\begin{array}{c}\text { Average change in } \\
\text { consumer surplus }\end{array}$ & $\begin{array}{c}\text { Average change } \\
\text { in tax revenue }\end{array}$ & Average change in welfare \\
\hline Rural & 101 & $-\$ 37.45$ & $\$ 58.81$ & $\$ 21.36$ \\
\hline Urban & 238 & $-\$ 34.88$ & $\$ 37.51$ & $\$ 2.62$ \\
\hline *Step fee: a) MPG $<$ median MPG pays 2 cents cents/mile; b) between median MPG to 20 pays 1.5 cents $/$ mile; c) MPG $>20$ pays 1 cent $/$ mile
\end{tabular}

Thus, while Sample Scenarios \#1 and \#2 were designed to prevent a VMT fee policy from discouraging adoption and use of more fuel efficient vehicles, they would result in placing rural households at a greater disadvantage relative to urban households, compared to a flat 1.2 cents-per-mile VMT fee. Both sample scenarios would not have a revenue-neutral impact, as all households would pay more in fees, although in general the sample scenarios would impose larger costs on higher income households than lower income households. 


\subsubsection{The Suits Index}

As in the static model, the Suits Index was also calculated for the OLS model. Under the gasoline tax, the Suits Index was approximately -0.133 compared to a Suits Index approximately equal to -0.142 under a flat 1.2 cents-per-mile VMT fee, implying that the VMT fee would shift some of the tax burden from the higher income groups to the lower income groups, making it slightly more regressive. The Suits index for Sample Scenario \#1 was -.145 , indicating a greater degree of regressivity than either the gasoline tax or a flat VMT fee. The Suits Index for Sample Scenario \#2 was -.111, indicating that, although everyone would pay more under Sample Scenario \#2, this policy would result in a less regressive tax structure than the other alternatives.

\subsection{SENSITIVITY TESTS ON THE REGRESSION MODEL}

Sensitivity tests were conducted to further validate the regression model. These tests showed how the model output variable (i.e., the dependent variable) varied as the input variables changed within a certain range. The output variable in the regression model was the total household vehicle miles driven in a year. The input variables included fuel cost per mile, income, urban/rural dummy, vehicle count, gender of household head, number of workers in household, and number of children in household. For instance, in anticipation of higher fuel prices in the future, one could conduct a model sensitivity test in which the fuel cost per mile of driving is artificially increased. The model-predicted reduction in household vehicle miles driven can then be observed and evaluated for reasonableness and validity.

In each of the three sets of the sensitivity tests, the authors varied the values of fuel price, vehicle fuel efficiency (MPG), and fuel tax respectively, while keeping the other variables intact. The initial values of the input variables in the model were set as follows based on the average values of the whole sample:

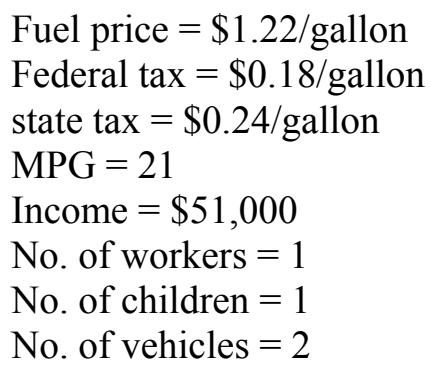

Results of the sensitivity tests are documented below.

\subsubsection{Changing fuel price}

To determine the impact of fuel price change, fuel price was varied from $\$ 1$ to $\$ 10$ per gallon in increments of 25 cents. The lowest income group was the most sensitive to changes in fuel prices. The lowest line on the first graph in Figure 5.1 shows that when fuel price was increased from $\$ 1$ to $\$ 10$ per gallon, the households with $\$ 10,000$ household annual income significantly reduced their household vehicle miles driven from 9,000 miles to about 6,000 miles. The sensitivity decreased with increases in household income, suggesting that the higher the income group, the lower the impact of a change in fuel price. Households with one vehicle were the most sensitive to a fuel price change, whereas there was no marked 
difference in sensitivity between households with two or more vehicles. Location, gender of household head, number of children in household, and number of workers in household were sensitive to fuel price increases at the beginning, but the sensitivity gradually declined as fuel price was increased.

\subsubsection{Changing vehicle fuel efficiency (MPG)}

To determine the impact of change in MPG, it was varied from 5 to $50 \mathrm{mpg}$ in increments of $5 \mathrm{mpg}$. As shown in Figure 5.2, the lowest income group was the most sensitive to changes in MPG. The sensitivity decreased with increases in household income. Households with one vehicle were the most sensitive to an MPG change, whereas there was no marked difference in sensitivity between households with two or more vehicles. Location, gender of household head, number of children in household, and number of workers in household were sensitive to changes in MPG at the beginning, but the sensitivity gradually declined as MPG was increased.

\subsubsection{Changing fuel tax}

To determine the impact of fuel tax changes, the state fuel tax was varied from $\$ 0$ to $\$ 1$ in increments of 5 cents. As shown in Figure 5.3, the lowest income group was the most sensitive to changes in fuel tax. The sensitivity decreased with increases in household income, and higher income groups were not as sensitive to changes in the fuel tax. Households with one vehicle were the most sensitive to a fuel tax change, whereas households with two or more vehicles were relatively insensitive to fuel tax changes. Also location, gender of the household head, the number of children, and number of workers in a household were not very sensitive to fuel tax changes.

Overall, the results of the sensitivity analysis suggested that the OLS model results were consistent with expectations and demonstrated the robustness of the model over reasonable ranges of key variables. 


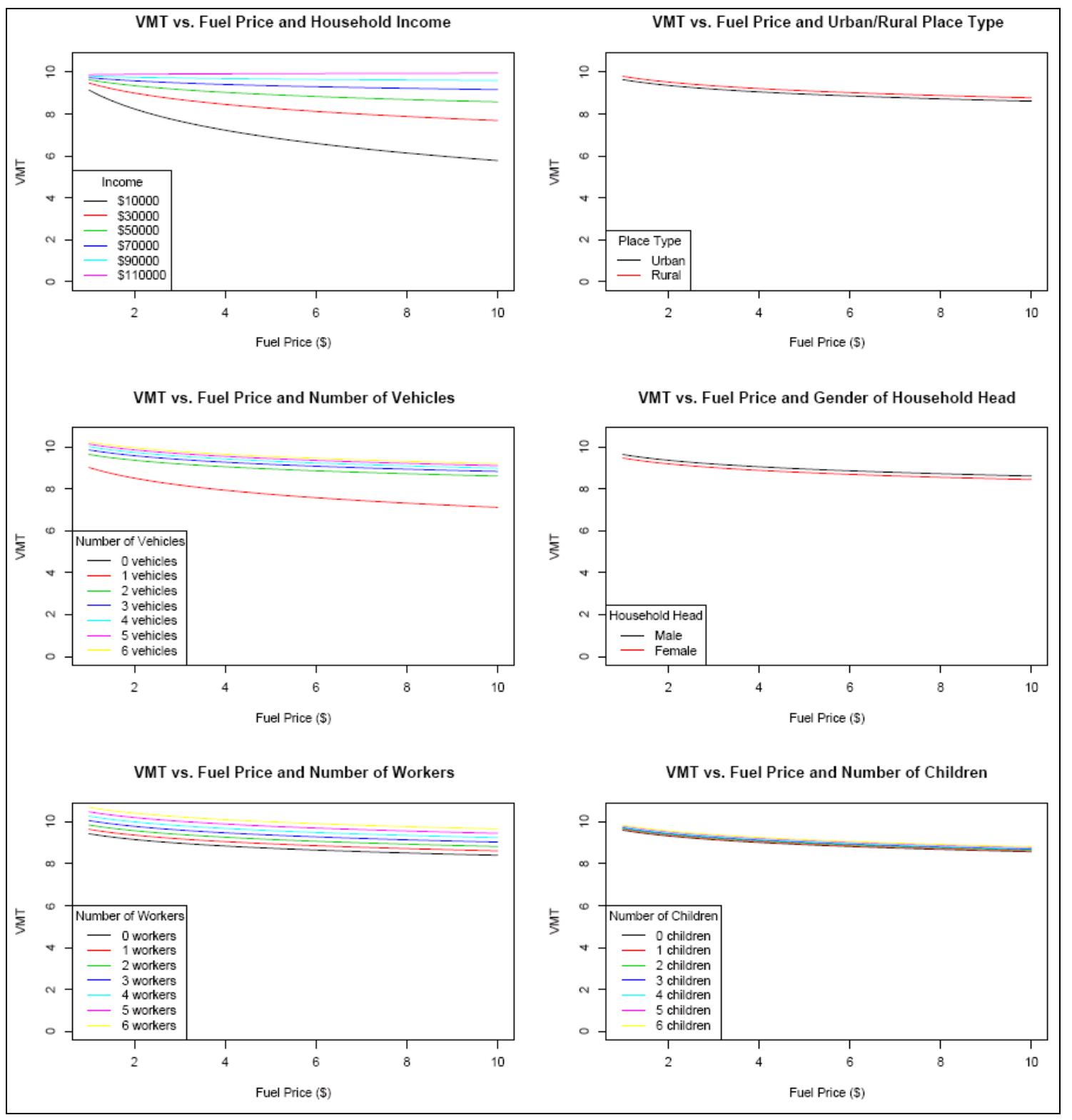

Figure 5.1: Sensitivity test results - changing fuel price 

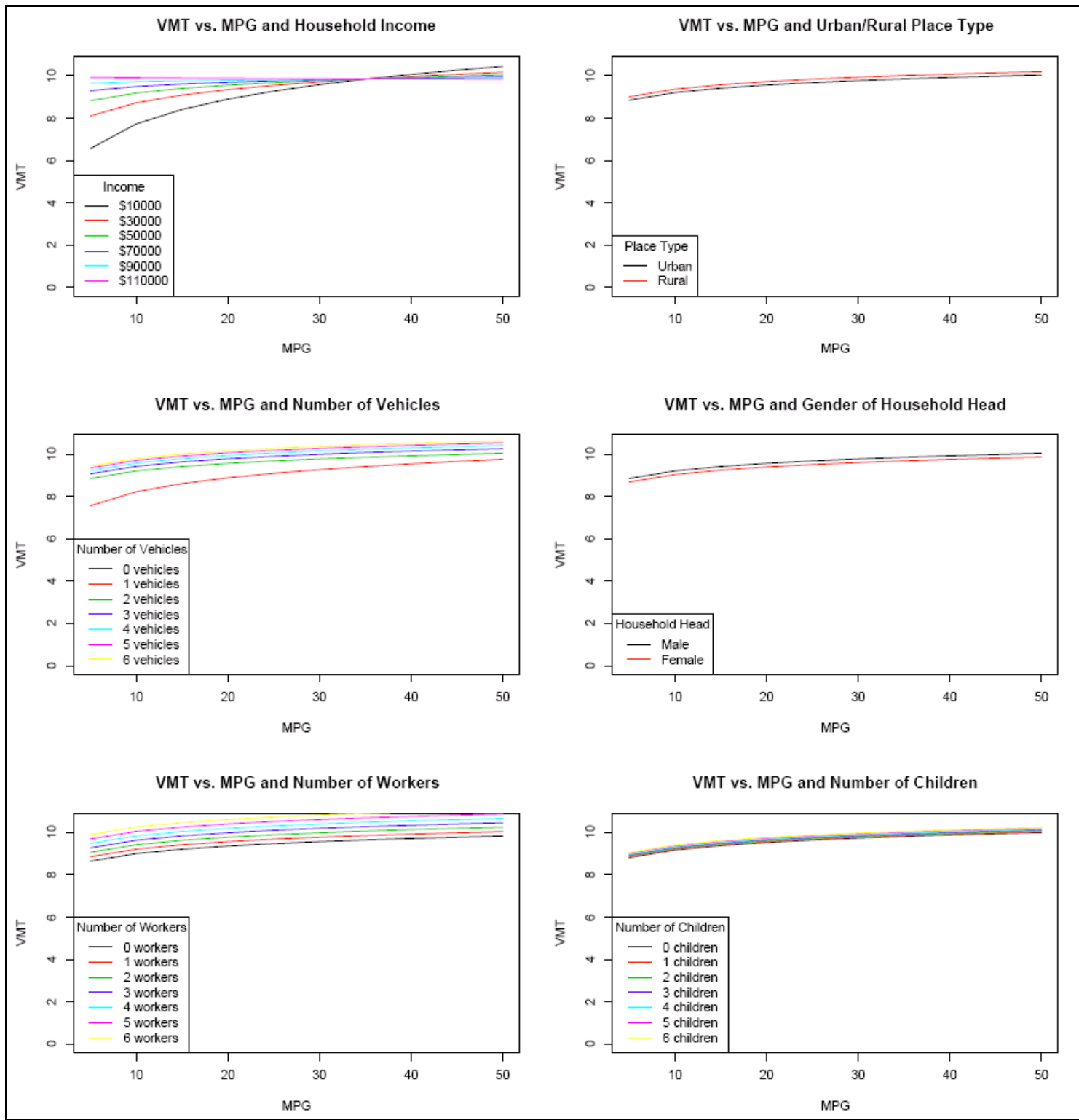

Figure 5.2: Sensitivity test results - changing household vehicle fuel efficiency (MPG) 


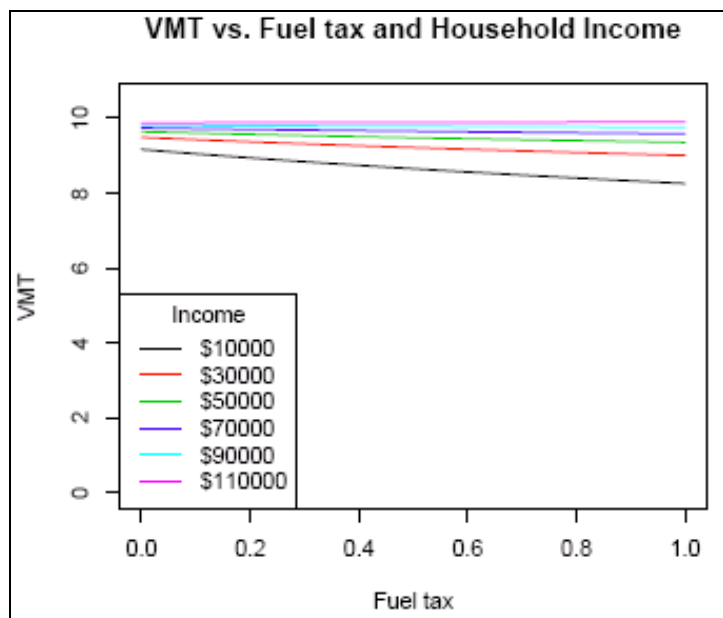

VMT vs. Fuel tax and Urban/Rural Place Type

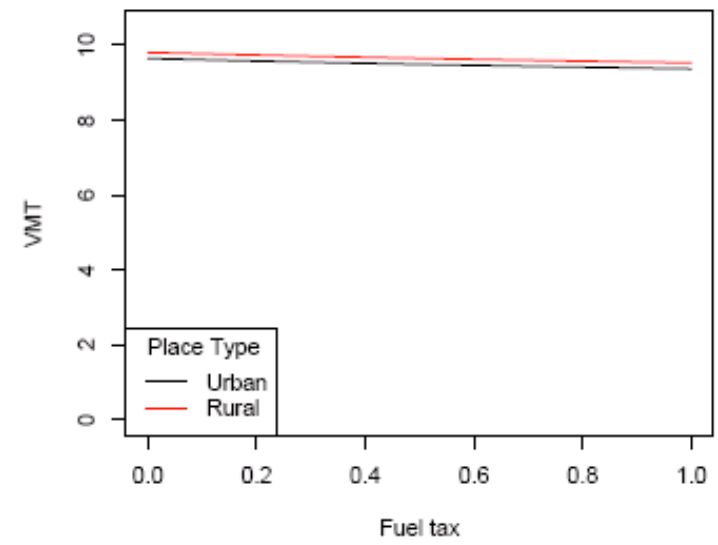

VMT vs. Fuel tax and Number of Vehicles

VMT vs. Fuel tax and Gender of Household Head
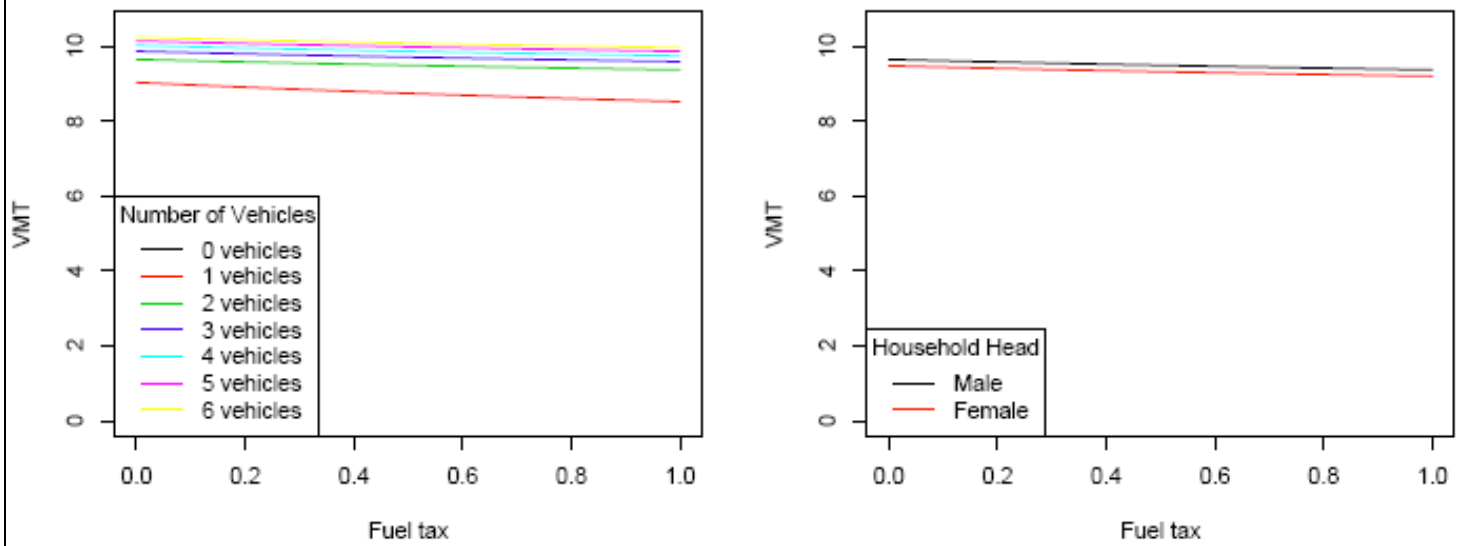

VMT vs. Fuel tax and Number of Workers

VMT vs. Fuel tax and Number of Children
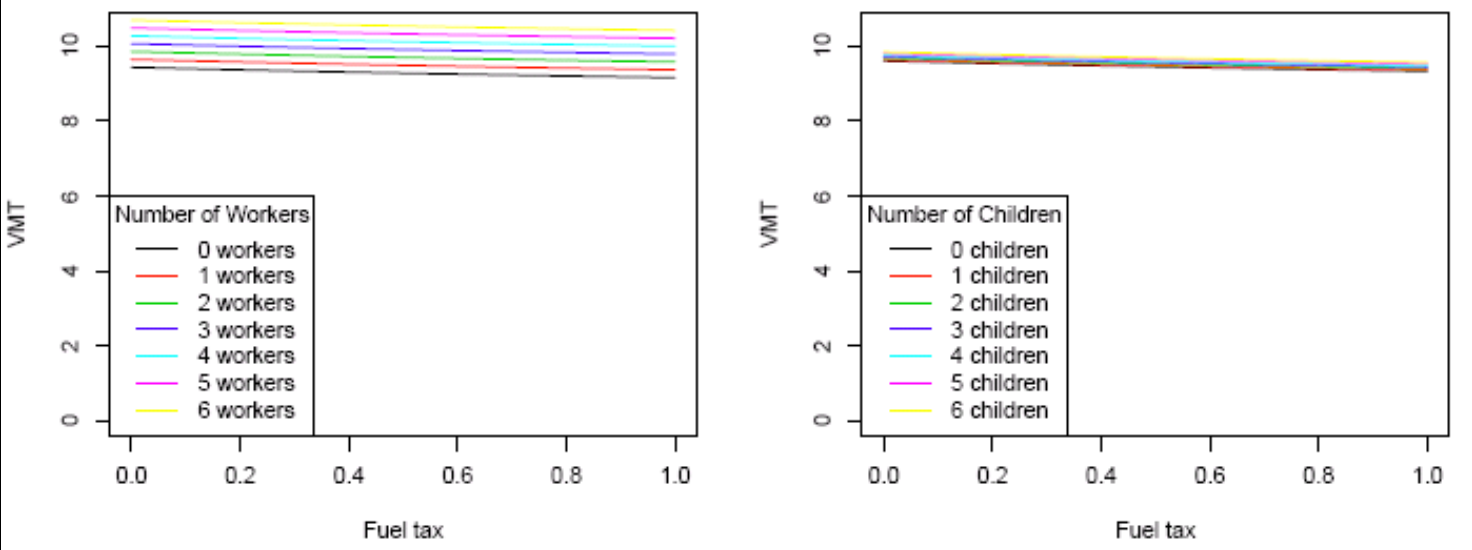

Figure 5.3: Sensitivity test results - changing fuel tax 


\subsection{EXPANDED SAMPLE REGRESSION RESULTS}

For comparison, the authors also conducted the OLS regression using the expanded, sevenstate data set obtained from the cluster analysis. The OLS results are presented in Table 5.9.

Table 5.9: OLS Results Using the Expanded Seven State Sample (n=3015)

\begin{tabular}{l|r|r|r}
\hline Variable name & Coefficient (7 state OLS) & Standard Error & \multicolumn{1}{c}{ t-statistic } \\
\hline Constant & -9.43126 & 2.143266 & -4.40 \\
\hline$P_{M}$ & -5.618888 & 0.8021254 & -7.00 \\
\hline$I$ & 1.512523 & 0.2035075 & 7.43 \\
\hline$P_{M} * I$ & 0.4509653 & 0.0761085 & 5.93 \\
\hline$P_{M} * S U B$ & 0.5578698 & 0.0980905 & 5.69 \\
\hline$U$ & -0.1091431 & 0.0333623 & -3.27 \\
\hline$C$ & 0.7225826 & 0.04566409 & 15.83 \\
\hline SUB & 1.636189 & 0.2657104 & 6.16 \\
\hline MALE & 0.1323724 & 0.0289016 & 4.58 \\
\hline WORK & 0.1739668 & 0.0171458 & 10.15 \\
\hline
\end{tabular}

With an $\mathrm{R}^{2}=0.44$, the explanatory power of the OLS model run using this expanded data set was not significantly different from that of the OLS model using the Oregon-only data set $\left(\mathrm{R}^{2}=0.46\right)$. Since a larger data sample should yield a higher $\mathrm{R}^{2}$ than a smaller sample if the samples are drawn from the same population, the fact that the $\mathrm{R}^{2}$ for the expanded sample OLS model did not increase suggests that there may still have been significant differences between Oregon and other states that were not taken into account. Since the purpose of this study was to examine the impact of the policy change on Oregon households, the authors decided to base the study results on the Oregon-only OLS regression coefficients rather than those obtained using the expanded data sample. The expanded data set was nevertheless expected to be useful for future estimation of the discrete-continuous choice model, which is more data intensive than the OLS model.

\subsection{SIMULTANEOUS EQUATION MODEL}

The preliminary results in the estimation of the simultaneous equation model (SEM) were unsatisfactory. Thus, given time limitations, the research team (in consultation with the technical advisory committee), decided to drop the simultaneous equation model from further consideration and focus on the OLS model and the discrete-continuous choice model. 


\subsection{DISCRETE-CONTINUOUS CHOICE MODEL}

As mentioned earlier, the discrete-continuous choice model is conceptually superior to the other models used in this study. However, given the complexity of the model and the data requirements, the investigators did not have time to completely develop this model and use it to provide a full distributional analysis. This chapter provides the preliminary results obtained in refining the model and using it to measure distributional impacts. Some possibilities for future research are also suggested.

\subsection{METHODOLOGY}

The model adopted here is similar to the one proposed by Kenneth Train (Train 1986). It is based on the assumption that households will simultaneously choose the number of vehicles to own, the type of vehicle and the annual miles driven in each vehicle.

The discrete-continuous model consists of a discrete model for the vehicle number choice and the vehicle type and a continuous model for the vehicle miles driven. A household first chooses the number of vehicles to own as shown in Figure 6.1. Based on the number of vehicles, it then chooses the types of vehicles to own. A household owning a single vehicle can own either a car or truck. Households owning two vehicles can choose to own either cars or trucks, or a car and a truck. Similarly, households with three vehicles can choose between all cars, all trucks, two cars and a truck, or two trucks and a car. As the vehicles a household chooses to own increases, the options available for the types or combinations of vehicles to own also increases. For simplicity purposes, households owning more than three vehicles were not considered in this analysis.

The vehicle usage, i.e., vehicle miles driven, by each household is dependent on the types of vehicles it owns. This model can be run at both the household level and the vehicle level; i.e., the total annual miles for each household can be taken as the dependent variable, or the vehicle miles driven for each vehicle can be considered. Since the vehicle-miles-driven model at the vehicle level could not be run (due to insufficient data), only the results of the vehicle-miles-driven model at the household level are presented. 


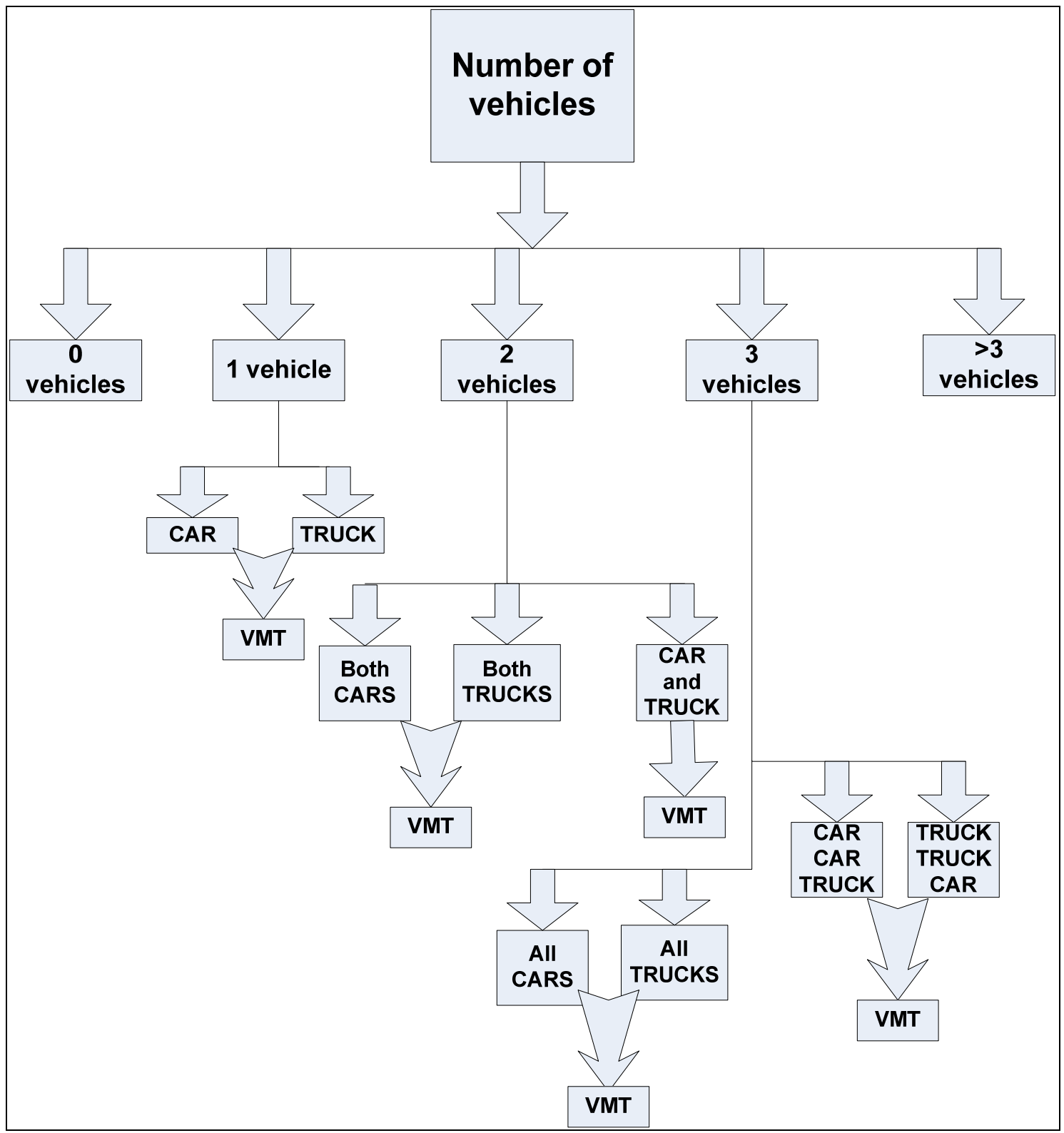

Figure 6.1: Diagrammatic representation of the discrete-continuous choice model

\subsubsection{Vehicle number choice model}

In this model a household could choose not to own any vehicle or one, two, or three vehicles. Households owning more than three vehicles were ignored. The vehicle choice model can be represented by Equation 6-1:

$$
N=f(I, U, H H)
$$


where the number of vehicles a household chooses to own $(N)$ is dependent on a number of factors, such as income $(I)$, household location $(U)$, and other household characteristics $(H H)$.

\subsubsection{Vehicle type choice model}

The vehicle type model can be represented by Equation 6-2:

$$
T=f(P v, P m, I, U, H H)
$$

where the type of vehicle a household chooses to own $(T)$ is dependent on a number of factors, including fuel cost per mile $(P m)$, the price of the vehicle $(P v)$, income $(I)$, household location $(U)$, and various other household characteristics $(H H)$.

\subsubsection{VMT model at the household level}

The VMT model can be represented by Equation 6-3:

$$
V M T=f(P m, I, U, H H)
$$

where the total annual miles a household drives $(V M T)$ is dependent on a number of factors such as fuel cost per mile $(P m)$, income $(I)$, household location $(U)$, and various other household characteristics $(H H)$.

The description of the variables used in the DCC model is presented in Appendix C, Section C.2.

\subsubsection{Alternative model specifications}

Different specifications can be used to run the models described above. Interactions between various variables can be tried, to capture the effects they have on the dependent variables.

\subsubsection{Interaction between policy variables}

For the vehicle type model, the fuel cost per mile and vehicle price were considered as a percentage of income, since it provided a better understanding on the vehicle type choice decisions made by the individual rather than the fuel cost per mile or vehicle price alone. Similarly, an interaction between the two variables was also considered $\left(P v^{*} P m\right)$.

$$
T=f\left(P v / I, P m / I, P v^{*} P m, U, H H\right)
$$

where the type of vehicle a household chooses to own $(T)$ is dependent on fuel cost per mile as a percentage of income $(P m / I)$, the price of the vehicle as a percentage of income $(P v / l)$, the interaction of the two $\left(P v^{*} P m\right)$, household location $(U)$, and various other household characteristics $(H H)$. 


\subsubsection{Interactions between the policy variables and cost variability by state}

Vehicle prices and gas prices are not constant for all states. Thus another model specification for the vehicle type choice model included the interaction between dummy variables for various states and fuel cost per mile $\left(\right.$ States $\left.^{*} \mathrm{Pm}\right)$ or vehicle price $\left(\right.$ States $\left.^{*} P v\right)$. This interaction was added to capture the effect to some extent.

$$
\begin{aligned}
& T=f(P v, \text { States } * P m, U, H H) \\
& T=f(P m, \text { States } * P v, U, H H)
\end{aligned}
$$

Similarly, for the vehicle use model the interaction between fuel cost per mile and income was considered $\left(P m^{*} I\right)$.

$$
V M T=f(P m, P m * I, I, U, H H)
$$

where the vehicle miles traveled on a vehicle $(V M T)$ is dependent on the fuel cost per mile $(P m)$, Income $(I)$, Household location $(U)$ and various other household characteristics $(H H)$.

Different specifications were tried for the models described and only the best model for each category is presented in this report.

\subsection{DATA}

The data for this model were obtained from the 2001 National Household Travel Survey (NHTS). The vehicle type model especially requires a large data set, and Oregon had only a limited number of households. To overcome this problem, cluster analysis was used to come up with six other states similar to Oregon, which included Colorado, Michigan, Minnesota, Utah, Virginia and Washington. The discrete-continuous choice model was thus run using the data from these seven states.

The descriptive statistics for the vehicle number choice model, the vehicle type choice model, and the vehicle use model are provided in Tables 6.1 through 6.3.

\subsubsection{Vehicle number choice model}

The number of vehicles a household owns was included in the household file and the vehicle file of the 2001 NHTS data set. The data set was arranged for households owning no vehicles, one vehicle, two or three vehicles. The model was estimated with reference to the households owning no vehicles. The descriptive statistics for this model are presented in Table 6.1. 
Table 6.1: Descriptive statistics for vehicle number choice

\begin{tabular}{|c|c|c|c|c|c|c|c|c|}
\hline & 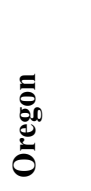 & $\begin{array}{l}\frac{0}{\tilde{T}} \\
\frac{0}{0} \\
\dot{0}\end{array}$ & 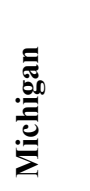 & 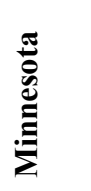 & 苞 & 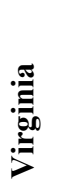 & 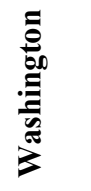 & हี \\
\hline Total observations & 407 & 466 & 994 & 681 & 200 & 737 & 705 & 4190 \\
\hline HHs with 0 vehicles & 19 & 17 & 41 & 23 & 6 & 31 & 32 & 169 \\
\hline HHs with 1 vehicle & 100 & 122 & 243 & 178 & 39 & 176 & 173 & 1031 \\
\hline HHs with 2 vehicles & 163 & 183 & 414 & 272 & 88 & 296 & 291 & 1707 \\
\hline HHs with 3 vehicles & 76 & 90 & 174 & 127 & 35 & 155 & 126 & 783 \\
\hline $\begin{array}{l}\text { HHs with more than } \\
\text { '3' vehicles }\end{array}$ & 49 & 54 & 122 & 81 & 32 & 79 & 83 & 500 \\
\hline Final observations* & & & & & & & & 3353 \\
\hline 0-vehicle HHs & 18 & 10 & 34 & 19 & 6 & 26 & 24 & 137 \\
\hline 1-vehicle HHs & 90 & 113 & 212 & 162 & 39 & 160 & 160 & 936 \\
\hline 2-vehicle HHs & 154 & 168 & 371 & 247 & 78 & 274 & 264 & 1556 \\
\hline 3-vehicle HHs & 68 & 85 & 157 & 119 & 34 & 144 & 117 & 724 \\
\hline
\end{tabular}

*The number of final observations is less than the total observations because the household income, location, and education of the household head were not reported for some households.

\subsubsection{Data for the vehicle type choice model}

As described earlier, vehicle type choice is a function of vehicle price, fuel cost per mile and other characteristics. The 2001 NHTS data set included the make and model code of each vehicle a household owned. The value of the vehicle in the year 2001 was considered regardless of the year it was manufactured. The vehicle prices were obtained from the 2001 Ward's automotive year book for all the available 2001 light vehicles in the U.S market according to the make and model (Wards Communications 2001). However, the 2001 Ward's automotive year book does not specify the prices of vehicles of outdated makes and models (e.g., Hyundai Excel which was manufactured during 1984-1994). Therefore, the households with these unavailable vehicle prices were dropped from the data set.

In order for the household choice between a car and truck to be captured, all vehicles were categorized in to these two vehicle groups. Different categorizations were tested based on the miles per gallon a vehicle achieves, vehicle dimensions, and vehicle weight. This information was obtained from the following sources:

\section{- NHTS Classification}

The 2001 NHTS data set included the variable 'Vehicle type' which divided the vehicle into eight categories: car, van, SUV, pickup truck, other truck, recreational vehicles, motorcycles and other. For the vehicle type choice model cars, vans and SUVs were grouped into the 'Car' category, and pickup trucks and other trucks were 
placed into the 'Truck' category. RV's and motorcycles were ignored, as the vehicle price data for RV's was not available.

This classification seemed reliable, as it was directly obtained from the NHTS data set. This approach also made the work of arranging the data easier. However, a few discrepancies were found in the data set; for example, a Ford pickup was categorized as a van.

- MPG Classification

Vehicles were divided into 'cars' and 'trucks' based on their miles-per-gallon rating. The vehicles were classified based on the EIA adjusted fuel efficiency figures from the NHTS data set. The vehicles which had less than 20 miles per gallon were categorized as 'trucks,' and those with 20 or greater miles per gallon were categorized as 'cars.' Future studies could explore categorizing the vehicles based on a threshold fuel efficiency value other than $20 \mathrm{MPG}$ to see if it gives better results.

This model displayed the correct signs for most of the coefficients and they were significant when compared to the results obtained from the NHTS classification. This was the second-best model after the vehicle weight classification.

\section{- Wards Classification}

Wards Automotive year book for 2001 divided vehicles in to various subcategories. ${ }^{7}$ Criteria for this segmentation were based on the body style, typical base price and size. For vehicles where size was a major factor in determining categorization, length was the lead determinant. Using the length criteria, the vehicles in the sample were categorized into 'small cars,' 'medium cars' and 'trucks.' All cars, including luxury and sports cars, were included under a 'cars' category and all SUVs, light trucks and heavy trucks were considered as 'trucks.' Various models were tested. This approach resulted in a more complicated model and thus required a bigger data set. The results are not presented in this report.

- Vehicle weight classification

Vehicle weights were obtained for each make and model of the vehicle from the internet auto guide (http://www.internetautoguide.com). The median vehicle weight was used to categorize the vehicles into 'cars' and 'trucks.'

After running several models using different specifications for the above classifications, the authors found that using vehicle weight classification gave better results with significant coefficients and correct signs than using the NHTS categories, the MPG categories, or the Wards categories. A future study could investigate a classification of the vehicles based on different weight ranges other than the median weight to see if it gives better results.

The descriptive statistics for the vehicle type model using the vehicle weight classification is presented in Table 6.2.

\footnotetext{
${ }^{7}$ Lower small car; Upper small car; Small specialty car; Lower middle car; Upper middle car; Middle specialty car; Large regular cab; Lower, middle and upper luxury car; Luxury specialty and sports car; Small and middle cross utility vehicle; Small, middle and large sport utility vehicle; Small, large and luxury vans; Small and Large pickups.
} 
Table 6.2: Descriptive statistics for vehicle type

\begin{tabular}{|c|c|c|c|c|c|c|c|c|}
\hline & Oే: & 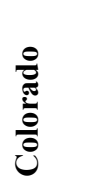 & 焉 & 营 & $\stackrel{\frac{5}{5}}{\varpi}$ & 䒿 & 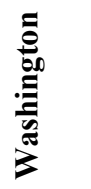 & تี \\
\hline \multicolumn{9}{|l|}{ One vehicle type } \\
\hline $\begin{array}{l}\text { Number of } \\
\text { households owning a } \\
\text { car }\end{array}$ & 32 & 52 & 86 & 53 & 13 & 95 & 70 & 401 \\
\hline $\begin{array}{l}\text { Number of } \\
\text { households owning a } \\
\text { truck }\end{array}$ & 21 & 26 & 83 & 52 & 12 & 39 & 35 & 267 \\
\hline Total & 53 & 78 & 169 & 105 & 25 & 134 & 105 & 669 \\
\hline \multicolumn{9}{|l|}{ Two vehicle types } \\
\hline $\begin{array}{l}\text { Number of } \\
\text { households owning } \\
\text { both cars }\end{array}$ & 20 & 26 & 39 & 36 & 12 & 55 & 32 & 220 \\
\hline $\begin{array}{l}\text { Number of } \\
\text { households owning a } \\
\text { car and truck }\end{array}$ & 34 & 46 & 90 & 63 & 17 & 74 & 63 & 387 \\
\hline $\begin{array}{l}\text { Number of } \\
\text { households owning } \\
\text { both trucks }\end{array}$ & 19 & 27 & 89 & 34 & 10 & 35 & 37 & 251 \\
\hline Total & 73 & 99 & 218 & 133 & 39 & 164 & 132 & 858 \\
\hline \multicolumn{9}{|l|}{ Three vehicle types } \\
\hline $\begin{array}{l}\text { Number of } \\
\text { households owning } \\
\text { all cars }\end{array}$ & 1 & 1 & 8 & 4 & 1 & 10 & 2 & 27 \\
\hline $\begin{array}{l}\text { Number of } \\
\text { households owning } \\
\text { all trucks }\end{array}$ & 2 & 3 & 9 & 5 & 1 & 6 & 8 & 34 \\
\hline $\begin{array}{l}\text { Number of } \\
\text { households owning } \\
\text { two cars and a truck }\end{array}$ & 5 & 17 & 14 & 7 & 6 & 16 & 10 & 75 \\
\hline $\begin{array}{l}\text { Number of } \\
\text { households owning } \\
\text { two trucks and a car }\end{array}$ & 4 & 9 & 15 & 11 & 3 & 13 & 13 & 68 \\
\hline Total & 12 & 30 & 46 & 27 & 11 & 45 & 33 & 204 \\
\hline
\end{tabular}

\subsubsection{Vehicle use model}

The vehicle use model was run at the household level. The NHTS data set included the total annual miles driven by each household and also the vehicle miles for each vehicle separately. A separate VMT model was developed for each category of vehicles a household chooses to own, based on the schematic in Figure 6.1. The descriptive statistics for this model are presented in Table 6.3. 


\begin{tabular}{|c|c|c|c|c|c|c|c|c|}
\hline & రే: & 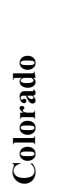 & 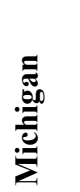 & 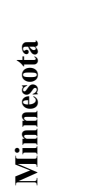 & 苞 & 㩊 & 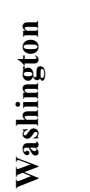 & $\underset{\tilde{\theta}}{\bar{\sigma}}$ \\
\hline \multicolumn{9}{|l|}{ One vehicle type } \\
\hline $\begin{array}{l}\text { Number of households } \\
\text { owning a car or truck }\end{array}$ & 50 & 75 & 169 & 102 & 22 & 128 & 98 & 644 \\
\hline \multicolumn{9}{|l|}{ Two vehicle types } \\
\hline $\begin{array}{l}\text { Number of households } \\
\text { owning both cars or both } \\
\text { trucks }\end{array}$ & 17 & 52 & 53 & 25 & 9 & 38 & 28 & 222 \\
\hline $\begin{array}{l}\text { Number of households } \\
\text { owning a car and truck }\end{array}$ & 19 & 45 & 35 & 25 & 8 & 28 & 26 & 186 \\
\hline Total & 36 & 97 & 88 & 50 & 17 & 66 & 54 & 408 \\
\hline \multicolumn{9}{|l|}{ Three vehicle types } \\
\hline $\begin{array}{l}\text { Number of households } \\
\text { owning all cars or all trucks }\end{array}$ & 1 & 1 & 4 & 9 & 2 & 4 & 2 & 23 \\
\hline $\begin{array}{l}\text { Number of households } \\
\text { owning two cars and a truck } \\
\text { (or) two trucks and a car }\end{array}$ & 2 & 1 & 12 & 6 & 2 & 11 & 7 & 41 \\
\hline Total & 3 & 2 & 16 & 15 & 4 & 15 & 9 & 64 \\
\hline
\end{tabular}

\subsection{ESTIMATION RESULTS}

All estimations were performed using the program LIMDEP Version 9.0. Results of the final models are shown in Tables 6.4, 6.5, and 6.6. The parameters of the discrete model were estimated for three alternatives (i.e., one, two or three vehicles), and the zero-vehicle condition was considered as the base alternative. The coefficients of the model indicate the propensity to own one, two, or three vehicles with positive values indicating an increase in the probability and negative values indicating a decrease in the probability. The same applies for the vehicle type and vehicle use models.

\subsubsection{Vehicle choice model}

The vehicle number choice model showed that income and location has a significant effect on the number of vehicles a household chose to own. As income increases, a household is more likely to own a vehicle. The probability of owning more vehicles (i.e., two or three) increases with income as shown in Table 6.4. Similarly, a household living in an urban location is less likely to own a vehicle than a household in a rural location; and the likelihood of owning more than one vehicle decreases for households living in an urban area. This seems reasonable, since people living in urban areas tend to have more access to other modes or transportation such as rail or bus, compared to those in rural areas.

Household characteristics also have a significant impact on a household's likelihood of owning vehicles. As the ratio of children to household size increases, households are more likely to own vehicles. Similarly, an increase in number of workers and the presence of a male household head increases the probability of owning vehicles. According to the results 
obtained from this model, households with a head belonging to a young or middle age group are less likely to own vehicles than households headed by older people. This result could be interpreted that young and middle-aged people are more active and flexible and prefer to use other modes of transportation.

Table 6.4: Estimation results for Vehicle ownership model

\begin{tabular}{|c|c|c|c|}
\hline \multicolumn{4}{|c|}{$\begin{array}{l}\text { Dependent variable: Number of vehicles a household chooses to own } \\
\text { Number of households }=3353\end{array}$} \\
\hline & One Vehicle & Two Vehicles & Three Vehicles \\
\hline Variable name & Coefficient & Coefficient & Coefficient \\
\hline Constant & $1.461 * *$ & $0.504 * *$ & $-0.834 * *$ \\
\hline Income (I) & $0.0003 * *$ & $0.0005 * *$ & $0.0006 * *$ \\
\hline Urban (U) & $-0.322 *$ & $-0.763 * *$ & $-1.131 * *$ \\
\hline male & $0.314^{*}$ & $0.526 * *$ & $0.710 * *$ \\
\hline Children/Household size & $1.174 * *$ & $2.118 * *$ & $1.743 * *$ \\
\hline Worker count & $0.478 * *$ & $1.464 * *$ & $2.034 * *$ \\
\hline Young & $-1.485 * *$ & $-2.173 * *$ & $-2.772 * *$ \\
\hline Middle & $-1.170 * *$ & $-1.848 * *$ & $-2.068 * *$ \\
\hline
\end{tabular}

\subsubsection{Vehicle type model}

Tables 6.5, 6.6, and 6.7 show results for the vehicle type model, for the one-, two-, and threevehicle households. As fuel cost per mile as a percentage of income increases, people are less likely to own any kind of a vehicle. The same is true for vehicle price as a percentage of income. The one-vehicle and two-vehicle type models suggest the same thing. The threevehicle model, however, gave an inconsistent result. This can probably be attributed to the insufficient data.

If a household is located in an urban area it is more likely to choose to own a car over a truck, and it is also more likely to choose $\mathrm{CC}^{8}$ over a $\mathrm{CT}$ or two trucks and will choose a CT over TT. The model was estimated with reference to the household owning two trucks. Similarly for the three-vehicle type, the signs of the coefficient indicate that an urban household will be less likely to choose CCC or CCT over TTT and TTT over TTC, although they are not statistically significant, as shown in Table 6.5.

Larger households are less likely to own a car over a truck. They are also less likely to own CC over a CT and a CT over TT. This coefficient for the three vehicle types is not statistically significant, though the signs indicate that larger households are more likely to own CCT over TTT and CCC. With an increase in household size the probability of choosing TTT over CCC and CCC over TTC is less. Households with more number of workers are likely to choose car over truck and CC over CT and TT over CT. Households with younger household head are likely to choose car over truck. Similarly, younger household heads are more likely to choose CC over CT and CT over TT more that the middle aged household heads.

\footnotetext{
${ }^{8}$ For simplicity, the following notations are used: CC-Both cars; CT-Both trucks ;TT-Both trucks; CCC-all cars; TTT-all trucks; CCT-Two cars and a truck; TTC-Two trucks and a car
} 
Table 6.5: Results for vehicle type models - one-vehicle households One-Vehicle households (Truck as the reference)

\section{Dependent variable: Type of vehicle (Car)} Number of households $=669$

\begin{tabular}{l|r}
\hline Variable & Coefficient \\
\hline Constant & -0.22 \\
\hline Fuel cost per mile as a percentage of income $\left(\mathrm{P}_{\mathrm{m}}\right)$ & -7.11 \\
\hline Vehicle price as a percentage of income $(\mathrm{Pv})$ & -0.97 \\
\hline Interaction between fuel cost per mile and vehicle cost per mile $(\mathrm{Pm} * \mathrm{Pv})$ & $0.02^{*}$ \\
\hline Urban $(\mathrm{U})$ & $0.62^{* *}$ \\
\hline Household size & $-0.35^{* *}$ \\
\hline Children/Household size & 0.36 \\
\hline Worker count & $0.40^{* *}$ \\
\hline Young & $0.51^{*}$ \\
\hline Middle & 0.12 \\
\hline$* *$ Indicates statistical significance at the .05 level & \\
$*$ Indicates statistical significance at the .10 level &
\end{tabular}

Table 6.6: Results for Vehicle type models - two-vehicle households

\begin{tabular}{|c|c|}
\hline \multicolumn{2}{|l|}{ Two Vehicle households (Both trucks - TT - as the reference) } \\
\hline \multicolumn{2}{|l|}{$\begin{array}{l}\text { Dependent variable: Type of vehicle (both cars }- \text { CC) } \\
\text { Number of households }=858\end{array}$} \\
\hline Variable & Coefficient \\
\hline Constant & $-0.99 * *$ \\
\hline Fuel cost per mile as a percentage of income $\left(\mathrm{P}_{\mathrm{m}}\right)$ & $-539.58^{*}$ \\
\hline Vehicle price as a percentage of income $(\mathrm{Pv})$ & -0.77 \\
\hline Interaction between fuel cost per mile and vehicle cost per mile $(\mathrm{Pm} * \mathrm{Pv})$ & $0.05 * *$ \\
\hline Urban $(\mathrm{U})$ & $0.90 * *$ \\
\hline Household size & $-0.37^{*}$ \\
\hline Children/Household size & -1.22 \\
\hline Worker count & $0.30 *$ \\
\hline Young & $1.37 * *$ \\
\hline Middle & $0.67 * *$ \\
\hline \multicolumn{2}{|l|}{$\begin{array}{l}\text { Dependent variable: Type of vehicle (car and truck - CT) } \\
\text { Number of households }=858\end{array}$} \\
\hline Variable & Coefficient \\
\hline Constant & -0.32 \\
\hline Fuel cost per mile as a percentage of income $\left(\mathrm{P}_{\mathrm{m}}\right)$ & $-539.58^{*}$ \\
\hline Vehicle price as a percentage of income $(\mathrm{Pv})$ & -0.77 \\
\hline Interaction between fuel cost per mile and vehicle cost per mile $(\mathrm{Pm} * \mathrm{Pv})$ & $0.05 * *$ \\
\hline Urban (U) & $0.41 * *$ \\
\hline Household size & -0.02 \\
\hline Children/Household size & -0.89 \\
\hline Worker count & -0.11 \\
\hline Young & $1.13 * *$ \\
\hline Middle & $0.87 * *$ \\
\hline
\end{tabular}


Table 6.7: Results for vehicle type models - three-vehicle households

\begin{tabular}{|c|c|}
\hline \multicolumn{2}{|c|}{ Three-Vehicle households (Two trucks and a car - TTC - as the reference) } \\
\hline \multicolumn{2}{|l|}{$\begin{array}{l}\text { Dependent variable: Type of vehicle (all cars - CCC) } \\
\text { Number of households }=204\end{array}$} \\
\hline Variable & Coefficient \\
\hline Constant & -1.28 \\
\hline Fuel cost per mile as a percentage of income $\left(\mathrm{P}_{\mathrm{m}}\right)$ & -1187.66 \\
\hline Vehicle price as a percentage of income $(\mathrm{Pv})$ & -1.63 \\
\hline Interaction between fuel cost per mile and vehicle cost per mile $(\mathrm{Pm} * \mathrm{Pv})$ & 0.50 \\
\hline Urban (U) & -0.62 \\
\hline Household size & -0.24 \\
\hline Children/Household size & -3.69 \\
\hline Worker count & 0.58 \\
\hline Young & 1.74 \\
\hline Middle & 0.51 \\
\hline
\end{tabular}

\begin{tabular}{l|r}
\hline $\begin{array}{l}\text { Dependent variable: Type of vehicle (all trucks - TTT) } \\
\text { Number of households }=\mathbf{2 0 4}\end{array}$ & Coefficient \\
\hline Variable & -0.26 \\
\hline Constant & -1187.66 \\
\hline Fuel cost per mile as a percentage of income $\left(\mathrm{P}_{\mathrm{m}}\right)$ & -1.63 \\
\hline Vehicle price as a percentage of income $(\mathrm{Pv})$ & 0.50 \\
\hline Interaction between fuel cost per mile and vehicle cost per mile $(\mathrm{Pm} * \mathrm{Pv})$ & -0.003 \\
\hline Urban $(\mathrm{U})$ & -0.41 \\
\hline Household size & 3.95 \\
\hline Children/Household size & 0.16 \\
\hline Worker count & -1.05 \\
\hline Young & -0.42 \\
\hline Middle & \\
\hline
\end{tabular}

Dependent variable: Type of vehicle (two cars and a truck - CCT)

Number of households $=204$

\begin{tabular}{l|r}
\hline Variable & Coefficient \\
\hline Constant & -0.66 \\
\hline Fuel cost per mile as a percentage of income $\left(\mathrm{P}_{\mathrm{m}}\right)$ & -1187.66 \\
\hline Vehicle price as a percentage of income $(\mathrm{Pv})$ & -1.63 \\
\hline Interaction between fuel cost per mile and vehicle cost per mile $(\mathrm{Pm}$ *Pv) & 0.50 \\
\hline Urban $(\mathrm{U})$ & -0.62 \\
\hline Household size & 0.01 \\
\hline Children/Household size & -2.91 \\
\hline Worker count & 0.46 \\
\hline Young & $1.99 *$ \\
\hline Middle & 0.32 \\
\hline$*$ Indicates statistical significance at the $5 \%$ level & \\
$*$ Indicates statistical significance at the $10 \%$ level &
\end{tabular}

\subsubsection{Vehicle use model}

Table 6.8 shows the results for the vehicle use model. Even though the coefficients are not significant for most of the variables, the signs do predict several possibilities. As the fuel cost per mile for a vehicle increases, households are more likely to drive fewer miles, except for households with three vehicles. People living in urban areas drive less compared to those in rural areas. Households with higher incomes and those with more workers are likely to drive higher miles. Similarly, a younger person is likely to drive more miles compared to an older person, except for two-vehicle households owning both cars and trucks. People living in an urban area are less likely to drive more miles. The model shows that the number of 
children and household size does not have a consistent effect on the number of miles a household drives.

Table 6.8: Results for vehicle use model

\begin{tabular}{|c|c|c|c|c|c|}
\hline \multicolumn{6}{|c|}{ Dependent variable: Annual household miles driven by a household } \\
\hline & \multirow{2}{*}{$\begin{array}{c}\text { One-vehicle } \\
\begin{array}{c}\text { Car or } \\
\text { truck }\end{array}\end{array}$} & \multicolumn{2}{|c|}{ Two-vehicle } & \multicolumn{2}{|c|}{ Three-vehicle } \\
\hline & & $\begin{array}{l}\text { Both cars } \\
\text { or trucks }\end{array}$ & $\begin{array}{c}\text { Car and a } \\
\text { truck }\end{array}$ & $\begin{array}{c}\text { All cars or } \\
\text { trucks }\end{array}$ & $\begin{array}{c}\text { Two cars and } \\
\text { a truck (or) } \\
\text { Two trucks } \\
\text { and a car } \\
\end{array}$ \\
\hline $\begin{array}{l}\text { Number of } \\
\text { observations }\end{array}$ & 644 & 222 & 186 & 23 & 41 \\
\hline Variable name & Coefficient & Coefficient & Coefficient & Coefficient & Coefficient \\
\hline Constant & $5.66 * *$ & $8.22 * *$ & $7.37 * *$ & $9.15 * *$ & $15.09 * *$ \\
\hline $\begin{array}{l}\text { Fuel cost per } \\
\text { mile }\end{array}$ & $-1.05 * *$ & $-0.45^{*}$ & $-0.53 * *$ & -0.28 & $2.02 * *$ \\
\hline $\begin{array}{l}\text { Fuel cost per } \\
\text { mile*Income }\end{array}$ & $0.0001 * *$ & 0.00001 & 0.00002 & 0.00002 & $-0.0002 * *$ \\
\hline Income & $0.0003 * *$ & 0.00005 & 0.00008 & 0.00007 & $-0.0006^{* *}$ \\
\hline Urban & $-0.17 *$ & -0.07 & -0.14 & -0.13 & -0.09 \\
\hline Children & -0.09 & 0.06 & -0.02 & 0.11 & -0.002 \\
\hline HHsize & -0.07 & 0.15 & 0.04 & -0.09 & -0.26 \\
\hline Wrkcount & $0.29 * *$ & $0.14 * *$ & 0.05 & 0.05 & $0.37 * *$ \\
\hline Young & 0.39 & -0.14 & 0.24 & 0.12 & $0.74 * *$ \\
\hline Middle & 0.35 & 0.06 & 0.12 & 0.23 & $0.42 *$ \\
\hline
\end{tabular}

Italicized variables are log transformed

** Indicates statistical significance at the $5 \%$ level

* Indicates statistical significance at the $10 \%$ level

\subsection{APPLICATIONS OF THE DISCRETE-CONTINUOUS-CHOICE MODELS FOR TRANSPORTATION POLICY ANALYSIS}

Public policies influence the mode, frequency and distribution of travel for consumers. Any policy which discourages people from buying and using vehicles, or which charges fees based on miles or emissions, have potential distributional impacts. Any of these policies could induce some drivers to drive less, own one vehicle instead of two, or choose to buy a car instead of an SUV. Discrete-continuous choice models can be used to estimate the longrun distributional effects of such polices.

\subsubsection{VMT fee}

Discrete-continuous choice models can be used to estimate the impact of a VMT fee policy as described in this section. The miles driven on a vehicle by a consumer depends on the type of vehicle he chooses to drive and also the availability of other vehicles. If the consumers are charged based on the miles driven, it might induce some to drive less or use more public transit or carpools. A family with multiple cars, who used to drive individually, might choose to travel together or carpool. Changes can be seen at both distributional and behavioral levels. DCC models can capture these effects. Some argue that a VMT fee might discourage people from buying more fuel efficient vehicles. It is apparent that these models can be used to estimate the long-run effects of such a policy. 


\subsubsection{Emission taxes}

Emission taxes can be charged on a mileage basis to reflect emission rates per mile. This is a policy often suggested to reduce environmental pollution. Cars produced in a given year are subject to emissions standards that have become increasingly stringent over time. Thus, the age of a vehicle may play an important role in determining the emissions, especially if older cars have higher emission rates.

DCC models can be used to estimate the effects of such a policy on car choices, driving behavior (such as miles driven), and the effects of those driving behaviors on emissions. If a vehicle emissions tax is imposed, then drivers may buy a newer, cleaner car or a smaller car with better fuel efficiency, fix their pollution control equipment, buy cleaner gas, or drive fewer miles. An emissions tax could induce consumers with different incomes or household characteristics to choose different combinations of these methods or choose other alternatives according to their economic efficiency. Some with old cars may switch to newer or smaller cars, while others may chose to take transit.

\subsubsection{Policies that discourage vehicle ownership and use}

Apart from the above policies, higher vehicle prices, fewer subsidies to buy new motor vehicles, higher parking policies, higher registration fees, etc., may discourage vehicle ownership and use. Providing increased subsidies to public transit, thereby increasing the efficiency and reducing fare charges, may encourage people to use transit. Policies such as congestion pricing schemes and other distance-based charges can encourage people to use more transit. All these policies have an impact on the driving behavior of the consumers.

The authors have developed a working discrete-continuous choice model which is capable of estimating the impact of a VMT fee. The current model estimates the probabilities of households owning a specific number of vehicles, type of vehicles, and household miles traveled under the current gasoline tax and a VMT fee in three stages. More time is required, however, to modify and further improve the existing DCC model so as to estimate the three models (vehicle number choice, vehicle type choice, vehicle use) simultaneously, which can give consistent coefficient estimates. Thus further research using a DCC model is recommended to help quantify the impacts of a VMT fee and other alternative policies.

In addition, the DCC model has been developed only at the household level; development of the model at the vehicle level was not possible due to insufficient data. Thus future research on a DCC model at the vehicle level will need a larger and more complete data set than what the 2001 NHTS could provide. 


\subsection{SUMMARY AND CONCLUSIONS}

Given the projected shortfalls in highway revenues available for building and maintaining highways, the state of Oregon has been exploring alternatives to the current state gasoline tax of \$.24 per gallon. The Road User Fee Task Force (RUFTF), appointed by the Oregon legislature to study the issue, suggested that a vehicle mileage fee might be considered as a replacement for the gasoline tax for light vehicles. Given concerns that were expressed regarding a change to a VMT fee structure, this study was undertaken to develop analytical techniques that can be used to examine the distributional impacts of alternative fee structures. The three major concerns were as follows:

- The change to a VMT fee would be regressive, placing disproportionate hardship on those in lower income groups.

- Rural areas in Oregon would be adversely impacted relative to urban areas.

- A change to a VMT fee would discourage people from acquiring alternative fuel vehicles or more fuel efficient vehicles and thus would be contrary to the state and national priority of reducing fossil fuel use.

This study developed three different methodologies that can be used to examine these issues. The authors first used a static model that assumes that households do not change their behavior in response to a change in the structure of user fees. Next the distributional effects of such a policy change were analyzed using the results from an OLS regression model that does consider the feedback effects on driving resulting from a change in user fees. These were simple models that did not incorporate long-run vehicle choice responses to the policy change. Thus, the static and OLS models could only deal with the first two concerns listed above. Accordingly, the study then developed a two-stage discrete-continuous choice model that was conceptually more satisfactory and potentially able to deal with the third concern, but which was much more complex and data intensive.

The results from both the static and the OLS models suggested that the income distributional impact of changing to an approximately revenue-neutral VMT fee of 1.2 cents per mile would result in a very small increase in regressivity relative to the regressive structure of the current gasoline tax. The impact was very small for the lowest income group, amounting to a change of less than one percent of their income. As a comparison, the increase in total gasoline expenditures that was caused by the near doubling of gasoline prices from $\$ 1.46$ / gallon to \$2.64/gallon between 2001 and 2006 was over five percent of income for the lowest income group.

Given that the impact on income groups was virtually identical in both the static and the more complex OLS regression models, it may be best for policymakers to use the simpler model, as it is easier to explain. Since the user fee change was a very small percent of income for all income groups, and there is a relatively inelastic demand for driving (especially in the short run), it makes sense that these two approaches gave similar results in this situation. The results from both of these models suggest that the VMT fee considered here would have a negligible impact on income distribution or on driving behavior. Indeed, the impact of the 
overall increase in gasoline prices between 2001 and 2006 had a much bigger impact on income distribution and still did not seem to have a significant impact on miles driven.

While the change to a VMT fee may slightly increase regressivity, the impact on rural areas was found to be opposite to that suggested by conventional wisdom. On average a household in a rural location would pay less under a 1.2 cents-per-mile VMT fee than under the current gasoline tax, whereas those in urban areas would pay slightly more. This was largely due to the lower overall average fuel efficiency in the rural vehicle fleet relative to the urban fleet and the greater number of miles driven on average by rural households.

On the final concern, that a VMT fee would discourage adoption of more fuel efficient vehicles, the discrete-continuous model offered an appealing approach from a theoretical point of view. However, the authors were not able to refine it enough to produce robust results. Findings from the static and OLS models suggested that the change to a VMT fee is not likely to create a significant disincentive to purchase more fuel efficient or hybrid vehicles. Once again this is because the change in fee structure has such a small impact on the cost of driving relative to the price of gasoline. Indeed, it is continued increases in gasoline prices, which dwarf the change in per mile user fees, that will be the factor giving people the incentive to purchase more fuel efficient cars regardless of whether Oregon has a gasoline tax or VMT fee structures such as the ones considered in this study.

It has been suggested that any disincentive effect to purchasing fuel efficient vehicles could be ameliorated by designing an appropriate VMT fee structure (Whitty and Imholt 2005; Whitty 2007). Using both the static and OLS models, the authors examined two sample scenarios other than a flat 1.2 cents-per-mile fee. While both alternate schemes eliminated the perceived disincentive, they were not revenue neutral; indeed, everyone would pay more in user fees under these scenarios.

The first sample scenario was to keep the gasoline tax of 24 cents per gallon for vehicles with fuel efficiency below 20 miles per gallon and apply a 1.2 cents-per-mile VMT fee for vehicles that achieve 20 miles per gallon or more. The second sample scenario was a "stepped" VMT fee such that vehicles getting less than the median miles per gallon would pay 2 cents per mile, those between the median and 20 miles per gallon would pay 1.5 cents per mile, and those vehicles with over 20 miles per gallon would pay 1 cent per mile.

While these sample scenarios would increase taxes paid by all, the impact was much greater on those in rural areas, who would pay relatively more than their urban counterparts. When regressivity was measured using the Suits index, the first scenario was found to be more regressive than the flat fee of 1.2 cents per mile, whereas the second scenario was less regressive than the flat fee of 1.2 cents per mile. In any case, both a VMT fee and the current gasoline tax were shown to be regressive forms of taxation.

An obvious conclusion is that it is not possible to use one policy instrument such as a flat VMT fee to achieve multiple policy objectives. Interestingly, a mileage fee has been proposed to help keep the highway finance system viable, while it has also been proposed as a way to tax vehicular emissions and as a way to structure driver insurance rates. Although these alternatives proposed for a mileage fee are seen as ways to curb environmental pollution and reduce accidents, it appears that they could increase the regressiveness of the tax system. 
Thus, policymakers need to consider other policy options that can be used, possibly simultaneously, to help achieve multiple goals. Suggested policies may be differentiated VMT fees (as considered in this study) or other pricing schemes such as congestion pricing or tolling roads and bridges. Parking policies, subsidies for alternative fuel or hybrid vehicles, additional fees or taxes on vehicles with low fuel efficiency and/or high pollution emissions, or subsidies for public transit may also be perceived as ways to achieve alternate policy results that seem to conflict with a VMT fee. The evaluation of these welfare-improving policies requires more sophisticated modeling tools that capture households' adjustments in vehicle fleet size, type, and use decisions. Although Pareto-improving policies on financing, energy conservation, and environmental conversation in the transportation sector are pursued, it is likely that these aforementioned policies will also create winners and losers, which deserves the attention of future research.

Whatever the combination of policies, there will still be the need to evaluate the potential distributional effects of regulatory action. To examine short run distributional changes, the static and OLS models provide reasonable results as changes in vehicle ownership are likely to take place over a long time horizon. The long-term distributional effects are likely to be somewhat different, since people in different income groups may have differing abilities to purchase newer vehicles, so the analysis becomes more complex. Given the long-run policy goal of promoting fuel efficient vehicles, the authors recommend further development of the discrete-continuous choice model, as it is much better able to deal with the long-term question of how people change their choice of vehicles in response to such policy changes. 


\subsection{REFERENCES}

Alm, James and Charles Sonnoga. 2005. Perfect Competition, Spatial Competition, and Tax Incidence in the Retail Gasoline Market. Fiscal Research Center, Andrew Young School of Policy Studies, Georgia State University. No. 112, pp. 1-4.

Ball, Jeffrey. 2007. Climate Economics: Fight over Who Pays for Emissions Curbs. Wall Street Journal. May 5, 2007. pp. A4.

Berkowitz, M.K., N.T. Gallini, E.J. Miller, and R.A. Wolfe. 1990. Disaggregate analysis of the demand for gasoline. The Canadian Journal of Economics. Vol. 23(2), pp. 253-275.

Bhat, C. R. and V. Pulugurta. 1998. A Comparison of Two Alternative Behavioral Choice Mechanism for Household Auto Ownership Decisions. Transportation Research. Vol. 32B, pp. 61-75.

Bhat, Chandra R. and Sudeshna Sen. 2004. Household Vehicle Type Holdings and Usage: An Application of the Multiple Discrete Continuous Extreme Value Model. Transportation Research Part B:Methodological. Vol. 40(1), pp. 35-53.

Cambridge Systematic, Inc. 2005. Future Highway and Public Transportation Finance: Phase I: Current Outlook and Short-Term Solutions. National Chamber Foundation.

Chamberlain, C. 1974. A Preliminary Model of Auto Choice by Class of Car: Aggregate State Data. Discussion Paper. Transportation System Center, U. S. Department of Transportation. Cambridge, MA.

Chouinard, Hayley and Jeffrey Perloff. 2004. Incidence of Federal and State Gasoline Taxes. Economic Letters. Vol. 83, pp. 55-65.

Chow, G. 1957. Demand for Automobiles in the United States. North-Holland Publishing Company, Amsterdam.

Crandall, Mindy and Bruce Weber. 2005. Defining Rural Oregon: An Exploration. Rural Studies Paper Series RSP 05-03, Rural Studies Program, Oregon State University.

De Corla-Souza, Patrick. 2001. Estimating the Benefits from Mileage-Based Vehicle Insurance, Taxes and Fees. Paper prepared for the TRB 2002 Annual Meeting. Transportation Research Board.

Dubin, A.Jeffrey and Daniel L. McFadden. 1984. An Econometric Analysis of Residential Electric Appliance Holdings and Consumption. Econometrica. Vol. 52(2), pp. 345-362.

Edlin, Aaron. 2003. Per-Mile Premiums for Automobile Insurance. In R. Arnott, B. Greenwald, R. Kanbur, and B. Nalebuff, eds. Economics for an imperfect world: essays in honor of Joseph Stiglitz. Cambridge: MIT Press. 
Federal Highway Administration (FHWA). 2002. Highway Statistics 2001.

http://www.fhwa.dot.gov/ohim/hs01/index.htm. Office of Highway Policy Information, Federal Highway Administration, U.S. Department of Transportation. Washington, DC.

Forkenbrock, David J. and Jon G. Kuhl. 2002. A New Approach to Assessing Road User Charges. Public Policy Center, University of Iowa.

Forkenbrock, David J. 2005. Implementing a Mileage-Based Road User Charge. Public Works Management \& Policy. Vol. 10, No. 2, pp. 87-100.

Goldberg, P.K. 1998. The Effects of the Corporate Average Fuel Efficiency Standards in the US. Journal of Industrial Economics. Vol. 46(1), pp. 1-33.

Greene, David L., James R. Kahn and Robert C. Gibson. 1999. Fuel Economy Rebound Effect for U.S. Household Vehicles. The Energy Journal. Vol. 20(3), pp. 1-31.

Haughton, J. and S. Sarkar. 1996. Gasoline Tax as Corrective Tax: Estimates for the United States, 1970-1991. The Energy Journal. Vol. 17, No.2, pp. 103-126.

Kain, J. and M. Beesley. 1965. Forecasting Car Ownership and Use. Urban Studies. Vol. 11.

Kockelman, Kara M. and Raheel Shabih. 2000. Effect of Vehicle Type on the Capacity of signalized Intersections: The Case of Light Duty Trucks. Journal of Transportation Engineering. Vol. 126, No. 6, pp. 516-512.

Kockelman, K. and Y. Zhao. 2000. Behavioral Distinctions: The Use of Light-Duty Trucks and Passenger Cars. Journal of Transportation and Statistics. Vol. 3, No. 3, pp. 47 -60.

Litman, Todd. 1999. Distance-Based Charges; A Practical Strategy for More Optimal Vehicle Pricing. Paper presented at the TRB $78^{\text {th }}$ Annual Meeting, Transportation Research Board. Washington, DC.

Litman, Todd. 2006. Distance-Based Vehicle Insurance as a TDM Strategy. Victoria Transport Policy Institute.

Mannering, F. and C. Winston. A. 1985. Dynamic Empirical Analysis of Household Vehicle Ownership and Utilization. Rand Journal of Economics. Vol. 16, No. 2, pp. 215-236.

Mannering, F. and D. A. Hensher. 1987. Discrete/continuous Econometric Models and Their Application to Transport Analysis. Transport Reviews. Vol. 7, No. 3, pp. 227-244.

McMullen, B. Starr. 2005. The Evolution of the U.S. Trucking Industry. In Belman, D. (ed.) Trucking in the Age of Information. Ashgate Press. pp. 1-22.

Merriss, John. 2004. Increasing Light Vehicle Weights and Cost Responsibility. Policy_ Notes. Oregon Department of Transportation, Policy Unit.

Mohring, H. and Harwitz, M. 1962. Highway Benefits: An Analytical Framework. pp. 57-90. Mogridge, M. 1967. The Prediction of Car Ownership. Journal of Transport Economics and Policy. Vol. 1, pp. 52-74. 
Morrison, Steven A. 1986. A Survey of Road Pricing. Transportation Research. Vol. 20A, pp. 89-97.

Parry, Ian W.H. and Kenneth A. Small. 2005. Does Britain or the United States Have the Right Gasoline Tax? American Economics Review. Vol. 95, pp. 1276-1289.

Proterba, James. 1991. Is the Gasoline Tax Regressive? In D. Bradford, ed. Tax Policy and the Economy. pp. 145-164.

Puller, S.L. and L.A. Greening. 1997. A Decomposition of the Household Adjustment to Gasoline Price Change. International Energy Markets: Competition and Policy.

Small, Kenneth A., Clifford Winston, and Carol A. Evans. 1989. Road Work: A New Highway Pricing \& Investment Policy. Brookings Institution.

Sorenson P. and Taylor B. 2005. Paying for Roads: New Technology for an Old Dilemma. Access. 26, pp. 2-9.

Srinivasan S. and Chandra R. Bhat. 2006. A Multiple Discrete-Continuous Model for Independent and Joint Discretionary-Activity Particiption Decisions. Transportation. Vol. 33(5), pp. 497-515.

Steininger, Karl W., Birgil Friedland and Brigitte Gebetsroither. 2006. Sustainability Impacts of Car Road Pricing: A Computable General Equilibrium Analysis for Austria. Ecological Economics. Vol. 63(1), pp. 59-69.

Transportation Research Board of the National Academies. 2006. The Fuel Tax and Alternatives for Transportation Funding. Special Report 285, Transportation Research Board. Washington, DC.

Train, K. 1986. Qualitative Choice Analysis: Theory, Econometrics and an Application to Automobile Demand. The MIT Press. Cambridge, MA.

U.S. Congressional Budget Office (CBO). 1990. Federal Taxation of Tobacco, Alcoholic Beverages, and Motor Fuels: A CBO Study. U.S. Congressional Budget Office. Washington, DC.

Walls, Margaret and Jean Hanson. 1999. Distributional Aspects of an Environmental Tax Shift: The Case of Motor Vehicle Emissions Taxes. National Tax Journal. Vol.52(1), pp. 5366.

Wards Communications Inc. 2001. Ward's Automotive Yearbook 2001. Wards Communications Inc. pp. 253-254.

West, Sarah E. 2001. Distributional Effects of Alternative Vehicle Pollution Control Policies. extended Working Paper. Department of Economics, Macalester College.

West, S.E. 2004. Distributional effects of alternative vehicle pollution control policies. Journal of Public Economics. Vol. 88, pp. 735-757.

West, Sarah E. 2005. Equity Implications of Vehicle Emissions Taxes. Journal of Transport Economics and Policy. Vol. 39, No. 1, pp. 1-24. 
West, Sarah E. and Roberton C. Williams III. 2004. Optimal Taxation and Cross-Price Effects on Labor Supply: Estimates of the Optimal Gas Tax. forthcoming, Journal of Public Economics. Earlier version available as NBER working paper \#10330 under the title "Empirical Estimates for Environmental Policy in a Second-Best Setting."

Whitty, James M. and Betsy Imholt. 2005. Oregon's Mileage Fee Concept and Road User Fee Pilot Program: Report to the 73rd Oregon Legislative Assembly. June 2005. http://www.oregon.gov/ODOT/HWY/RUFPP/ruftf reports.shtml.

Whitty, James M., Jack Svadlenak and Darel Capps. 2006. Public Involvement and Road User Charge Development: Oregon's Experience. Oregon Department of Transportation.

Whitty, James M. 2007. Oregon's Mileage Fee Concept and Road User Fee Pilot Program: Final Report. November 2007. http://www.oregon.gov/ODOT/HWY/RUFPP/ruftf_reports.shtml

Zhao, Y. and K. Kockelman. 2000. Household Vehicle ownership by Vehicle Type: Application of a multivariate Negative Binomial Model. Transportation Research Board $81^{\text {st }}$ Annual meeting, Washington D.C.

Zupnick, Jan William. 1975. The Short Run Incidence of a Tax Induced Rise in the Price of Gasoline. Journal of Economics Issues. Vol. 9, No. 2, pp. 409-414. 


\section{APPENDICES}





\section{APPENDIX A: INCOME GROUPS}

The NHTS assigns households into one of 18 categories. We assigned the median value of each category to each household.

Table A.1: Income groups

\begin{tabular}{|c|r|r|}
\hline $\begin{array}{c}\text { Income } \\
\text { Category }\end{array}$ & Income Ranges & $\begin{array}{c}\text { Value Assigned to } \\
\text { Household }\end{array}$ \\
\hline 1 & $\$ 0 \sim \$ 5,000$ & $\$ 2,500.00$ \\
\hline 2 & $\$ 5,000 \sim \$ 9,999$ & $\$ 7,499.50$ \\
\hline 3 & $\$ 10,000 \sim \$ 14,999$ & $\$ 12,499.50$ \\
\hline 4 & $\$ 15,000 \sim \$ 19,999$ & $\$ 17,499.50$ \\
\hline 5 & $\$ 25,000 \sim \$ 29,999$ & $\$ 22,499.50$ \\
\hline 6 & $\$ 30,000 \sim \$ 34,999$ & $\$ 27,499.50$ \\
\hline 7 & $\$ 35,000 \sim \$ 39,999$ & $\$ 32,499.50$ \\
\hline 8 & $\$ 40,000 \sim \$ 44,999$ & $\$ 37,499.50$ \\
\hline 9 & $\$ 45,000 \sim \$ 49,999$ & $\$ 47,499.50$ \\
\hline 10 & $\$ 50,000 \sim \$ 54,999$ & $\$ 52,499.50$ \\
\hline 11 & $\$ 55,000 \sim \$ 59,999$ & $\$ 57,499.50$ \\
\hline 12 & $\$ 60,000 \sim \$ 64,999$ & $\$ 62,499.50$ \\
\hline 13 & $\$ 70,000 \sim \$ 74,999$ & $\$ 67,499.50$ \\
\hline 14 & $\$ 75,000 \sim \$ 79,999$ & $\$ 72,499.50$ \\
\hline 15 & $\$ 80,000 \sim \$ 99,999$ & $\$ 77,499.50$ \\
\hline 16 & $\$ 100,000$ or greater & $\$ 150,000.00$ \\
\hline 17 & &
\end{tabular}

Due to the relatively small number of Oregon households in the NHTS sample, this meant that there were very few households in some of the above 18 income groups. Accordingly, we reorganized Oregon households into six income groups as indicated below in Table A.2 so as to provide a reasonable number of households in each category.

Table A.2: Oregon Income Groups

\begin{tabular}{|c|l|}
\hline Income Group & \multicolumn{1}{|c|}{$\begin{array}{c}\text { Income Range } \\
\text { Group }\end{array}$} \\
\hline 1 & $\$ 0 \sim 14,999$ \\
\hline 2 & $\$ 15,000 \sim 29,999$ \\
\hline 3 & $\$ 30,000 \sim 44,999$ \\
\hline 4 & $\$ 45,000 \sim 59,999$ \\
\hline 5 & $\$ 60,000 \sim 74,999$ \\
\hline 6 & $\$ 75,000 \sim 200,000$ \\
\hline
\end{tabular}

\footnotetext{
${ }^{9}$ The 2001 NHTS does not have an upper bound for this last income group. According to the Census 2000 for Oregon, only $1.8 \%$ of all households have a total income greater than $\$ 200,000$.
} 
A-2 


\section{APPENDIX B: SUITS INDEX, GRAPHS AND TABLES}

The Suits Index is another way to measure the regressivity of a tax, or to compare the changes in regressivity as a result of a structural change. In our case, we can compare the regressivity of the gas tax to the VMT fee. The Suits Index is convenient in that it provides one number that can be compared across tax regimes.

Similar to the Gini Coefficient, the 45 degree line represents the points were the proportion of the tax paid by each income group exactly equals the proportion of the population. Points above the 45 degree line suggest lower income groups pay more than their proportion of total income, suggesting a regressive tax. Similarly, points below the 45 degree line would suggest lower income families pay a lower proportion of a tax than their proportion of income, suggesting a progressive tax. West (2002) and Walls and Hanson (1999) both conclude a per-mile emissions fee is regressive, by calculating a Suits Index.

The Suits Index is computed as:

$$
S=1-\frac{1}{5000} \int_{0}^{100} T(Y) d y
$$

We multiply the area by $\frac{1}{5000}$ to keep the Suits Index bounded by -1 and 1 , since the area of the upper or lower triangle will be 5000. A value of -1 suggests a perfectly regressive tax where the lowest income group bares the entire tax burden. On the other extreme, a value of 1 suggests the highest income group bares the entire tax burden. A Suits Index equal to 0 implies we are on the 45 degree line and the tax is exactly proportional. Thus, we are attempting to calculate the area between the curve and the 45 degree line. Since we only have 6 income groups, and thus 6 discrete points, we can approximate the integral as:

$$
\int_{0}^{100} T(Y) d y \approx \frac{1}{2} \sum_{i=0}^{6}\left\{\left[T\left(y_{i}\right)+T\left(y_{i-1}\right)\right]\left(y_{i}-y_{i-1}\right)\right\}
$$




\section{B.1 SUITS INDEX BASED ON OREGON STATIC MODEL}

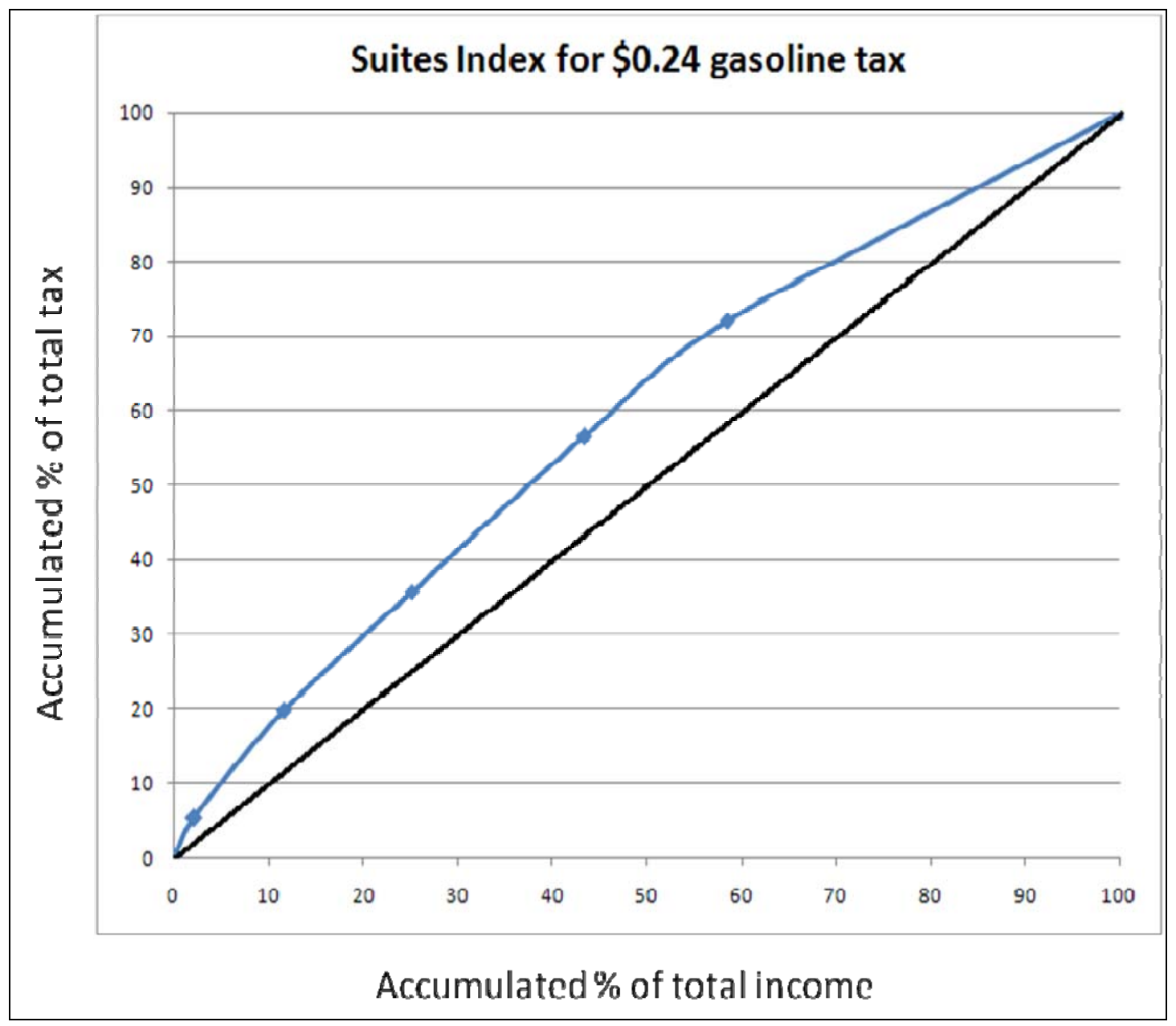

Figure B.1.1: Suits index for $\$ 0.24$ gasoline tax

Suits Index $=-\mathbf{0 . 1 7 6 2 3}$

Table B.1.1: Suits index based on income group for $\mathbf{\$ 0 . 2 4}$ gasoline tax

\begin{tabular}{|c|c|c|}
\hline Income group & Accumulated income (\%) & $\begin{array}{c}\text { Accumulated tax } \\
(\%)\end{array}$ \\
\hline 1 & 2.179938882 & 5.380472998 \\
\hline 2 & 11.64535438 & 19.79382503 \\
\hline 3 & 25.18959838 & 35.77177459 \\
\hline 4 & 43.36117767 & 56.47871052 \\
\hline 5 & 58.5510772 & 72.04696128 \\
\hline 6 & 100 & 100 \\
\hline
\end{tabular}




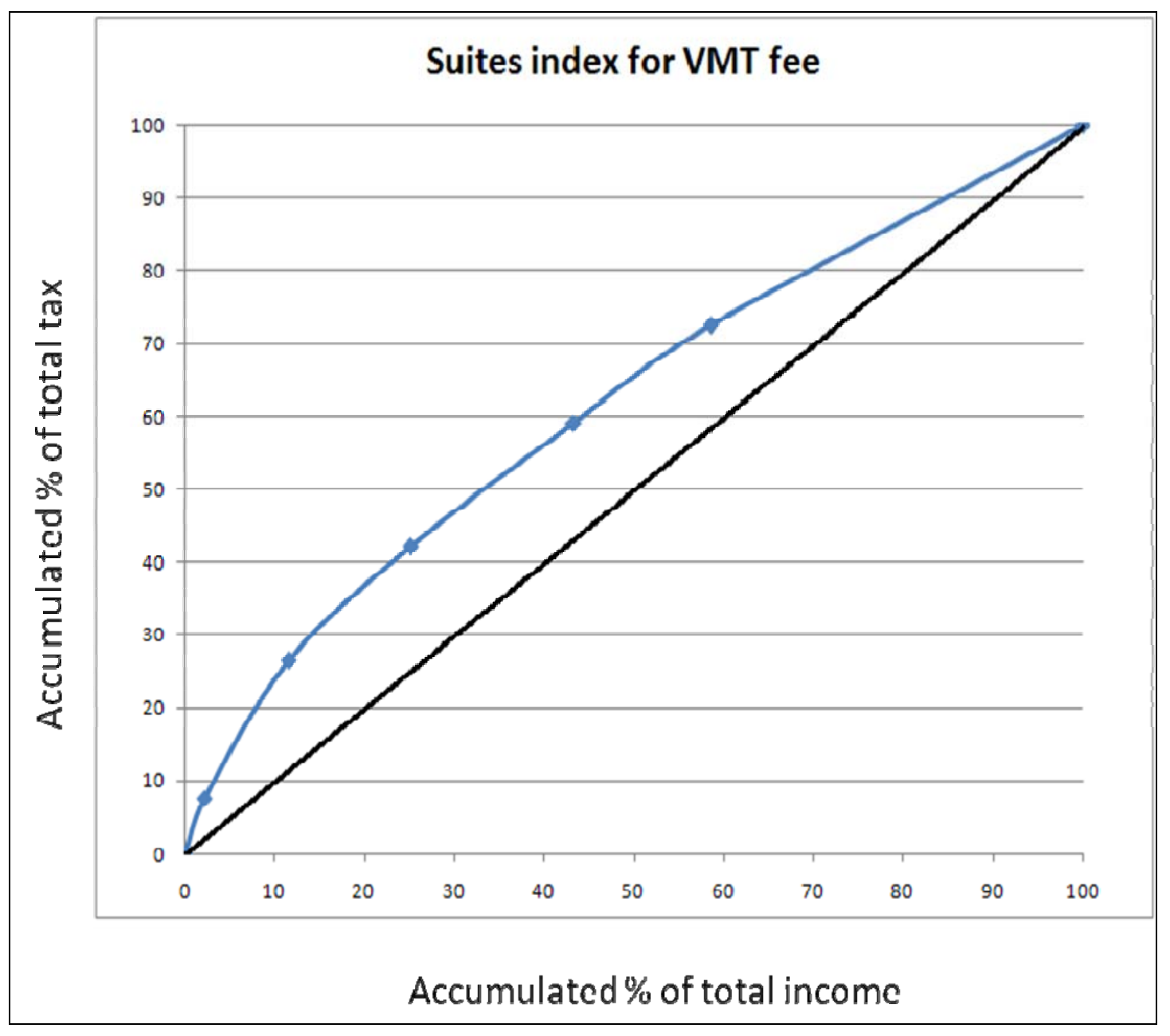

Figure B.1.2: Suits index for VMT fee

\section{Suits Index $=-\mathbf{- 0 . 2 2 5 4 2}$}

Table B.1.2: Suits index based on income group for VMT fee

\begin{tabular}{|c|c|c|}
\hline Income group & Accumulated income (\%) & $\begin{array}{c}\text { Accumulated tax } \\
(\%)\end{array}$ \\
\hline 1 & 2.179938882 & 7.545591225 \\
\hline 2 & 11.64535438 & 26.45669222 \\
\hline 3 & 25.18959838 & 42.12619447 \\
\hline 4 & 43.36117767 & 59.05973543 \\
\hline 5 & 58.5510772 & 72.50101607 \\
\hline 6 & 100 & 100 \\
\hline
\end{tabular}




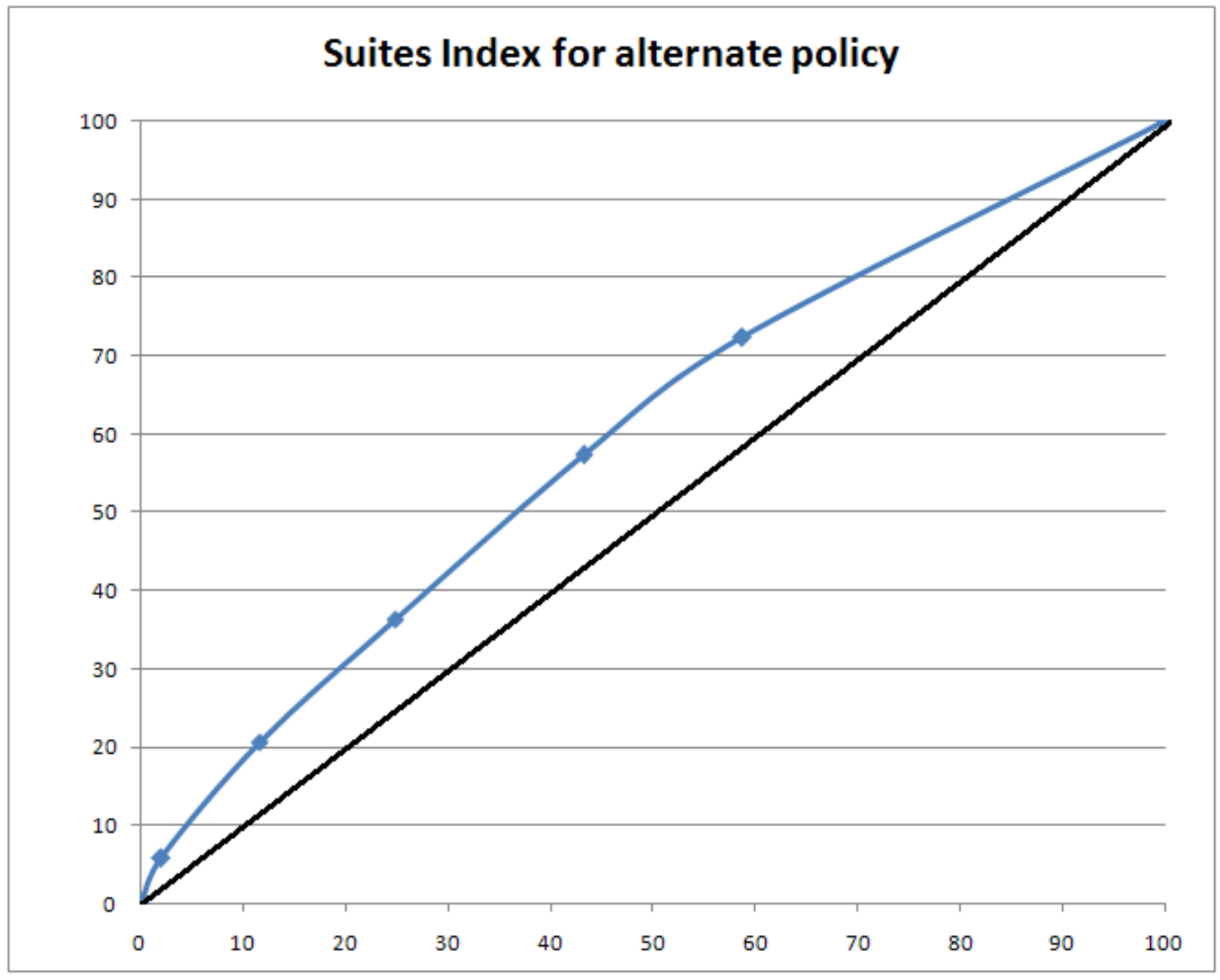

Figure B.1.3: Suits index for Sample Scenario \#1

Suits Index $=-\mathbf{0 . 1 8 4 9 3}$

Table B.1.3: Suits index based on income group for Sample Scenario \#1

\begin{tabular}{|c|c|c|}
\hline Income group & Accumulated income (\%) & $\begin{array}{c}\text { Accumulated tax } \\
(\%)\end{array}$ \\
\hline 1 & 2.179938882 & 5.785054908 \\
\hline 2 & 11.64535438 & 20.59514314 \\
\hline 3 & 25.18959838 & 36.30203978 \\
\hline 4 & 43.36117767 & 57.31056656 \\
\hline 5 & 58.5510772 & 72.30439055 \\
\hline 6 & 100 & 100 \\
\hline
\end{tabular}




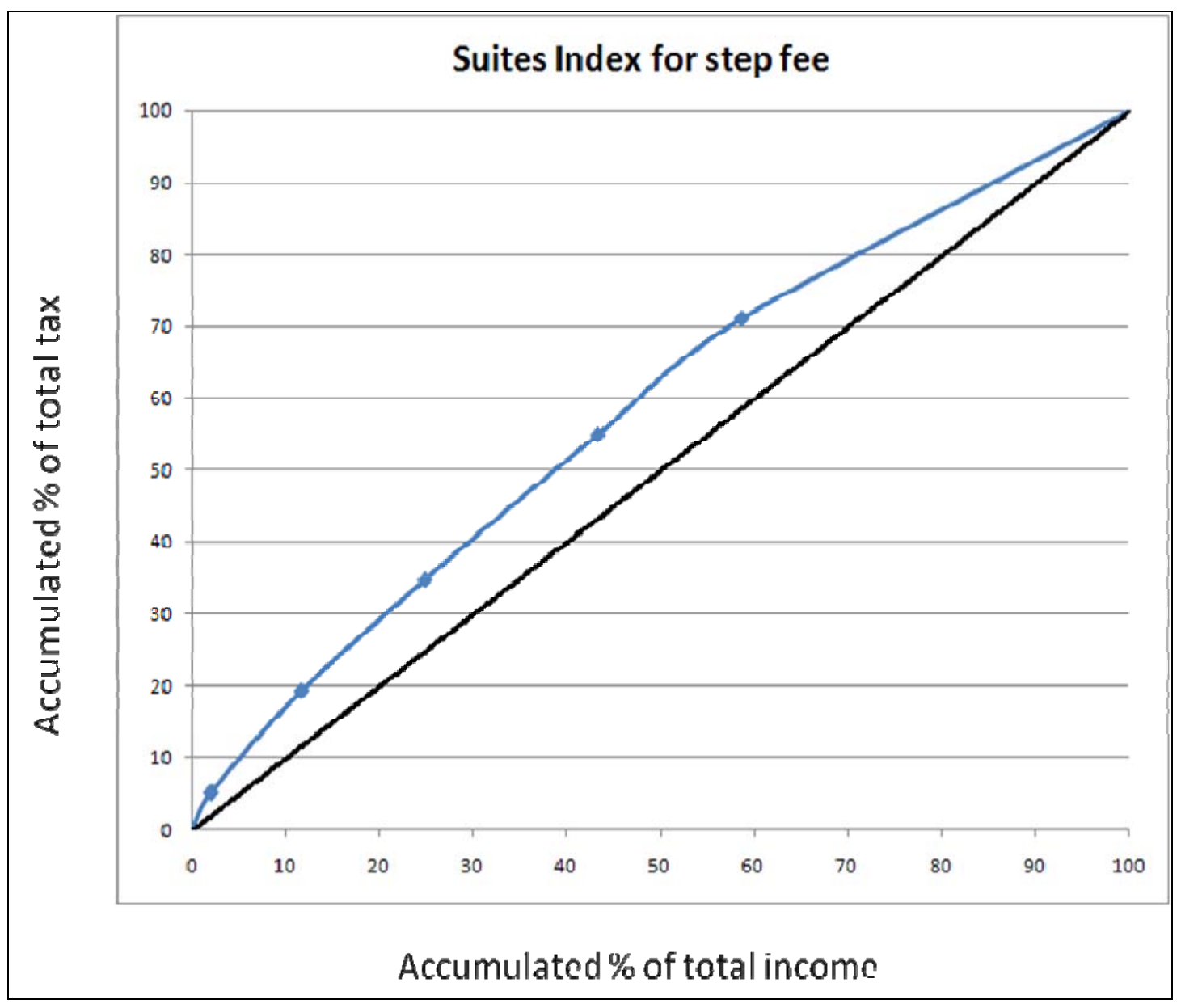

Figure B.1.4: Suits index for Sample Scenario \#2

\section{Suits Index $=-\mathbf{- 0 . 1 6 1 6 5}$}

Table B.1.4: Suits index based on income group for Sample Scenario \#2

\begin{tabular}{|c|r|r|}
\hline Income group & Accumulated income (\%) & $\begin{array}{c}\text { Accumulated tax } \\
(\%)\end{array}$ \\
\hline 1 & 2.179938882 & 5.136838462 \\
\hline 2 & 11.64535438 & 19.256235 \\
\hline 3 & 25.18959838 & 34.7640426 \\
\hline 4 & 43.36117767 & 54.93690353 \\
\hline 5 & 58.5510772 & 71.1466093 \\
\hline 6 & 100 & 100 \\
\hline
\end{tabular}




\section{B.2 SUITS INDEX BASED ON OREGON OLS MODEL}

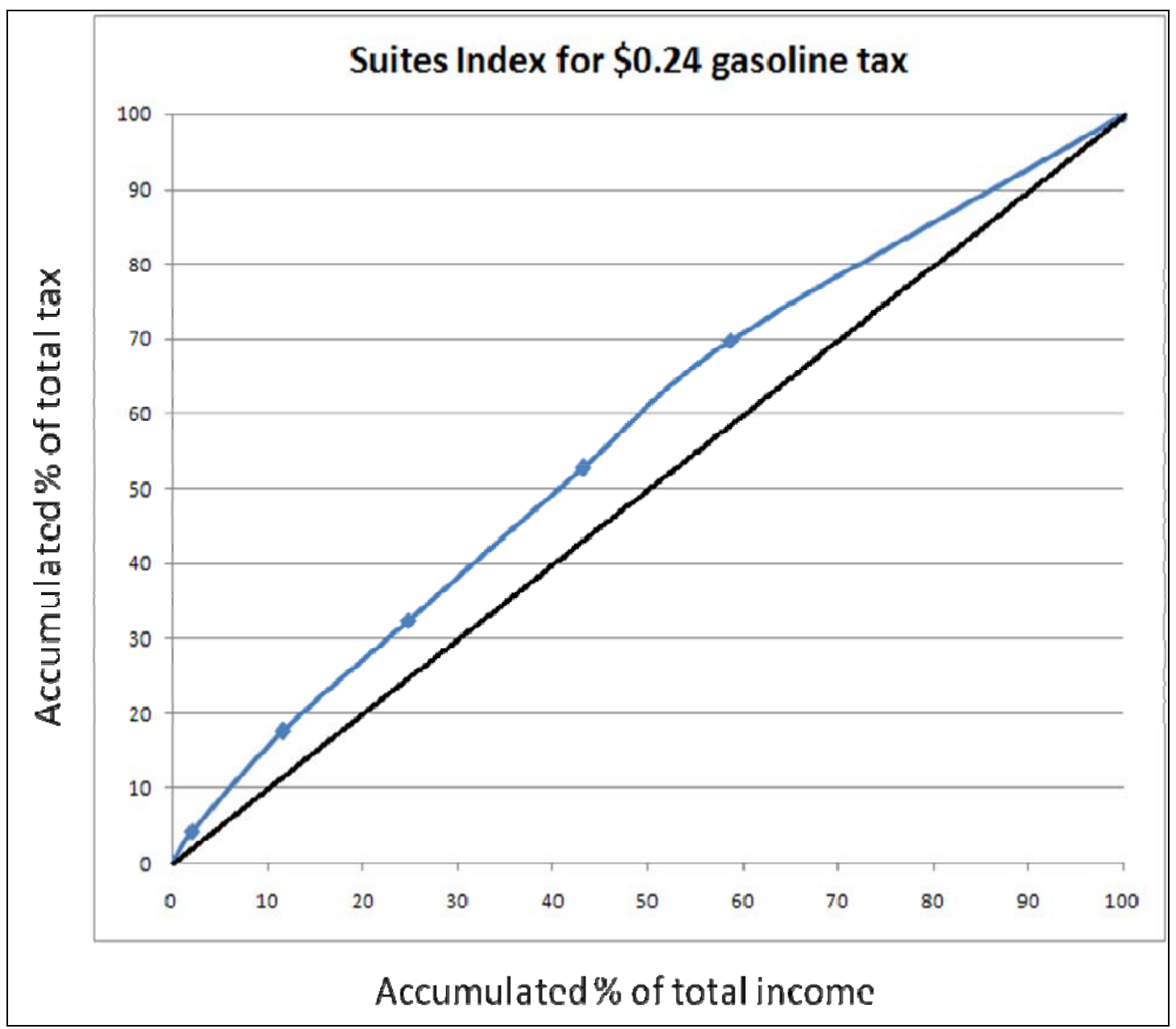

Figure: B.2.1: Suits index for $\$ 0.24$ gasoline tax

\section{Suits Index $=\mathbf{- 0 . 1 3 3}$}

Table B.2.1: Suits index based on income group for $\$ 0.24$ gasoline tax

\begin{tabular}{|c|c|c|}
\hline Income group & Accumulated income (\%) & $\begin{array}{c}\text { Accumulated gas tax } \\
(\%)\end{array}$ \\
\hline 1 & 2.080566517 & 4.262081525 \\
\hline 2 & 11.66367121 & 17.52323622 \\
\hline 3 & 24.92327769 & 32.47211488 \\
\hline 4 & 43.28629319 & 52.69766516 \\
\hline 5 & 58.77005121 & 69.69442618 \\
\hline 6 & 100 & 100 \\
\hline
\end{tabular}




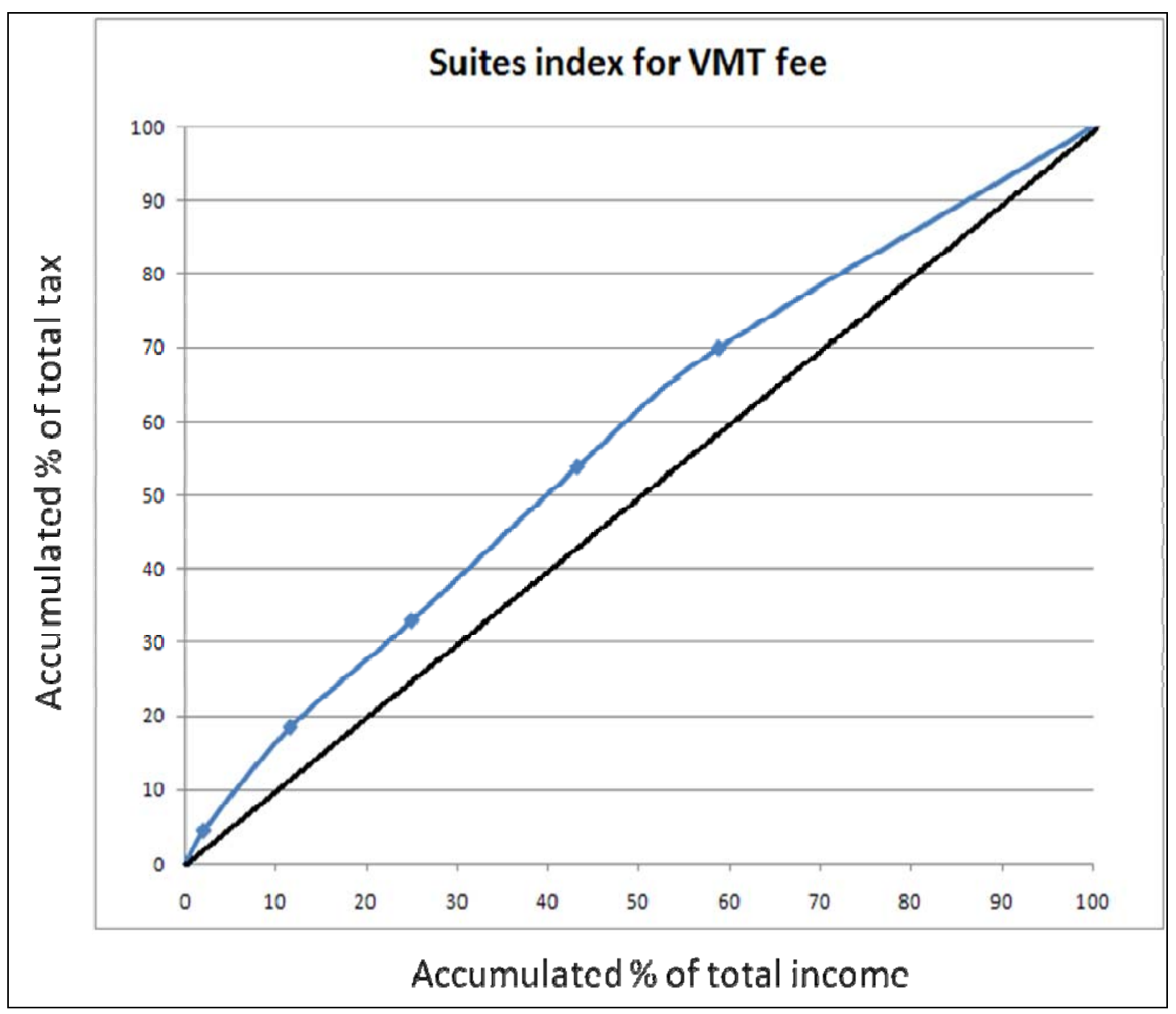

Figure: B.2.2: Suits index for VMT fee

\section{Suits Index $=\mathbf{- 0 . 1 4 2}$}

Table B.2.2: Suits index based on income group for VMT fee

\begin{tabular}{|c|c|c|}
\hline Income group & Accumulated income (\%) & $\begin{array}{c}\text { Accumulated VMT } \\
(\%)\end{array}$ \\
\hline 1 & 2.080566517 & 4.552139586 \\
\hline 2 & 11.66367121 & 18.47365438 \\
\hline 3 & 24.92327769 & 32.97689647 \\
\hline 4 & 43.28629319 & 53.88760427 \\
\hline 5 & 58.77005121 & 70.05302579 \\
\hline 6 & 100 & 100 \\
\hline
\end{tabular}




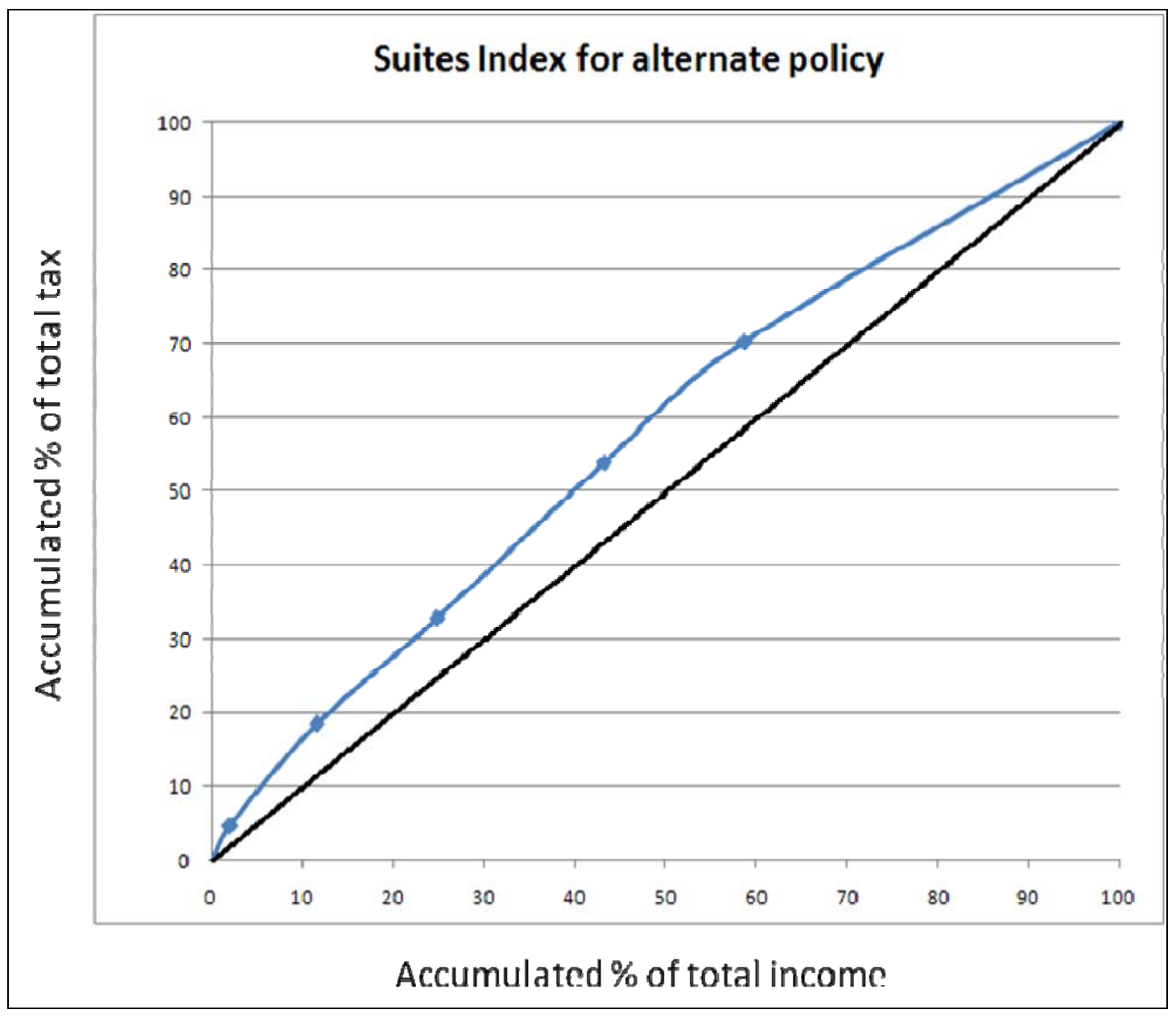

Figure: B.2.3: Suits index for alternate policy

\section{Suits Index $=\mathbf{- 0 . 1 4 4 6 6}$}

Table B.2.3: Suits index based on income group for alternate policy

\begin{tabular}{|c|c|c|}
\hline Income group & Accumulated income (\%) & $\begin{array}{c}\text { Accumulated tax } \\
(\%)\end{array}$ \\
\hline 1 & 2.080566517 & 4.62185976 \\
\hline 2 & 11.66367121 & 18.3890603 \\
\hline 3 & 24.92327769 & 32.74655801 \\
\hline 4 & 43.28629319 & 53.90247825 \\
\hline 5 & 58.77005121 & 70.34788312 \\
\hline 6 & 100 & 100 \\
\hline
\end{tabular}




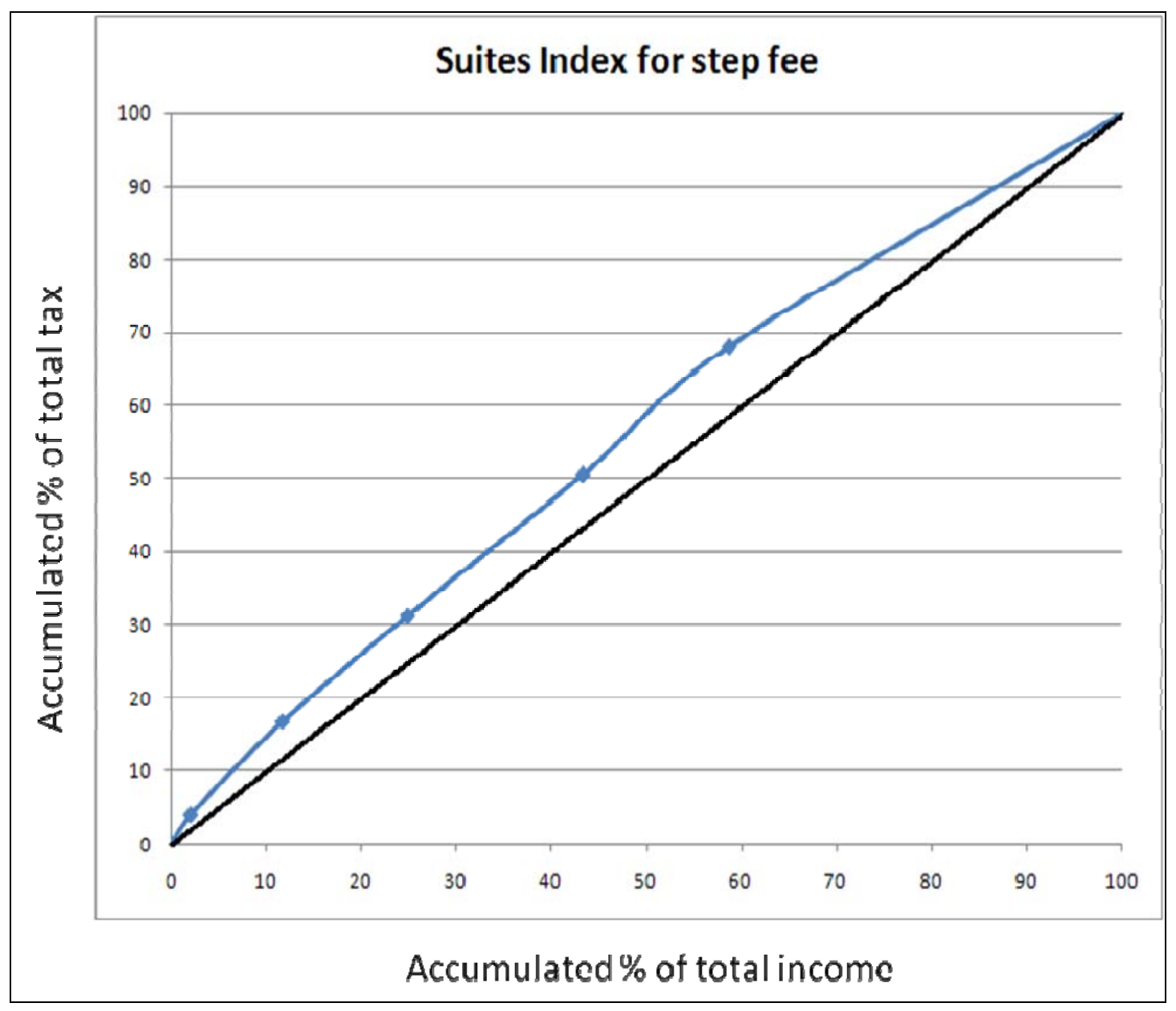

Figure: B.2.4: Suits index for step fee

Suits Index $=\mathbf{- 0 . 1 1 0 7 2 0}$

Table B.2.4: Suits index based on income group for step fee

\begin{tabular}{|c|r|r|}
\hline Income group & Accumulated income (\%) & $\begin{array}{c}\text { Accumulated step fee } \\
\text { (\%) }\end{array}$ \\
\hline 1 & 2.080566517 & 4.009637876 \\
\hline 2 & 11.66367121 & 16.69068834 \\
\hline 3 & 24.92327769 & 31.20241687 \\
\hline 4 & 43.28629319 & 50.37868655 \\
\hline 5 & 58.77005121 & 68.13748159 \\
\hline 6 & 100 & 100 \\
\hline
\end{tabular}


B-10 


\section{APPENDIX C: DETAILED DATA DESCRIPTIONS}

\section{C.1 DETAILED DESCRIPTION OF VARIABLES FOR OLS ANALYSIS}

The data used in the OLS estimation is based on the NHTS data, or were derived from the NHTS data set. All variables used are described below. If the variable was modified, it is described in this table.

\begin{tabular}{|c|c|c|}
\hline Variable & Variable Name & Description \\
\hline$P_{M}$ & $\begin{array}{l}\text { Fuel Cost Per Mile } \\
\text { Under the Gasoline } \\
\text { Tax }\end{array}$ & $\begin{array}{l}\text { Weighted average by miles driven. The fuel cost per } \\
\text { mile used in the estimation is the fuel cost per mile } \\
\text { under the gasoline tax. Fuel cost per mile for } \\
\text { vehicle } i \text { is defined as: } \\
\frac{P_{i}}{M P G_{i}} \\
\text { Where } P_{i} \text { is the reported fuel price and } M P G_{i} \text { is the } \\
\text { EIA adjusted fuel efficiency in the NHTS data. If } \\
\text { the MPG was not reported for a particular vehicle, } \\
\text { the average for reported vehicle MPG was used for } \\
\text { the missing value(s). Thus, for a household with } \\
\text { two vehicles, } \\
P_{M}=\ln \left[\left(\frac{m_{1}}{M}\right) \frac{P_{1}}{M P G_{1}}+\left(\frac{m_{2}}{M}\right) \frac{P_{2}}{M P G_{2}}\right] \\
\text { Where } m_{1} \text { is the reported miles for vehicle } 1, m_{2} \text { is } \\
\text { the reported miles for vehicle } 2 \text { and } M=m_{1}+m_{2} \text {. }\end{array}$ \\
\hline$I$ & Household Income & $\begin{array}{l}\text { NHTS reported income group. Households put } \\
\text { themselves in one of } 18 \text { income categories based on } \\
\text { income ranges. We then assigned households the } \\
\text { median value for their category. For example, } \\
\text { income group } 3 \text { was defined as a household that } \\
\text { earns between } \$ 10,000 \text { and } \$ 14,999 \text {. Thus, for this } \\
\text { household, } I=\ln (12,499.50) \text {. }\end{array}$ \\
\hline SUB & Substitution Indicator & $\begin{array}{l}\text { Dummy variable equal to } 1 \text { if the household owns } \\
\text { more than one type of vehicle and } 0 \text { otherwise. This } \\
\text { is based on the NHTS variable for "vehicle type." } \\
1=\text { Car/Station Wagon } \\
2=\text { Van } \\
3=\text { SUV } \\
4=\text { Pickup Truck } \\
5=\text { Other Truck } \\
6=\mathrm{RV} \\
7=\text { Motorcycle } \\
91=\text { Other } \\
\text { We treat values } 4 \text { and } 5 \text { as the same, and consider } \\
\text { these as "trucks," though this was not an issue in the } \\
\text { Oregon OLS sample. } \\
\text { For example, if a household owns two cars, SUB=0. }\end{array}$ \\
\hline
\end{tabular}




\begin{tabular}{|c|c|c|}
\hline & & If a household owns a car and a van, $\mathrm{SUB}=1$. \\
\hline $\mathrm{U}$ & Location Indicator & $\begin{array}{l}\text { Dummy variable equal to } 1 \text { if the household is } \\
\text { located in an urban area, } 0 \text { otherwise. Location } \\
\text { indicators are based on the Census } 2000 \text { definition. } \\
\text { According to the Census } 2000 \text {, an urban area is } \\
\text { defined as an area with: } \\
\text { 1. "Core census block groups or blocks that } \\
\text { have a population density of at least } 1,000 \\
\text { people per square mile and } \\
\text { 2. "Surrounding census blocks that have an } \\
\text { overall density of at least } 500 \text { people per } \\
\text { square mile." } \\
\text { (From U.S. Census Bureau, Available at: } \\
\text { http://www.census.gov/geo/www/ua/ua_2k.html. } \\
\text { Accessed on August } 24,2007 \text { ) }\end{array}$ \\
\hline$C$ & Vehicle Count & $\begin{array}{l}\text { This variable was modified from the vehicle count } \\
\text { variable in the NHTS dataset. If a household } \\
\text { reported zero miles driven on a vehicle, that vehicle } \\
\text { was excluded, and subtracted from the NHTS } \\
\text { vehicle count variable. Also, if miles for a vehicle } \\
\text { was missing, it was again assumed the vehicle was } \\
\text { not used and was subtracted from the NHTS vehicle } \\
\text { count. }\end{array}$ \\
\hline MALE & $\begin{array}{l}\text { Gender of Household } \\
\text { Respondent Indicator }\end{array}$ & $\begin{array}{l}\text { Dummy variable equal to } 1 \text { if the household } \\
\text { respondent is a male, } 0 \text { otherwise. Unmodified from } \\
\text { the NHTS data set, except that the NHTS uses } \\
\text { values } 1 \text { and } 2 \text {, which we changed to } 0 \text { or } 1 \text {. } \\
\text { NHTS: Defines Male }=1 \text {, Female }=2 \text {. We change the } \\
\text { NHTS variable to Male }=1 \text {, Female }=0 \text {. }\end{array}$ \\
\hline WORK & $\begin{array}{l}\text { Number of Workers } \\
\text { in Household }\end{array}$ & Unmodified variable from the NHTS dataset. \\
\hline CHILD & $\begin{array}{l}\text { Number of Children } \\
\text { in Household }\end{array}$ & $\begin{array}{l}\text { Derived from the NHTS dataset. We define the } \\
\text { number of children as the total number of people in } \\
\text { the household minus the number of adults. }\end{array}$ \\
\hline$P_{M} * I$ & $\begin{array}{l}\text { Product of Fuel Cost } \\
\text { Per Mile and Income }\end{array}$ & $\begin{array}{l}\text { This is an interaction term between the fuel cost per } \\
\text { mile for the household and the household income. } \\
\text { This allows for different elasticities for different } \\
\text { income groups. }\end{array}$ \\
\hline$P_{M} * S U B$ & $\begin{array}{l}\text { Product of Fuel Cost } \\
\text { Per Mile and the } \\
\text { Substitution Indicator }\end{array}$ & $\begin{array}{l}\text { This is an interaction term between the fuel cost per } \\
\text { mile for the household and the substitution dummy } \\
\text { variable. This allows for different elasticities for } \\
\text { households with multiple vehicle types and those } \\
\text { without. }\end{array}$ \\
\hline
\end{tabular}




\section{C.2 DESCRIPTION OF VARIABLES FOR DCC ANALYSIS}

Variables for the DCC are the same as those defined for the OLS except for those differences listed below.

\begin{tabular}{|l|l|l|}
\hline Pm & $\begin{array}{l}\text { Fuel cost per mile as } \\
\text { a percentage of } \\
\text { income }\end{array}$ & $\begin{array}{l}\text { Derived for each vehicle from the vehicle file of } \\
\text { the NHTS data set. It is computed as gas cost } \\
\text { (GSCOST) divided by miles per gallon } \\
\text { (EIADMPG). This value is then divided by } \\
\text { income. }\end{array}$ \\
\hline Pv & $\begin{array}{l}\text { Vehicle price as a } \\
\text { percentage of income }\end{array}$ & $\begin{array}{l}\text { For each make and model as given in the vehicle } \\
\text { file of the NHTS data set, the vehicle prices were } \\
\text { obtained from the Ward's year book 2001. This } \\
\text { vehicle price is then divided over income. }\end{array}$ \\
\hline HHsize & $\begin{array}{l}\text { This value is obtained directly from the 2001 } \\
\text { NHTS data set. }\end{array}$ \\
\hline Children/hhsize & $\begin{array}{l}\text { Children as a } \\
\text { percentage of } \\
\text { household } \\
\text { size }\end{array}$ & $\begin{array}{l}\text { The number of children is obtained by subtracting } \\
\text { the number of adults (given in the NHTS data) } \\
\text { from the household size. }\end{array}$ \\
\hline Middle & $\begin{array}{l}\text { Age of the household } \\
\text { respondent }\end{array}$ & $\begin{array}{l}\text { The NHTS data set has an age variable. This is } \\
\text { divided in to three categories Young (age }<=30) ; \\
\text { Middle (age }>30 \text { and }<=60) \text { and Senior (age }>60) .\end{array}$ \\
\hline
\end{tabular}


C-4 


\section{APPENDIX D: CONSUMER SURPLUS, REVENUE AND WELFARE DEFINITIONS}

To calculate the change in consumer surplus for the individual household, we use the following equation,

$$
S U R P L U S=\frac{1}{2}\left\{\left(P_{M}-P_{V M T}\right) *\left(M I L E S_{G A S}+M I L E S_{V M T}\right)\right\}
$$

The difference $\left(P_{M}-P_{V M T}\right)$ determines the sign of the change. If the fuel cost per mile under the VMT $\left(P_{V M T}\right)$ fee exceeds the fuel cost per mile under the gasoline tax $\left(P_{M}\right)$, we expect a reduction in total consumer surplus as we move upward along the linear demand curve. Similarly, if the fuel cost per mile decreases under the new policy, we expect household miles to increase as it becomes cheaper for households to drive and thus, increase the total consumer surplus as we move downward along the linear demand curve.

Revenue collected by the state agency for each household is calculated using the following equation,

$$
\text { REVENUE }=0.012 * \operatorname{MILES}_{V M T}-\left\lfloor\left(\frac{0.24}{H H M P G}\right) * M I L E S_{G A S}\right\rfloor
$$

Household miles are based on the predicted (fitted) values estimated by the model, first under the gasoline tax $\left(M I L E S_{G A S}\right)$, then under the VMT fee $\left(M I L E S_{V M T}\right)$. To calculate the net gasoline taxes collected, we consider only the $\$ 0.24$ collected per gallon sold. Since we do not estimate the miles driven on individual vehicles, we cannot calculate the gasoline tax revenue collected by vehicle. Instead, we use the weighted average household fuel efficiency ( $H H M P G)$ to calculate the per-mile cost in terms of the gasoline tax. We consider only a flat-rate VMT fee, and we can calculate the revenue collected by multiplying the per-mile fee $(\$ 0.012)$ by the predicted household miles under the VMT fee.

Since we do not calculate a supply function, we use the revenue collected by the state agency to calculate the welfare changes, rather than the standard producer's surplus. Thus, welfare for each household is calculated as,

$$
\text { WELFARE }=\text { SURPLUS }+ \text { REVENUE }
$$


D-2 


\section{OTREC \\ AND EDUCATION CONSORTIUM}

P.O. Box 751

Portland, OR 97207

www.otrec.us

OTREC is dedicated to stimulating and conducting collaborative multi-disciplinary research on multi-modal surface transportation issues, educating a diverse array of current practitioners and future leaders in the transportation field, and encouraging implementation of relevant 